\title{
LEARNING THE CULTURE OF NATURAL FAMILY LIVING THROUGH PARTICIPATION IN AN ONLINE COMMUNITY OF PRACTICE
}

\author{
A Dissertation \\ Presented to \\ The Faculty of the Curry School of Education \\ University of Virginia \\ In Partial Fulfillment \\ Of the Requirements for the Degree \\ Doctor of Philosophy \\ by
}

Carolyn M. Pinkerton, BA in Spanish, MA in Education, and MS in Curriculum and Instruction

May 2010 
(C) Copyright by Carolyn M. Pinkerton All Rights Reserved May 2010 


\begin{abstract}
The purpose of this study was to examine how mothers participate in an online community, MotheringDotCommunity (MDC), to learn the culture of natural family living (NFL) through an ethnographic case study. Natural family living (NFL) is a lifestyle that promotes holistic well-being. Families focus on nurturing their physical, emotional, and spiritual health. Attachment parenting (AP) is part of NFL. In AP, parents quickly and consistently respond to their children's needs in order to promote a strong parent-child attachment; this involves practices such as always responding to a child's cries, keeping children within close proximity, and practicing gentle discipline. MDC is an online forum where women can both provide and receive information and support regarding NFL.
\end{abstract}

Data were collected through daily online observations of MDC, archived messages, and interviews with 12 MDC participants. In addition, four MDC member profiles were created in order to highlight the learning process and patterns of activity that occur within the online community. Data were analyzed using the framework of communities of practice, the idea that people learn a practice by interacting within a community.

The findings revealed three major themes: (1) by creating and sharing information and receiving community support, MDC members are empowered and encouraged to challenge institutions, (2) through their participation at MDC, women both learn and adapt their identities as NFL mothers, and (3) MDC serves different roles for different 
members; for some members, MDC is a community of practice, while for others, the forum solely serves as an information resource. 


\section{Educational Leadership, Foundations, and Policy \\ Curry School of Education \\ University of Virginia \\ Charlottesville, Virginia}

\section{APPROVAL OF THE DISSERTATION}

This dissertation, Learning the Culture of Natural Family Living through Participation in an Online Community of Practice, has been approved by the Graduate Faculty of the Curry School of Education in partial fulfillment of the requirements for the degree of Doctor of Philosophy.
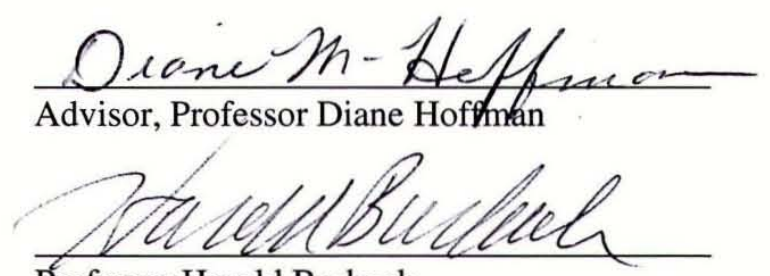

Professor Harold Burbach

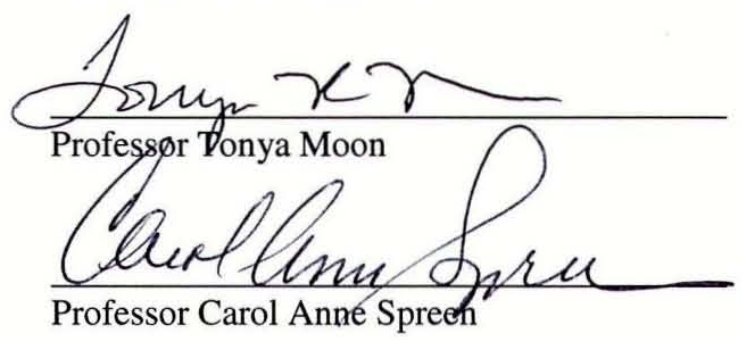


This dissertation is dedicated to my loved ones

\section{and}

to mothers everywhere, no matter their tribe 


\section{ACKNOWLEDGEMENTS}

I used to run away from home as a child. I did not go too far, and my destination was always the same: the elementary school where my older sisters attended. My parents would go retrieve me from the school and find me sitting in a desk, my arms stretched upwards and my hands clasped together on the desk. I did not leave the classroom easily as I loved being there and wanted to stay at the school. My parents had no idea at that time just how long I would stay in the classroom, both as a student and as a teacher. My love for education has remained constant, as has the solid support from my parents. For their continual encouragement and love, I am deeply grateful.

There are many teachers to thank for compelling me to earn my Ph.D. Dr. Colleen Gilrane was the first professor to make me truly excited about education, and I look back to my internship year of student teaching with great fondness. I have taught side by side with three excellent teachers, Melinda Webster, Kelly Walker, and Stephanie

Sebolt. I value what they taught me as master teachers and as friends. And I am thankful for the professor who told me I could not and should not earn my doctorate as a young woman. He has no idea how his discouragement and doubt fueled me to succeed.

I am indebted to Diane Hoffman for all the she has taught me, for her support and insight in my study of learning to mother, and for always making me laugh. Each faculty member I have worked with at the University of Virginia has contributed to the scholar and researcher I am today by generously sharing their expertise and providing feedback along the way. 
Writing is a solitary endeavor, yet I never felt alone throughout the dissertation process. Phone calls, emails, and meetings with my cohort carried me through times when I did not know if I could cross the dissertation finish line. Beth Lloyd and Melissa Levy were always quick to answer emails and help brainstorm ideas. My sweet dog Maya never judged my shabby appearance during the long days of writing, and she seemed to know when to nudge my hand when we both needed to go for a walk. My friends listened when I talked about my study and provided distractions when I needed a break. Not only did my circle of friends help me through the dissertation process, but they reminded me of how blessed I am to be surrounded by such good people.

Finally, although they have no idea about how much I looked into their lives, I am grateful for MotheringDotCommunity. Studying how women learn natural family living has been both informative and fascinating. I thank them for being such a lively tribe, and I am glad I got to be a part of it. 


\section{TABLE OF CONTENTS}

Page

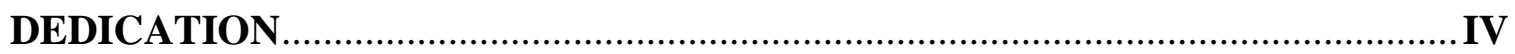

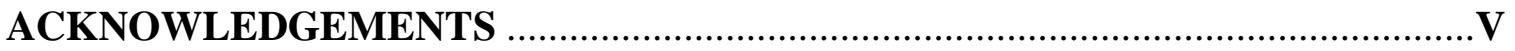

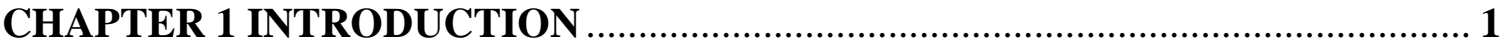

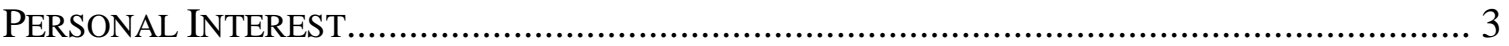

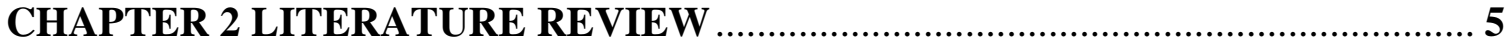

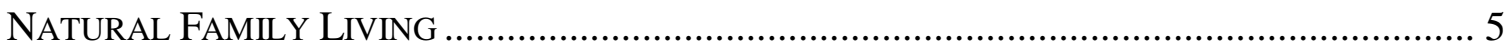

DISCOURSE ON MOTHERHOOD ............................................................................... 15

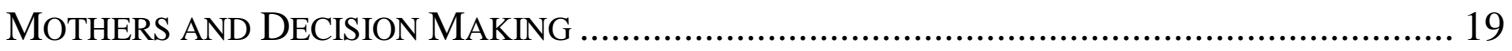

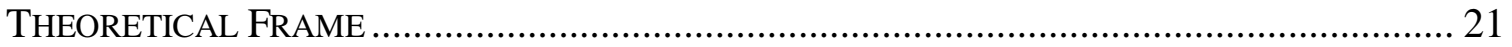

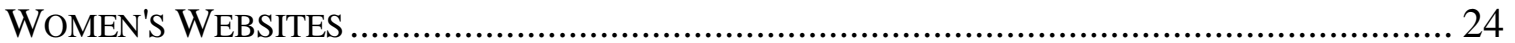

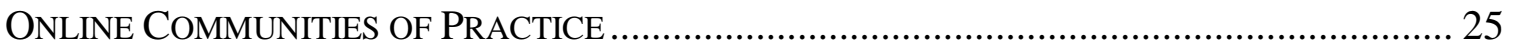

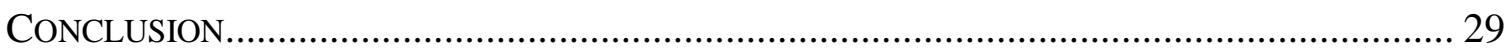

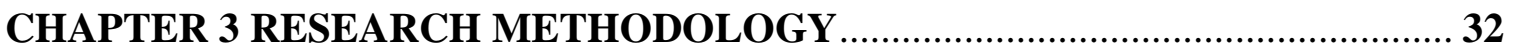

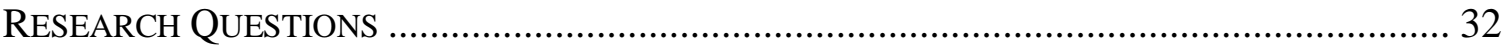

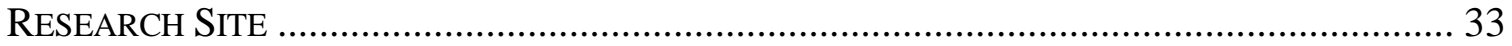

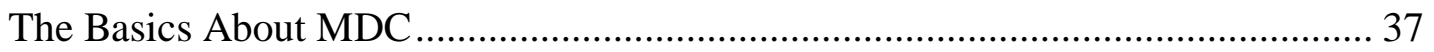

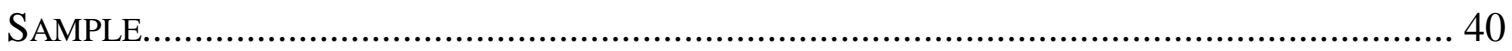

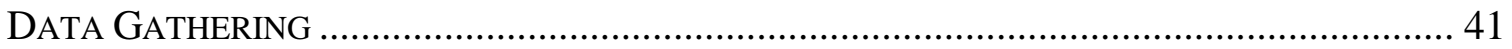

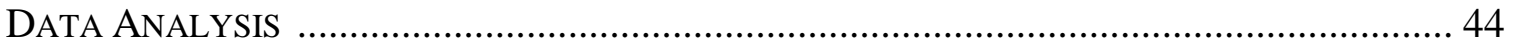

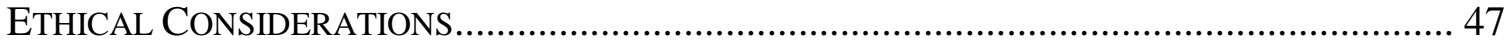

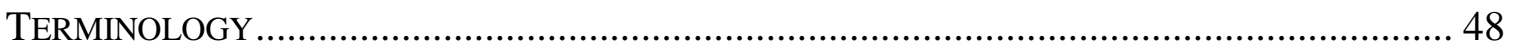

RESEARCHER ROLE AND STUDY LIMITATIONS................................................................. 48

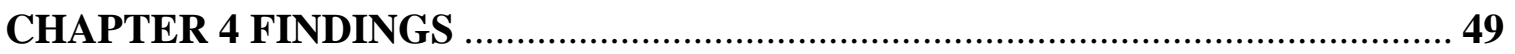

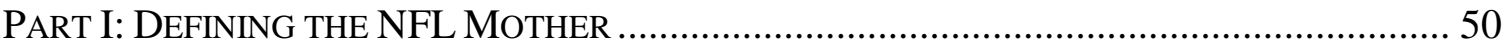

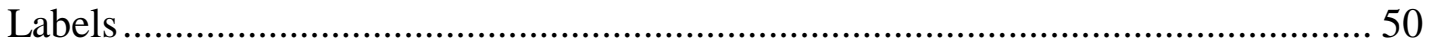

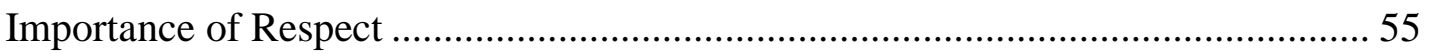

Mothering as Spiritual, Instinctual, Intuitive, and Natural .................................... 58

Emphasis on Education and Challenging the Norm ……….....................................5 59

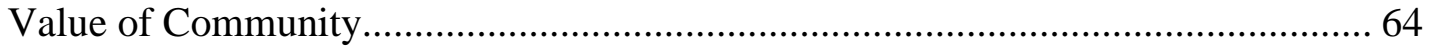

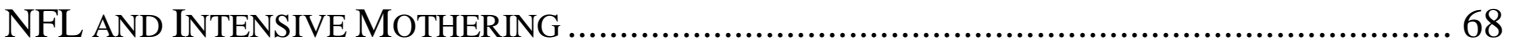

Intensive Mother-Child Bond and Constant Close Proximity to Child .................... 68

Extensive Research and In-Depth Knowledge …………...................................... 70

Burn out and Rage ………........................................................................ 72

PART II: MOTHERINGDOTCOMMUNITY AS A COMMUNITY OF PRACTICE............................. 75 


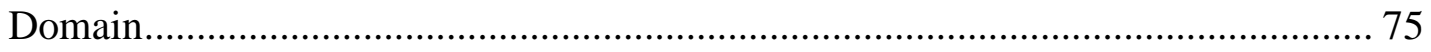

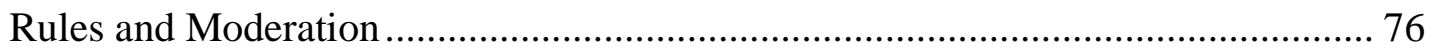

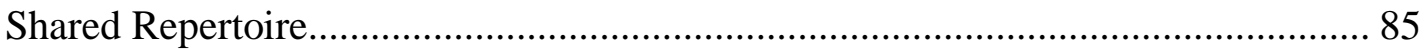

Language and Symbols ..................................................................... 86

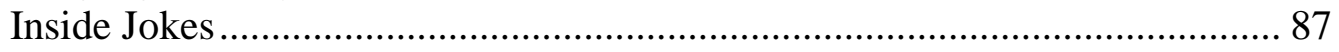

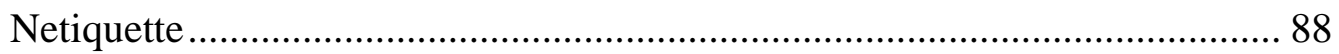

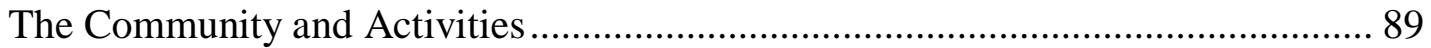

Creating Online Identities .................................................................. 90

Finding Your Tribes................................................................................ 93

Documentation Projects ..................................................................... 97

Exchanging Information ....................................................................... 98

Building Relationships and Community ................................................ 100

Providing Support ............................................................................ 101

Fighting and Debating......................................................................... 105

Sharing the Message of NFL ........................................................... 113

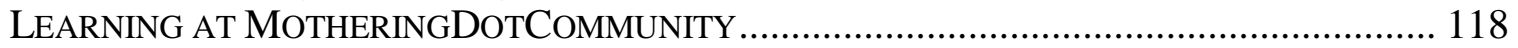

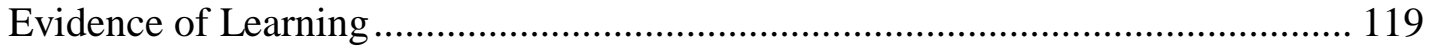

Members' History with NFL and MDC .......................................................... 125

Member Profile: Kathryn ............................................................ 128

Member Profile: Maisy ................................................................. 134

Member Profile: Wendy .......................................................................... 146

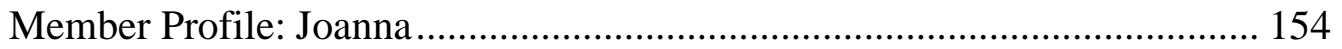

AdVANTAGES AND DiSADVANTAGES OF MOTHERINGDOTCOMMUNITY........................ 162

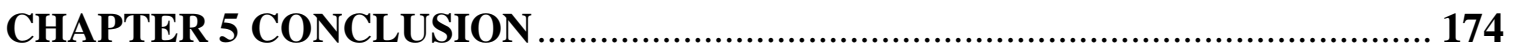

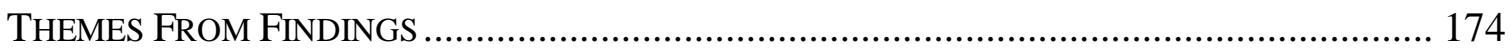

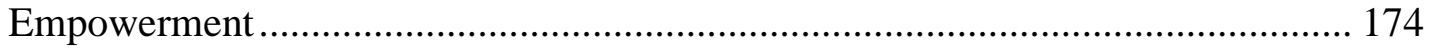

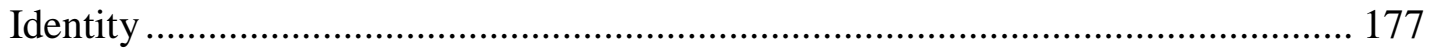

The Role of MDC in Members' Lives .............................................................. 180

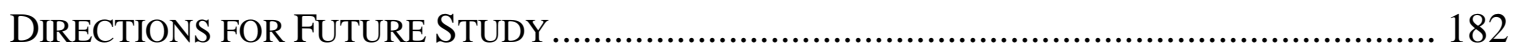

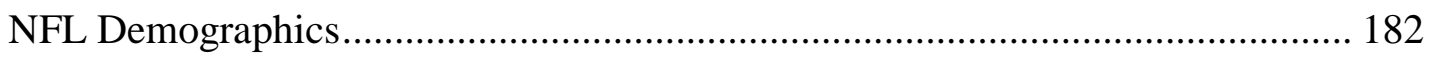

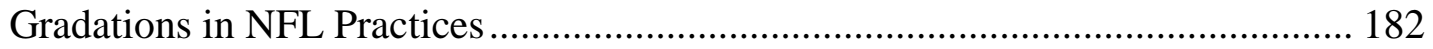

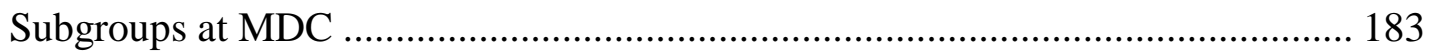

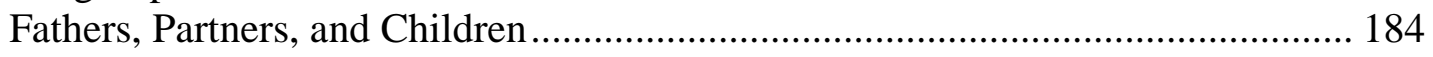

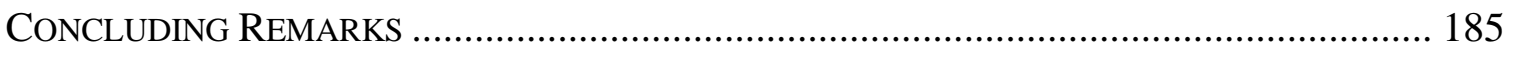

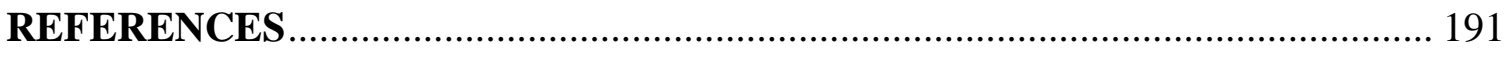

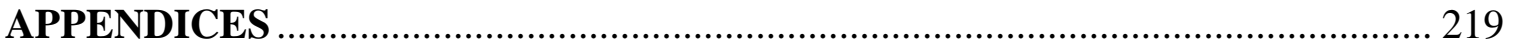

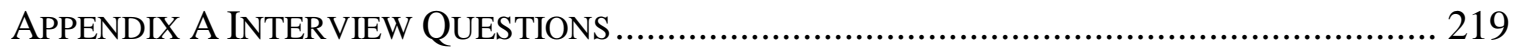

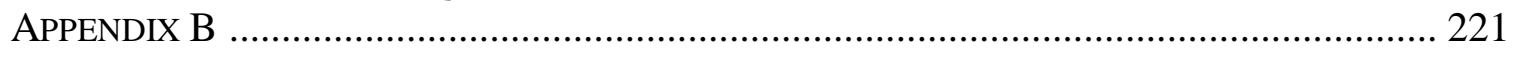




\section{CHAPTER 1 \\ INTRODUCTION}

Breast or bottle? Disposable or cloth diapers? Sleep in the crib or in the family bed? These are only a few examples of the choices women have to make when raising a child today. Doctors, family, friends, and a multitude of childhood experts all offer strong opinions about how women should raise their children. Information about childrearing can be found in the news, books, magazines, and internet sites (Douglas \& Michaels, 2004). With so many parenting choices to be made and with multitudes of people chiming in with their opinions, how does a woman filter through it all to make decisions and learn how to mother her own child?

In the past, women have learned how to care for children from their mothers, sisters, and grandmothers who lived nearby (Apple, 2006). Families today are more geographically mobile, eroding the family network that women had previously relied on for information about mothering (Drentea \& Moren-Cross, 2005). Women have also learned how to mother by staying at home and interacting with other stay-at-home moms (Litt, 2000). These interactions served as a time for women to share child-rearing techniques, observe mothers in action first-hand, and provide support for one another (Litt, 2000). However, more women are in the work force today, thus reducing the opportunities for stay-at-home moms to interact with other stay-at-home moms (Drentea \& Moren-Cross, 2005). Other sources of information for mothers include plenty of experts, such as doctors and childhood psychologists (Apple, 2006). Advice might be 
passed along through conversations or found in one of the expert authored books that make up a multi-billion dollar industry of childcare literature (Hoffman, 2008).

In addition, more and more mothers are turning to the internet today to find support and information regarding child-rearing (Madge \& O’Connor, 2006). Women can read scholarly works about child development on the American Academy of Pediatrics' website, or more light-hearted and personal stories on mothers' blogs. Websites are dedicated to exploring parenting issues and cater to varying parenting styles and interests. For example, a woman wanting to learn about natural family living (NFL) can go to www.mothering.com. NFL supports a holistic lifestyle where people nurture their physical, emotional, and spiritual well-being. At www.mothering.com, women can read about how to live a natural lifestyle, including practices such as having a drug free birth, breastfeeding babies, and eating organic foods.

Parenting websites often host online forums. In these forums, members post and respond to each others' messages. Mothers are able to receive information and support from other mothers across the world at any hour. Mothering online forums can potentially be communities of practice. A community of practice is a set of people who come together to learn about a specific practice, such as mothering, through their participation in the group (Wenger, 1998).

While literature abounds on the topic of motherhood across all disciplines, there is a lack of research that examines how women actually learn to become mothers. In particular, there is a deficit of research examining how women use the internet as a resource for learning how to mother. To help fill this gap in the literature, I conducted an ethnographic case study to examine how women learn to mother by participating in an 
online community about NFL mothering. My research site was MotheringDotCommunity (MDC), the discussion forum on Mothering.com. By conducting interviews and reading archived messages, I analyzed how women learn the beliefs and practices of the NFL culture. In addition, I investigated whether MDC has the components of an online community of practice.

\section{Personal Interest}

I became interested in how women learn to be mothers 10 years ago when my oldest sister had her first son. Overnight, she took on the title of mother. With this new identity, she was expected to joyfully put her son's needs before her own, regardless if she was tired or sick or wanting time to herself. Despite my sister's training and extensive experience as a labor and delivery nurse, she still felt nervous and unsure of herself around her infant. I watched her cry when she realized she would have to supplement formula into his feedings. Based on her own research and knowledge as a nurse, my sister had planned to solely breastfeed her son for the first six months of his life. When reality forced her to change her plan, she felt guilty for not meeting her own expectations. Watching my sister struggle to learn and fit into this new role of mother made me realize that the transition into motherhood is not always a seamless and effortless act. Although motherhood might be rewarding, it certainly is no cake walk.

My interest in thinking about motherhood reemerged during my graduate ethnography class. For the course project, I observed mothers around town and noted different mother types. Some mothers appeared energetic and were surrounded by other women, while others were quiet and alone with only their child for company. I began to wonder how women become certain mother types. Do they purposefully become a 
certain type of mother, or are their parenting styles unintentional? What are the rewards and challenges that come with each mothering type?

I later studied motherhood by working with my advisor on her study that investigated the sources of information mothers use to guide their methods of disciplining. The mothers interviewed provided well thought out, articulate answers about their views on childrearing and discipline. They often cited childhood experts as being influential in their parental decisions. Many mothers also cited the internet as a source of information and support. I realized that these women actively think about the types of mothers they want to be, conduct extensive research about parenting, and implement research findings into their lives to become the mothers they long to be. This is very different from how my own mother, whose only childcare book was from Dr. Spock, had learned to mother.

Interviewing the mothers in my local area left me with unanswered questions. I wondered why mothers decided to follow certain experts in the first place. How did they filter through all the information that is available? I wanted to know how mothers put all that they learned into action. What made a woman decide to listen to one expert over another? In summary, I wondered one main question: how do women learn to mother? This lingering question was what ultimately drove me to my dissertation topic of examining how women learn to be a NFL mother through an online community. 


\section{CHAPTER 2}

\section{LITERATURE REVIEW}

\section{Natural Family Living}

In the mid-1990s, Chris Bobel (2002) began her study on NFL mothers ${ }^{1}$. At the start of her research, Bobel had to "aggressively" seek out NFL mothers and literature about the lifestyle (p. 166). Nowadays, Bobel writes that the ideas of NFL have become "ubiquitous" and that this form of mothering is consistently growing in popularity (p. 166). The NFL mother is invested in caring for the mental, physical, and spiritual wellbeing of her child. She embraces a simple, natural lifestyle. The NFL philosophy believes that above all, mothers are the ultimate experts in knowing what is best for their children (O’Mara, 2000).

When asked to define NFL, Peggy O'Mara (2005), the owner of Mothering and an icon in the NFL world, writes that it is about discovering what is natural for each family, and not about following a set of rules. O'Mara sees NFL not as a fad, but rather about "... getting back to our roots as humans and rediscovering the parenting skills that have sustained humans throughout history and prehistory," (p. 8). When learning to be a mother, O’Mara was influenced by Margaret Mead, an anthropologist who observed how "tribal people" integrate babies into all aspects of their societies (p. 8). She was also inspired by the ideas of La Leche League, an organization dedicated to promoting breastfeeding and attachment parenting, a parenting philosophy promoting strong bonds

\footnotetext{
${ }^{1}$ Bobel referred to this group of women as natural mothers in her research.
} 
between the parent and child. In defining NFL, O'Mara details some of the practices, such as drug-free births, breastfeeding, keeping babies close to the body as much as possible, eating natural foods, being cautious of medical interventions, practicing gentle discipline, and being part of communities.

Attachment parenting (AP) is part of NFL, and according to O'Mara (2000), it is the oldest form of child-rearing. O'Mara shares findings from researchers who spent time in tribes where parents practiced AP. For example, Jean Liedloff found that the Yequana Indians, a tribe in a South American jungle, carried their babies at all times. Liedloff (as cited in O'Mara, 2000) observed that the Yequana were the happiest people with obedient, well-behaved children who almost never cried or fought with one another. Jean-Pierre Hallet (as cited in O’Mara, 2000) lived with the Efe Pygmies of Zire's Ituri Forest, and he observed that their babies were continuously held close to bare skin and nursed on demand until five years old. The babies slept between the mother and father and were shown a great deal of physical affection. Pygmies are said to be "selfrespecting and totally secure" and live a "cooperative, joyful lifestyle that is wholly free of aggression," (O’Mara, p. 115).

The mother-child dyad is promoted as the gold standard in NFL. NFL believes that no one can meet a child's needs as well a mother, and women are urged to "honor" this mother-child attachment (O'Mara, 2000, p. 117). The mother is advised to be the central figure in her child's life, spending the majority of her time with her baby for at least the first three years. In a Mothering article that explains the bonds of attachment between a mother and child, the author writes "in order to maintain emotional equilibrium, babies require a consistent and committed relationship with one caring 
person. As you might expect, the research indicates that the person best suited for this relationship the mother," (Porter, para. 3, 2003). If the mother does leave her child, even if for a brief moment, the child could suffer psychological damage (O’Mara, p. 116).

Although O'Mara recognizes that some separation between the mother and child is inevitable, she urges mothers to adopt the practice of taking their babies everywhere with them (2000, p. 117). She writes:

. . adopting the mindset of taking your baby with you wherever you go can do wonders for your bond with your child and your child's sense of security. There will be time later, when your child is older, for getaways on your own. (p. 117).

If a mother must return to work after giving birth, O'Mara encourages women to see if their jobs will allow them to bring their babies, explaining that "in tribal cultures, women might gather food or weave baskets, with their babies either carried with them in a sling, or cared for by other members of the village..." (p. 117). Mothers should consider taking a job that is compatible with bringing their babies to the worksite, such as selling real estate, shop keeping, or cleaning homes (O’Mara, p. 117). Finally, O’Mara suggests that women should examine their family finances and if possible, they should consider working part-time, delaying going back to work, or quitting work altogether. After all, O’Mara concludes, “every mother is a working mother,” (p. 117).

Respect is a cornerstone tenet of NFL. In her book on NFL, O'Mara uses the word respect in regards to others and their privacy, children, our bodies, and nature (2000, p. 2, 7, 10, 71, 85, 152, 177, 192, 196, 209, 210, 215, 217, 218, 243, 265, 271, 297, 289, 295). O’Mara writes that “Children and adults are not different. We have the same feelings....Children need to be involved in the problem-solving of the family....Children deserve to be acknowledged in public. Children deserve to be treated 
with respect [italics added]," (O’Mara, 2001). Respect places children as equal members in the NFL family.

NFL believes allowing children to express their emotions is a form of respect. To illustrate, if a child is having a temper tantrum, NFL experts state that the mother should allow it to happen rather than force her will to make it stop (Solter, 1992; Wipfler, 2002). She should allow the child to wiggle, writhe, and cry as much as necessary, and be near the child during the event (Wipfler, para. 21-22). The mother should verbally reassure the child she is close by during the tantrum, and be ready to provide affection between "child and listener" at the end (Wipfler, para. 21). Other disciplinary actions such as time-outs, rewards, and punishments are listed as unnecessary and ineffective methods that lead to undesirable consequences, such as a child feeling unloved (Solter, 1992). Instead, NFL encourages the mother to ". . . treat each situation as the unique challenge that it is, and try to be flexible and creative, all the while giving our children the love and respect [italics added] they deserve," (Solter, para. 19).

The strong belief in the importance of respecting children is what drives NFL practices. NFL believes that all children are "basically good, trustworthy, and authentic," (O’Mara, 2000, p. 32). O’Mara urges parents to embrace and respect the idea of the "perfectibility" (p. 328) of children. In doing so, O’Mara states that it is easy to follow children's lead rather than molding them "to our own wishes," (p. 328). Sarah, a mother who practices attachment parenting, describes how respect shapes her mothering practices. Sarah writes (2008):

He was never left to cry it out, but was respected enough to be taken seriously and held. He was never spanked, but was respected enough to be disciplined nonviolently. Parental love was never been withdrawn, because we respect that he needs our unconditional acceptance and love. He slept in our bed, because we 
respected his need to feel close to us during the night. He was breastfed because we respected his need for closeness and nutrition. He was respected enough to know that he would wean only when he was ready, and leave the family bed only when he was ready.

As he got older and breastfeeding and family beds were no longer in the picture, he is respected enough to be listened to when he's upset. We respect him enough to use active listening with him. We respect him enough to give him the freedom to explore everything that interests him. We respect him enough to give him specific reasons why he can't do something particular he asks to do, instead of just saying 'Because I said so.' We respect him enough to model the behavior we expect; we ask him 'please' and tell him 'thank you'. We respect him enough to never force him to say he's sorry, especially if he's not. We respect his observations of his own needs; if he needs time alone, he may take however long he needs. If I am in the wrong, I respect him enough to apologize to him. (ID).

Sarah succinctly describes the bulk of AP practices and how they all stem from respecting children.

Spiritual is another high frequency word used in NFL to describe mothering, and through this word, the practice of caring and nurturing a child takes on a divine purpose. By viewing mothering through the spiritual lens, the MDC mother ponders and holds reverent even the most basic functions of childcare. For example, author Davis describes breastfeeding as a spiritual practice as it required a deep commitment in an article for Mothering (2003). While Davis first tried to multi-task while nursing her son, doing things such as checking emails and returning phone calls, she came to focus solely on nursing over time. Davis found nursing her son provided quiet times of solitude, and she would practice deep breathing during their time together. She explains her deep breathing thoughts during nursing:

Breathing in, I am nursing my lovely baby. Breathing out, I am mother. I tried several hundred variations on this theme: Breathing in, I love my baby. Breathing out, I feel calm. Breathing in, my baby wants milk. Breathing out, milk flows freely. (Davis, para. 7). 
Nursing took priority over everything else in her life. Focusing only on nursing her son during feedings required concentration and self-discipline (para. 3). Davis made her nursing corner a "sacred place" by having flowers, pillows, and water nearby (para. 8). Davis focused either on her son or the activity out her window, slowing down and appreciating the view outside (para. 8). In addition, in the middle of the night while nursing her son, Davis would think about other women around the world nursing their children, and she felt connected to them (para. 9).

For author Schultz, caring for her sick child was a spiritual experience (2001). She gave all of her attention and focus to caring for her ill daughter, and writes that the brief moments she had to herself in the bathroom provided her with a giddy sense of brief freedom (para. 5). At the end of the day, she felt frazzled and restless, yet also calm and centered (para. 9). She writes "It is a spiritual experience to serve your child in sickness, to let fly all your important tasks, to coax her small system back to health," (para. 9).

Even elimination communication (EC), the practice of not using diapers on babies, can be seen as a spiritual practice. Buckley writes about her experience with using EC for her infant daughter (n.d.). She had to be close to her daughter at all times, and be highly attuned to her daughter's body language (n.d.). Buckley memorized her daughter's schedule, noting that she had to eliminate about every ten minutes for the first few hours in the morning (n.d.). Buckley (n.d.) believes that EC is one of many mothering practices that can allow women to practice "devotion, awareness, selflessness, and unconditional love. .." (para. 30). She ends her article by writing:

Our intellectual capacities may (or may not) be diminished, but our hearts and instincts can bloom, and we can practise the mindfulness that allows us to be totally in the present - in love with our babies and children - which is where they are. (para. 43). 
Mother and author Dimof learned that everyday activities can be made into a path of practice that provide opportunities for meditation (2004). This means that Dimof takes the most common mothering activities, such as “. . .changing diapers, cleaning, doing dishes, cooking, chauffeuring," and uses them as moments of meditation by giving them her full attention (para. 18).

Three other words: instinctual, intuitive, and natural, are also highly used by NFL and AP experts. Dr. Sears, a well-known AP leader, states that NFL is “. . . what comes naturally when we trust our own intuitions," (O’Mara, 2000, p. ix). O'Mara believes that NFL's practices meet at “. . the intersection of instinct and science," (2005, p. 10). For example, NFL believes that mothers who keep their babies close to them at all times are acting upon a biological instinct that helps keep infants safe. In the Mothering article "The science of attachment: The biological roots of love," Porter presents studies by psychologists, such as Bowlby and Ainsworth, to bolster the claim that biology drives practices that promote attachment and bonding between parents and children (2003). NFL urges women to follow their maternal instincts, and provides scientific evidence to reassure them that what they are doing is indeed correct.

NFL believes mothers who listen to their instincts will naturally do what is best for their children. To illustrate, Mothering published an article where author McTamaney shares her experience about having a caesarean section and practicing attachment parenting while in the hospital. Rather than have the baby sleep in a separate nursery, McTamaney and her partner kept the baby in their room. The new mother nursed her baby easily, joyfully, and on demand. She quickly healed from her surgery, allowing her to be discharged a day early from the hospital. In contrast, McTamaney describes a new 
mother she observed at the hospital who seemed disconnected to her infant. When a nurse took the mother's baby to a separate nursery to sleep, the mother did not kiss the infant goodbye or show other signs of affection. McTamaney concludes that the mother was not practicing attachment parenting and therefore was "already disconnected from the life she'd had within her only a day before," (n.d., para. 5).

McTamaney believes that following her intuition not only helped her to bond with her child, but it also led her to "the best practice!" for herself and the baby (n.d., para. 8). She explains that she and her partner did not take any birth education classes because they trusted that love would correctly guide them in doing what was best. She writes:

We didn't choose attachment parenting because we had done long research about its benefits; we chose it because, when we knew our son was coming, we couldn't bear the thought of not being with him all the time. We didn't choose to sleep as a family because of scientific research on cosleeping; we chose it because we loved the way our son felt beside us. (para. 8)

Intuition was the only resource necessary for McTamaney and her partner to do what they felt was best for their child.

Intensive mothering, the practice of a woman putting the majority of her resources into raising her child (Hays, 1996, p. 5) accurately describes the NFL lifestyle. With NFL, a mother's work is to begin before she is even pregnant. Before conception, NFL encourages women to establish baby friendly lifestyles. This includes reducing stress, increasing one's social support network, exploring parenting expectations with partners, beginning to think about birth, and taking care of the soul (O’Mara, p. 9, 2000). Next, when a woman is pregnant, she is told to remember that she not only affects her child's physical health in utero, but its emotional health as well. O’Mara writes:

You can create a nurturing place in the womb through your positive feeling about your baby. Your emotions of love and protectiveness towards your infant will be 
communicated to the baby in utero. Conversely, feelings of fear, anxiety, and ambiguity can affect the baby. (2000, p. 6).

After working towards a healthy pregnancy, the mother is encouraged to try for a drugfree child birth. O'Mara explains that a drug free birth is ideal because "A mother avails herself of an ecstatic birth chemistry that unlocks a dormant, instinctual maternal intelligence; a baby begins life without having imprinted on drugs and awake enough to successfully breastfeed," (O’Mara, 2005, p. 8). In addition, having a drug free labor can change how a woman views herself. O’Mara writes “A woman who experiences labor relying on her own inner resources knows she is strong. Approaching birth in this way can mean giving birth to a new version of yourself," $(2000$, p. 27). Thus, NFL views childbirth as a transformative experience, and a chance for a woman to change her identity.

If the childbirth process does not radically change a woman, being with her infant will. Women are told that after childbirth, their priorities will shift, and friendships may change (Boyd, n.d). In the Mothering article "The Secret Language of Motherhood," author Boyd recounts the first time she left her daughter at twelve weeks to have dinner with her childless friends. When reflecting upon the conversations she had with her friends, she felt unfulfilled. Boyd writes:

The conversations I was having my baby were with far more meaningful to me, at that moment, than any political debate or gossip session in which I'd ever taken part. . . my conversations - and my idea of what things need to be said and discussed - would never be the same again, because of this small, wordless creature (para. 16, n.d.).

Boyd discovered a deep connection with her daughter, and she preferred the wordless conversations with her baby to conversations with her childless friends. This change in 
conversational preference is one that only she and other mothers can understand, hence the title "The Secret Language of Motherhood," (n.d.).

Being part of a community is a valued experience in NFL. In O'Mara's editorial titled "Longing for Community," she traces the history of being part of a group (2009a). O’Mara claims that humans first perceived themselves as being part of a dyad before being an individual, concluding that community is therefore "an intrinsic need of human beings," (p. 8). According to O’Mara, communities fill humans' emotional need for “uninhibited communication, mutual understanding, and common valuing," (p. 8). Community also allows women to experiment with new ideas as a mother, such as homebirths and Waldorf schools, and provides role models (O’Mara, p. 10). O’Mara believes that people do not find community, but that they attract it (p. 10). She urges readers to "visualize what it would look like if you felt part of a tribe. .." (p. 10). O'Mara also points readers to a popular article from Mothering titled "Finding Your Tribe" by Teresa Pitman (p. 10). Pitman tells her story about forming a tribe with a friend by spending their days together cleaning, cooking, and watching their children (2000).

NFL mothers believe that the culture of their community is different from mainstream society (Bobel, 2002). When addressing the audience at the Holistic Moms Network, a group that promotes NFL, O'Mara said 'When I'm here I'm with you, I feel part of family; I feel part of a different culture that's much more reassuring to me than the larger culture sometimes is," (2007). NFL mothers resist the institutions and experts of daycare, education, health care, the world of work, and consumerism (Bobel, 2002). 
They choose instead to keep their children close to their sides and to homeschool, use alternative medicines, stay out of the work force, and live simply.

By promoting for women to stay out of the work force and partake in domestic activities, Bobel (2002) argues that NFL is oppressive to women. To be certain, NFL strongly promotes mothers staying at home. O'Mara writes about the myth of quality time, stating that "“quality time' is a convenient way to rationalize combining your career and children," (2000, p. 119). MDC membership reveals, however, that mothers do work both in and out of the home. The tension of what NFL promotes and the actual reality of members' lives is discussed later in the findings.

\section{Discourse on Motherhood}

Popular literature is brimming with books on motherhood. Typing "motherhood" in the search box on Amazon.com brings up over 67,000 titles. Many of these books are written by mothers who are boldly fighting the perfectionist housewife stereotype. The books have front cover images of smooshed cupcakes and frazzled moms, and have sassy titles such as "Sippy Cups Are Not for Chardonnay: And Other Things I Had to Learn as a New Mom," and "The Three-Martini Playdate: A Practical Guide to Happy Parenting." Many books have a confessional tone: "Confessions of a Slacker Mom;" "Dirty Little Secrets from Otherwise Perfect Moms;" "Smotherhood: Wickedly Funny Confessions from the Early Years;" and "The Imperfect Mom: Candid Confessions of Mothers Living in the Real World" are just a few examples. For women who fear motherhood will sap away their sex appeal, there are books like "Rock Star Momma: The Hip Guide to Looking Gorgeous Through All Nine Months and Beyond;" "Hot Mama: How to Have a Babe and Be a Babe;" and "I'm Too Sexy for My Volvo: A Mom's Guide to Staying 
Fabulous!" Women who consider themselves to be "thinking" moms can pick up a copy of "Mothers Who Think: Tales Of Real-life Parenthood" and other literary tales about motherhood like "Motherhood is not for Wimps: No Answers, Just Stories." There are books for the younger mom, the older mom, the lesbian mom, the alternative mom, the Jewish mom, the single mom. There are books about post-partum depression, and girlfriend to girlfriend guides to motherhood. Finally, there are books for women who decide not to enter into motherhood.

The titles of the popular books on mothering unveil existing stereotypes and expectations about mothers. The confessional style books demonstrate that women are aware of existing expectations about how mothers should act and feel. A woman confessing to letting her son wear his shirt backwards to school shows that there is a perceived expectation for mothers to make sure their children are properly dressed and groomed. The book titles also reveal an existing stereotype that mothers are at risk for becoming unattractive and dull. Lastly, the titles create an expectation that motherhood is extremely challenging. An expectant first-time mother may feel she is preparing for battle when reading the titles of the multitude of guides for mothering in the mainstream literature.

During the last decade, the study of motherhood has greatly expanded and branched into many academic disciplines. Motherhood is explored by fields such as feminism, psychology, human development, anthropology, and child and family studies (Arendell, 2000). After reviewing the past decade of scholarly work on mothering, Arendell (2000) writes:

Scholarly work on mothering focuses on the person who does the relational and logistical work of child rearing. Definitions of mothering share a theme: the 
social practices of nurturing and caring for dependent children. Mothering, thus, involves dynamic activity and always-evolving relationships. (p. 1192).

Hot topic debates, such as abortion, welfare reform, reproductive technologies, and women's employment have been centered on definitions of mothers and mothering (Glenn, 1994; Luker, 1996). Arendell (2000) found that studies about mothering range from general conceptual models to in-depth examinations of specific social and psychological variables.

Arendell (2000) writes that the "increasingly voluminous" (p. 1193) scholarship on mothering can be divided into two fields of focus. The first body of literature conceptualizes motherhood, creating theories and exploring ideologies of mothering. Works that conceptualize mothering often come from the field of feminist constructionism (Arendell, 2000). In this body of literature, feminists investigate and challenge the ideologies of motherhood and believe that mothering is culturally organized (Chodorow, 1978; Hays, 1996; Rich, 1997). They take words like family, childhood, and mothering and explore variations on their definitions (Arendell, 2000). No longer focused solely on white, middle-class women, feminist scholarship on mothering has broadened to include more racially and ethnically diverse populations and practices, such immigrant mothers and mothers who use drugs (Arendell, 2000). Other subjects that deviate from white, middle-class mothers are mothers who are changing demographic trends (having children later, having children when unwed), returning to work, and using assisted reproductive technologies (Arendell, 2000). Finally, scholars create and debate theories over whether the basic motherhood experience is universal or if context makes each mother's experience unique (Arendell, 2000). 
The second theme in the study of motherhood is the phenomenology of mothering. Scholars examine the experiences and emotions of mothers. In doing so, researchers highlight the tensions in motherhood; motherhood can be both joyful and stressful, empowering and constraining, fulfilling and depressing (Arendell, 2000). Other areas of focus include women's maternal satisfaction, distress, employment and childcare, and social support. Finally, research looks at mothers in economic distress, such as homeless mothers, and the impact different social policies have on families.

Recently the concept of intensive mothering has also received much attention in the motherhood literature. Hays (1996) coined the term "intensive mothering" in her book about women who value raising their children above all else. Intensive mothering requires women to invest all of their resources (money, time, and emotions) into raising their children (Hays, 1996). In other words, the mother is "not a subject with her own needs and interests," (Bassin, Honey, \& Kaplan, 1994, p. 2). In Mommy Myth, authors Douglas and Michaels (2005) discuss the negative experiences of women dealing with the unrealistic expectations of intensive mothering. In other scholarly works, researchers trace the roots and implications of intensive mothering. Arendell (2000) believes intensive mothering is the normative standard "by which mothering practices and arrangements are evaluated,” (p. 1195). Indeed, Drentea and Moren-Cross describe motherhood to be "intensive, repetitive and anxiety producing," (2005, p. 921). Furthermore, pregnancy and childbirth can be a vulnerable time for women's mental health (Mauthner, 1998).

The mommy wars is a topic that has received much attention in both scholarly works and the media (Douglas \& Michaels, 2005). The mommy wars is the ongoing 
debate about whether mothers should be in the work force or stay at home with their children. Magazines covers display images of women decked out in business suits, trying to juggle a brief case in one hand and a baby in the other, while the stay-at-home moms are shown driving their children from one activity to another in mini-vans. On one side of the debate are feminists who urge women to remain in the work force (Hewlett, 2007; Hirshman, 2006). At the same time, former career women discuss their satisfaction with leaving the work force to be at home with their children (Hamman, 2006). In the middle are those who have tried to a call truce between both sides (Perkowtitz, 2005; Stone, 2008). The mommy wars debate examines the ideology of what makes a good mother while also looking at the experiences of women both in and out of the workforce.

Mothers and Decision Making

Over time, the resources mothers have used to inform their decisions about childcare have changed. In the early $19^{\text {th }}$ century, mothers relied on their intuition and the women in their surrounding community to guide them in making parenting decisions, and the first child care manual was published in 1811 (Apple, 2006). In the mid $19^{\text {th }}$ century, a multitude of changes restructured the American family and the role of the mother: the size of families reduced, the economy switched from primarily agricultural to industrial and service-based, and technology, like electricity, changed mothers' workloads and positions in the family (Apple, 2006). More childcare books were published and doctors emerged as childhood experts (Apple, 2006).

In the early 20th century, mothers were turning more and more often to medical and scientific experts for childcare advice, following the ideology of what Apple refers to as "scientific mothering," (2006). She argues that scientific motherhood causes women 
to feel less competent in their mothering abilities; the more women learn about being a trained mother, the more they feel they need input from medical and scientific experts (Apple, 2006). During this time, some mothers continued to turn to friends and family for advice while others remained confident in their own abilities (Apple, 2006). However, women were increasingly turning to doctors and other experts for "the latest, most modern" childcare advice (Apple, p. 33). In addition, doctors and psychologists cemented their roles as experts by studying the emotional growth of children and documenting developmental milestones throughout the first half of the $20^{\text {th }}$ century (Apple, 2006).

In 1946, Dr. Benjamin Spock published his first book on child care that was an immediate best-seller (Apple, 2006). After World War II, books by Dr. Brazelton and Penelope Leach joined the best-selling ranks with Dr. Spock; all three support intensive mothering and the idea that all children are priceless and good (Hays, 1996). In the mid $20^{\text {th }}$ century, various women's movements (civil rights, natural childbirth, women's liberation, and antiwar) contributed to the diminishing role of the authoritarian physician (Apple, 2006). By late 20th century, women stopped being unquestioning and subservient to the childhood "experts" (Apple, 2006). Rather than follow doctors' direct orders, mothers were encouraged to adapt advice as needed and to view themselves as the experts' partners in raising children (Apple, 2006).

Mothers today have an amazing amount of resources to guide them in making parenting decisions. In 1995, over 60 new books on motherhood were published, compared to the only four to five new books published each year in the early 1970s. 
Women have a large amount of books to choose from to prepare for motherhood. Author

Tsing Lo (2003) describes her collection of parenting books as a new mother:

On my battered Ikea night table stands a wobbly tower of self-help books. They say everything there is to know about me, an anxious fortysomething new mother. From the top they are What to Expect the First Year, The Womanly Art of Breastfeeding, The Baby Book: Everything You Need to Know About Your Baby From Birth to Age Two, Becoming the Parent You Want to Be, The Girlfriends' Guide to Pregnancy, On Becoming Baby Wise, Surrendering to Motherhood, Your Second Child (a book that has literally never been opened), and, yes, sign of the times, Parenting for Dummies. (p. 1).

In addition to books, there are plenty of magazines for mother to choose from to inform them about parenting. Examples of magazine titles include Parents, Scholastic Parent and Child, Brain Child, American Baby, Working Mother, Green Parent, Family Fun, Pregnancy, Parenting Early Years, Fit Pregnancy, Cookie, Baby Couture, Martha Stewart Kids, Parenting School Years, and Junior. To prepare for childbirth, women can take Lamaze or Bradley classes. There are also radio shows, television programs, and internet sites all dedicated to providing mothering advice. Women can attend seminars, retreats, and lectures to learn how to sharpen their mothering skills (Hulbert, 2003).

It is important to note, however, that experts are not the sole source of information for mothers. Women's social networks and backgrounds still influence their decision making. Walker (2001) explains that “...advice of parenting programs is not accepted or rejected in a vacuum, but often within the context of discussions within the participants' existing social networks," (p. 186).

\section{Theoretical Frame}

The theoretical frame used to explore my research comes from the learning theory of communities of practice. A community of practice is a group of people who come together over a shared interest (Wegner, 2001). The concept for communities of practice 
comes from the social learning theory, a belief that learning is not just a cerebral activity, but rather is a process that occurs within a network of social relationships (Bredo, 1997). Learning that occurs in a community of practice is referred to as a social practice called situated learning. To be considered a community of practice, a group must come together over a shared, specific interest that involves a practice (Wenger, 2001). For example, a set of mothers with a shared interest in healthy eating does constitute a community of practice. However, if the same group of mothers regularly meets to share where the best co-ops are in town, swap recipes, and demonstrate healthy cooking techniques, they could possibly be a community of practice.

Communities of practice can come in a variety of different forms. Wenger (2001) writes:

Some are quite small; some are very large, often with a core group and many peripheral members. Some are local and some cover the globe. Some meet mainly face-to-face, some mostly online. Some are within an organization and some include members from various organizations. Some are formally recognized, often supported with a budget; and some are completely informal and even invisible. (para. 4).

In addition, some communities of practice are long-standing with rich traditions, while others last for only a year (Wenger, 2001). A benefit to having such a wide variety in the format of communities of practice is that people are more likely to find their own niche.

In order to learn and share knowledge with one another, members of a community of practice engage in mutual interactions. Mutual interactions occur through activities such as email exchanges, dinner conversations, and watching others practice their craft. Wenger explains that the mutual engagements in communities of practice are not always kind and gentle. He writes (1998): 
In real life, mutual relationships among participants are complex mixtures of power and dependence, pleasure and pain, expertise and helplessness, success and failure, amassment and pain, expertise and helplessness, success and failure, amassment and deprivation, alliance and competition, ease and struggle, authority and collegiality, resistance and compliance, anger and tenderness, attraction and repugnance, fun and boredom, trust and suspicion, friendship and hatred. Communities of practice have it all. (p. 77).

Newcomers to a community of practice can serve as a source of conflict. Newcomers may clash with the old-timers as they are likely to have competing viewpoints about a practice (Lave \& Wenger, 1993, p. 115). Since communities of practice are not homogenous in their makeup, “...conflict is a ubiquitous aspect of human existence," (Lave \& Wenger, p. 15). The conflict eventually subsides as newcomers gain more power through increased participation (Lave \& Wenger, 1993).

Members mutually engage with one another through the negotiation of joint enterprise (Wenger, 1998). Through the negotiation of joint enterprise, the community defines what is significant to their group and shapes the practice (Wenger, 1998). Over time, the negotiation of joint enterprise shapes a community of practice's shared repertoire. A shared repertoire consists of gestures, symbols, stories, actions, concepts, ways of doing things, words, routines, and tools (Wenger, 1998).

Participation in a community of practice can be political, personal, intimate, competitive, and/or cooperative (Wenger, 1998). Member participation occurs at different levels. Newcomers may start with legitimate peripheral participation, meaning that they spend their time observing others in the community (Lave \& Wenger, 1991). Legitimate peripheral participation is not a passive event, but rather a way for new members to be absorbed into the culture of practice. Members can observe who is involved in the community, what others are doing, how members conduct their lives, and 
what is needed to become full practitioners (Lave \& Wenger, 1991). Peripheral participation lets newcomers see how old-timers collaborate, collide, and collude. Wenger (1998) lists a number of factors that influence members' levels of participation:

(1) how we locate ourselves in a social landscape, (2) what we care about and what we neglect, (3) what we attempt to know and understand and what we choose to ignore, (4) with whom we seek connections and whom we avoid, (5) how we engage and direct our energies, and (6) how we attempt to steer our trajectories. (p. 167-168).

A member's level of participation in a community of practice is not just a choice of the individual. Existing members may limit how much another member can participate depending on status.

Members have different paths of involvement in each community of practice.

Some newcomers are on the inbound trajectory, meaning they want to become a full time participant, while other members will always remain on the periphery. For newcomers to become veterans, they need to have access to a wide variety of activities, members, resources, and participation opportunities (Lave \& Wenger, 1991). Learning the language of a group is an important part of becoming a full member. Not only does language teach about the activity, but it allows people to participate in the group dialogue and act as active members (Lave \& Wenger, 1991). Veteran members might be on the boundary trajectory, meaning they link the group to other communities of practice (Wenger, 1998). Finally, the members on the outbound trajectory will eventually leave a community of practice.

\section{Women's Websites}

Websites aimed at women, such as MDC, have been both criticized and praised. Some critics believe that by focusing on domestic duties, such as cleaning and cooking, 
women's websites confine women to traditional gender roles (Genusa, 2001; Madge \& O'Connor, 2006). Specifically, women's websites focused on mothering are said to recreate “. . . the circle of motherhood as a female-dominated sphere, thus reinforcing male and female inequality," (Drentea \& Moren-Cross, 2005, p. 938). However, as Bobel's (2002) research shows, NFL mothers would argue that they enjoy their domestic roles.

Others believe that women's websites empower women. For example, when women share their own personal experiences and their messages are archived in the forums, the women's messages become sanctioned knowledge of the community (Eble \& Breault, 2002). By sharing their stories and information, members occupy positions of agency in the production of knowledge (Blair \& Takayoshi, 1999). Furthermore, by collecting information from other mothers rather than relying solely on childhood experts, like pediatricians, the power is shifted back towards mothers (Drentea \& MorenCross, 2005). Finally, there is the argument that women's websites have both their pros and cons, and that women's online sites are “... neither egalitarian utopias nor spaces devoid of communicative power for women," (Hawisher \& Sullvian, 1999, p. 269). Therefore, MDC can be viewed as an online community of practice that is both “liberating and constraining to women," (Madge \& O’Connor, 2004, p. 30).

\section{Online Communities of Practice}

A new type of community of practice has become increasingly popular today: online communities of practice. In 2001, $79 \%$ of internet users surveyed by the US Pew Internet and American Life Project indicated that they were a member of at least one online community (Lai, Pratt, Anderson, \& Stigter, 2005). Through online communities, 
people interact with others all over the world. Online communities of practice span from broad topics, like parenting, to the specific, such as parenting to children with special needs.

Online communities of practice and traditional communities of practice share similarities and differences. Online communities of practice are usually designed topdown, meaning one person forms a group and decides on the community domain. In contrast, traditional communities of practice stem from existing groups and have leaders that naturally emerge over time. Both negative and positive interactions occur in traditional and online communities of practices; being online doesn't sanitize the messiness that occurs with human interactions. In addition, both traditional and online communities of practice focus on specific topics. Wellman (1999) writes that the relationships in online communities can be "quite narrow, existing for information processing," (p. 5). Lastly, people often belong to more than one online community of practice, the same as with traditional communities of practice (Wellman, 1999).

Putting a community of practice online is not a simple transfer of communication mediums. There are important questions to consider when thinking about online communities of practice. For example, can tacit knowledge really be transferred online? Tacit knowledge, the intangible information people carry around in their minds, is difficult to share with others and it can be even more challenging to explain in the online world. People often pick up tacit knowledge through observations of others. When online, learners are limited to how much they can observe a practice take place. However, multimedia components today, such as pictures and streaming videos, make viewing practices possible. A NFL mother can post pictures of the garden she's growing 
to provide her family with organic produce, while another may share a video on how to create a homeopathic tincture for children.

An additional challenging question is whether community members can come to trust each other and build relationships without face-to-face interactions. Trust is very important for a community of practice as it allows members to feel safe to share knowledge and learn from each other. Nichani and Hung (2002) explain that without trust, "members would hoard their knowledge and experience and would not go through the trouble of sharing with or learning from others," (p. 51). Some believe that trust can only be developed over time through face-to-face interactions (Lai et al., 2005). Others retort that although building trust online may be more difficult, it is still possible (Palloff \& Pratt, 1999). Speaking from his own experiences with online communities, Rheingold (1998) writes:

You can't kiss anybody and nobody can punch you in the nose, but a lot can happen within those boundaries. To the millions who have been drawn into it, the richness and vitality of computer-linked cultures is attractive. . (p. 274).

For Rheingold and others, being online does not preclude building a trusting relationship.

There are multiple benefits to having a community of practice online. To start with, members can quickly receive responses to their questions. To illustrate, a member of an online community shares the story of when he found a tick on his daughter's head (Rheingold, 1998). He posted a question to his online community about the tick and received answers within minutes. Not only did he receive helpful information, but he also felt a sense of comfort and security knowing people were readily available to help him (Rheingold). While being online can provide instant gratification, it also creates a space where members can have the time to think and reflect about their questions and 
responses. Having more time to think about what to say can lower the anxiety level of people who are often nervous during face-to-face conversations. In addition, being online allows people to quickly find specific groups that they may not be able to find in their local communities. For women who live in areas where there are few NFL mothers, the internet may serve as a major information source for them. A convenience factor also makes online communities of practice appealing (Wellman, 1999). For tired mothers, being able to participate from the comfort of their homes at any hour can be a bonus. Finally, being anonymous when online can allow people to feel safe to share personal issues. As a popular New Yorker cartoon states, “on the Internet, nobody knows you're a dog," (Steiner, 1993). A mother might feel more at ease sharing her frustrations and disappointments with women online than with the women she meets in person.

Of course, there are also downsides to communities of practice being online. Just as the internet is helpful in quickly transmitting useful information, it can also spread incorrect information. However, Rheingold (1998) points out that people can also be fooled by telephone and face-to-face communications. The main difference between these forms of communication is how quickly information can spread through the internet (Wellman, 1999). Another challenge of online communities is that it is easy for members to have low levels of participation or to abruptly quit. Still, it appears that even with weak ties, members do reciprocate support because helping out others "can increase selfesteem, respect from others and status attainment," (Wellman, p. 9). An additional difficulty to being online is that the cloak of anonymity can make it easier for members to display hostility and judgment. When reflecting about her experience with an online natural-mothering community, Eis (2008) writes: 
What really turned me off was the judgmental tone of some of the posts I read....it was like a wacky interactive game show: Where do you stand? I am here; you are there. If you don't agree, there can be no bridge between us. (p. 43).

There is a large amount of dialogue surrounding the issue of how to foster a positive spirit for online communities, demonstrating that this is a challenge that community members are aware of (Lai et al., 2005; Lave, 1993; Lave \& Wenger, 1991).

Conclusion

Reviewing the literature reveals that there are gaps in the bodies of literature pertinent to this study. To begin with, there are not many empirical studies that examine online communities of practice (Stuckey, 2004). Additionally, there are few studies that examine mothers and their usage of the internet. Women's websites are the least discussed in studies regarding electronic communication, and cybermothers are a "poorly documented virtual community," (Madge and O'Connor, 2004, p. 201). In particular, missing are studies that investigate the context of mothers' everyday lives and the role the internet plays in them (Madge \& O’Connor, 2004). Existing studies focus on how mothers use the internet as a form of social support (Drentea \& Moren-Cross, 2005; Dunham, Hurshman, Litwin, Gusella, Ellsworth, \& Dodd, 1998; Mickelson, 1997; Sarkadi \& Breber, 2004). However, research is lacking on how women's participation in an online community affects their learning of mothering. This study has built upon existing literature of how mothers make their parenting decisions as well as fill in the gaps on cyber-mothers by examining an online community.

Motherhood is another topic in need of further research. Despite the growing amount of literature on mothering, Arendell (2000) states that there are major gaps to be filled in the areas about the meanings of motherhood, mothers' relationships with others, 
and the activities of mothers. At this time, there lacks in-depth research that examines the process of mothers' learning that takes place in these social networks. In particular, there is a lack of research that closely examines the learning that takes place in an online community of mothers. By looking at both the ideology of NFL and the experiences of mothers interacting in an online forum, this study on how women learn the culture of NFL helps to fill in these gaps as identified by Arendell (2000). In addition, this research explored the relationships NFL mothers have with other mothers, childcare experts, and their own children.

Finally, the NFL lifestyle is in need of further research (Bobel, 2002). For example, although NFL is supposedly based on doing what is natural and intuitive, Bobel (2002) argues that the mothers seem to be "dutifully following a script," (p. 99). Missing from the literature are studies that examine how women learn the NFL script. This study has helped to fill in the gap in the NFL literature by focusing on how women learn the beliefs and practices of NFL. Furthermore, Bobel writes that studies are needed to examine the role of community and the NFL mother:

In this information age, perhaps it is time to develop theoretical models that help us detect the creation of community via text-in the form of both printed word and online communication-and understand how this elusive sense of community can support individuals. . . In addition, we need to develop ways to measure the impact of such communities. (p. 169).

The internet is changing how online communities operate. NFL mothers have found a space in the online world at MDC and have opportunities to interact with others in new ways. It is important to study how the internet impacts women's lives (Miyata, 2002) and how women learn the culture of NFL. This study has helped to fill in these 
literature gaps by examining women's experiences in learning a specific type of mothering, NFL, at MDC. 


\section{CHAPTER 3 \\ RESEARCH METHODOLOGY}

Research Questions

Based on the interviews conducted with Dr. Hoffman, this study started with the observation that many women today do not just do whatever they feel is natural in terms of mothering, nor do they simply mimic the methods of their own parents. Instead, the women interviewed shared that they reflected upon and researched about the kind of mothers they would like to be, and then implemented their findings into their parenting practices. In addition, the interviews with mothers revealed that women often turn to the internet as a source of information and support. For these reasons, I chose to conduct an ethnographic case study to investigate how women learn the culture of NFL through their participation in an online community such as MDC. Guiding my research were the following questions:

1. How do women construct NFL mothering?

a. What do women describe as the beliefs of NFL mothering?

b. How do women's described NFL beliefs influence their mothering practices?

2. What is the culture of MDC?

a. How do mothers interact and participate in the community?

b. What are the patterns, trends, and artifacts of the community?

3. What role does MDC play in women's learning of NFL mothering? 

a. When/why do women turn to MDC?
b. How is learning demonstrated in MDC?
c. What do mothers assert to have learned from MDC?

\section{Research Site}

In the beginning of my research, I planned on examining two different websites aimed at the NFL mother. I began by reviewing the Holistic Moms Network (www.holisticmomsnetwork.org). On this site, women shared practical information with each other, such as what medicines to take when fighting a cold and the summaries of recently released reports. There lacked, however, a sense of community. Women did not share personal information, nor did they seem to have established relationships with one another. In addition, the activity level on the website was low with around three to four new topics being posted a day.

Moving on, I began researching MDC. In this forum, I found an extremely active community. When logging in at eight in the morning, I would find hundreds of new topics already posted from members around the world. The members actively posted in all the forums, bickered with each other, and checked in to see how other members were doing. It appeared that MDC served as a learning environment for the members. For these reasons, I chose to focus solely on MDC for the rest my research.

MDC is part the online forum for Mothering magazine. Founded in 1976, Mothering magazine is geared towards readers interested in NFL. In each edition, the magazine addresses "contemporary health, personal, environmental, medical, and lifestyle issues" through the NFL lens (About Us, n.d.). O'Mara bought the magazine in 
1980 and now serves as both the editor and publisher. She has authored books about birthing and raising children naturally and she is a regular contributor to the magazine.

Mothering magazine went online in 1998. The Mothering website receives heavy visitor traffic; it is listed to be the number one social network for parents on the entire Web, is one of the top 3,500 sites, and has 9 million page views per month (Rate Card, 2009). MDC has approximately 136,000 members that come from over 65 countries. With their shared values and proactive stance, MDC readers are described as a being like a family (Media Kit, 2009).

The average age of the Mothering.com reader is 32 years old, and $65 \%$ have a college degree (Media Kit, 2009). The average household income for online readers is \$73,200 (Media Kit, 2009). Mothering describes the typical online reader as being a woman who:

.. . cares passionately about the health and well-being not only of her baby but also of herself, her family, the planet, and humanity. She is highly social, outspoken, and freethinking. Her thoughts and opinions carry weight, not just in our online forums, but also among her closest friends, in playgroups, on playgrounds, in schools, and throughout her community. (Media Kit, 2009).

Mothering.com readers can access current and archived articles, along with videos, webinars, and links to blogs.

At MDC, readers can find information about NFL and discuss a wide range of topics. The community forum is arranged in the following manner (sub-forums are listed in italics):

\begin{tabular}{l}
\hline Forums \\
\hline Welcome to MotheringDotCommunity \\
Pleased to Meet You \\
Currently in Mothering Magazine \\
Finding your Tribe \\
$\quad$ Finding your tribe archives $/ 2008$, tribal areas \\
\hline
\end{tabular}


Questions and Suggestions, Racism: a moment of reflection and healing, Testing One, Two, Three,

Natural Family Living Workshops

Parenting

Parenting

Family Safety

Gentle Discipline

The Family Bed and Nighttime Parenting

Ages and Stages

NICU \& Preemie, Parenting, Life with a Babe, Toddlers, The Childhood Years,

Preteens and

Teens

Surviving Abuse

Family Life

Adoptive and Foster Parenting

Blended and Step Family Parenting

Parenting the Gifted Child

Special Needs Parenting

Parenting Multiples

Multicultural Families

Life as a Parent

Stay at Home Parents, Single Parenting, Queer Parenting, Working and Student

Parents, Dads

\section{Pregnancy and Birth}

Fertility

Infertility, Trying to Conceive, Family Planning

I'm Pregnant

The Case Against Circumcision, Vaccinations, Due Date Clubs, Pregnancy Archives Birth and Beyond

Birth Stories, Homebirth, Unassisted Childbirth, Birth Professionals, VBAC, Healing

Birth Trauma

Postpartum Depressions

Pregnancy and Birth Loss

Pregnancy After Birth Loss, Trying to Conceive After Loss, Pregnancy and Birth Loss Archive

\section{Breastfeeding}

Breastfeeding

Breastfeeding Beyond Infancy

Child-Led Weaning

Breastfeeding Challenges

Lactivism

\section{Health}

Nutrition and Good Eating

Nutrition and Good Eating Archives, Traditional Foods, Vegetarian and Vegan

Living, Meal Planning

Health and Healing 
Allergies, Dental, Fitness and Weight Management, Health and Healing Archives, Mental Health

Vaccinations

Vaccinations Archives, Selective and Delayed Vaccination, I'm Not Vaccinating

The Case Against Circumcision

\section{Education}

Learning at School

Waldorf, Montessori, Other (Reggio Emilia, Sudbury, Democratic), Comparisons

Learning at Home and Beyond

Homeschool Curriculum and Resources Reviews, Unschooling

\section{Natural Family Living}

Activism

Activism Archives, War and Politics

Arts and Crafts

Yarn Crafts, Diaper Making, Toys and Dolls, Sew-Serge-Embroider, Fine Arts, Craft

Workshop-Tutorials, Patterns and How-To's

Babywearing

Babywearing Reviews, Babywearing Guidelines, Resources, and Advertising

Information

Books, Music, and Other Media

Television, Book Clubs, TV-Free

Diapering

Diaper Making, Diapering Reviews, Diapering Guidelines, Resources \& FAQs, The

Daily Diaper-Your Guide to MDC's Diapering WAHMs, Elimination Communication

Diggin in the Earth

Diggin' in the Earth Archives

Grief and Loss

Grief and Loss Resources

Mindful Home Management

Decluttering, Organizing, and Simplifying, Country Living/Off the Grid, Natural Home \& Body Reviews, Frugality \& Finances, Pets, Natural Body Car, Reduce, Reuse, and Recycle, Green Living

Mothers Writing Group

Writing for the Web

Natural Family Living Reviews

Natural Home and Body Reviews, Homeschool Curriculum and Resources Reviews, Biz Opps and Services Reviews, Babywearing Reviews, Diapering Reviews

New and Current Events

Politics, News and Current Events Archives

Personal Growth

Spirituality

Religious Studies

Talk Amongst Ourselves: Games, Polls

WAHM Well

Work At Home Resources and FAQs, WAHM Well Rules and Guidelines, Biz Opps \& Services Reviews, Work at Home Job Board, WAHM Connect-Your Guide to MDC 
Work at Home
The MDC Trading Post
WAHMarket
The Trading Post
$\quad$ Babywearing, Birth and Baby Supplies, Children's Clothing, Clothing for Adults and
$\quad$ Maternity, Crafts, Diapers and Diapering Supplies, Homeschooling, Natural Home
$\quad$ and Natural Home \& Body Care, Household Goods and Electronics, Toys, Games,
Books, Music and other Media, Miscellaneous, Canada Trading Post
Free For Shipping
In Search Of
MDC Swaps
Holiday Helper
Holiday Helper 2009
$\quad$ Families in Need-Item Database, Canada Families in Need-Item Database

The Basics about MDC

With purple and white font and a straightforward layout, the information design and navigation of MDC's homepage is easy to scroll through and read, which are important elements in supporting online social interaction (Preece, 2001). There is a search bar for looking through archived messages. MDC's forum topics are listed in a column on the left side of the homepage. MDC's homepage is filled with advertisements, mainly for childcare and baby products. There are advertisements, however, that seem out of place on a NFL website. Weight loss products, movie rental businesses, disposable diapers, and even pizza restaurants have all been advertised on MDC. Members can pay a fee to view the forum without advertisements and pop-ups. Anyone can read through current and archived messages, but readers must register in order to start new messages or reply to other threads. When registering, people must first provide their birth dates in order to make sure they are 18 years or older based on the Children's Online Privacy Protection Act. Members must also indicate that they have read the forum rules, which include not posting messages that are "obscene, vulgar, sexually-oriented, hateful, threatening, or otherwise violative of any laws," 
(www.mothering.com/motheringdotcommunity-user-agreement). The new member then chooses a screen name and her desired privacy settings. Privacy settings allow a member to decide whether each piece of personal information (contact information, profile picture, visitor messages, photo albums, about me, friends, and group memberships) can be seen by either the community, only registered members, only contacts, or only friends. MDC membership is free, but paid memberships are also available. Advertising is not allowed in members' signatures, but for a $\$ 45$ annual fee, members can promote their businesses and have an avatar in their profiles. For $\$ 5$ a year, members get an avatar, unlimited smilies, a title change, increased capacity for private messages, an album with space for 50 photos, and unlimited selling privileges in the MDC trading post. Members can also pay for ad-free browsing and for access to other forums where people sell and trade goods.

MDC membership is open to the public, unlike a traditional community of practice where membership is normally closed (Lai, Pratt, Anderson, \& Stigter, 2006). There are restrictions, however, to accessing certain forums. Members must have 50 posts and have been registered for 60 days before being able to access The Trading Post, Talk Amongst Ourselves, Parents As Partners and the WAHM (Work at Home Mom Well). The Swaps Forum requires members to have 150 posts and to have been registered for six months. Surviving Abuse is a private forum that members must request to join. To be considered for Surviving Abuse membership, women must have over 500 posts and have been a member for over a year. MDC explains:

This is not to exclude people who may have a very real need for such a forum and the support offered therein, but is one of few possible security measures we can take to create a safe place for members to share their stories and feelings. (Georgia, 2009) 
MDC has not always had forum restrictions. Although details are not provided, it is explained that the member restrictions have been formed to deal with issues that have occurred over time (Georgia, 2009). Creating forum restrictions demonstrates that MDC members reflect on what is not working for the community and make necessary changes to aid in their online experiences being more effective.

MDC has a lengthy, yet clear, user agreement. It is explained that the Mothering website is intended to be a gathering place for people to read and discuss NFL issues. MDC also includes a statement of purpose:

The MotheringDotCommunity discussion boards serve an online community of parents considering, learning and practicing attachment parenting and natural family living. Our discussions on the boards are about the real world of mothering and are first and foremost, for support and information. Some subjects regularly covered in the magazine and on these boards include:

\begin{tabular}{l|l|l} 
Non-adversarial & Breastfeeding & Natural Remedies for \\
CooperativeFamily Living & Circumcision & Childhood Illnesses \\
\hline Natural Pregnancy & Vaccinations & Homeschooling \\
\hline Drug-Free Childbirth & Health and Healing & Cloth Diapering \\
\hline Homebirth & Discipline w/out Punishment & Babywearing and \\
\hline Midwifery/Doula Attended & Alternatives in Education & Attachment practices \\
\hline Births & & To name a few ... \\
Siblings present at births & &
\end{tabular}

Mothering invites you to read and participate in the discussions on the MotheringDotCommunity forums. In doing so we ask that you agree to respect and uphold the integrity of this community. Through your direct or indirect participation here you agree to make a personal effort to maintain a comfortable and respectful atmosphere for our guests and members by adhering to the User Agreement. (www.mothering.com/mdc/webpurpose.html/). 
Through MDC's clear statement of purpose, readers can decide if they want to be a part of the community.

\section{Sample}

As previously mentioned in the literature review, the average reader on Mothering.com is affluent and college educated. Although race and ethnicity is not recorded by the website, MDC's forums, such as groups created for women of color, gay and transgender mothers, and different religious backgrounds, indicate that there is diversity amongst MDC mothers. Still, the literature suggests that women who regularly access the computer and participate in forums have resources that indicate they are of a higher socioeconomic status (Drentea \& Moren-Cross, 2005).

I interviewed 12 women ranging from the ages of 26 to 35 years old. Occupations included being a student $(n=4)$, a stay-at-home mom $(n=2)$, a former bank teller, a

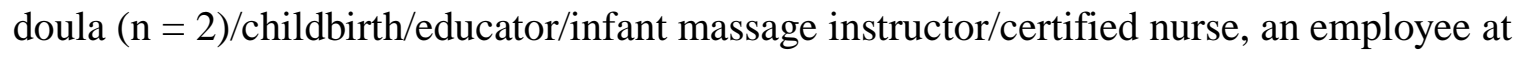
a policy organization, and an owner of a consignment store (one woman did not provide her occupation). The women all had one to two children aging from infants to six years old. The four women I interviewed in person were all white, college educated women. I chose not to ask the race and socioeconomic background of the mothers interviewed via email. I worried that without being able to build a rapport with the interviewees in person, asking for demographic information in an email could possibly be off-putting.

I identified contacts through purposeful sampling. I looked for women living in my town and surrounding area and also for women who frequently post to MDC. I emailed members through the MDC email center. I provided information that explained 
the purpose and background of my study. I scheduled four interviews with women living close by and eight through emails.

In addition, I created four different MDC member profiles. For the profiles, I identified women who had different lengths of memberships, ranging from under a year to six years. Additional criteria for choosing members to profile included having posts from 2009 and a count total of at least 50 posts.

\section{Data Gathering}

I conducted an ethnographic case study on MDC. After visiting the field site, MDC, I joined the group and introduced myself as a graduate student interested in learning more about NFL. Joining allowed me to search through archived messages, and a certain number of posts were required in order to obtain access to restricted forums.

My data gathering began with participant observations at MDC. During the week, I spent an average of three to five hours in the forums, reading through past and current messages. The majority of my data collecting occurred from mid-March to mid-January, and I spent an average of three to five hours a day during the week in the forums for a total of approximately 150-180 participant observation hours. Observations times varied, but would occur either during the morning staring at eight o'clock, throughout the afternoon, and into the evening until ten o'clock. There was steady activity on the forums at all of those times.

I spent one week acclimating myself to MDC, taking note of busy times on the forums, who were frequent posters, and learning the symbols and explicit rules of the community. While my time at MDC was spent observing more than participating, I did 
engage in the forum activities by posting questions, comments, and greetings. I totaled 56 postings at the end of the study.

Daily field notes helped me to record a "thick description" of what I saw taking place in the current messages (Geertz, 1973, p. 10). This thick description aided me in uncovering the webs of meaning at MDC (Geertz, 1973) and to learn the implicit rules of the community. I noted the details pertaining to MDC's culture. For example, I recorded the language of MDC, which includes hundreds of acronyms. Observing current activity at MDC also allowed me to learn about NFL and stay current on the lifestyle's hot topics. In addition, I read through the past postings of active members. By reading through past postings of members, I observed how members changed their patterns of activity over time and learned more about MDC and NFL.

In addition to my field notes, I also kept a reflective log about my impressions about MDC and NFL. In my reflective field notes, I recorded my impressions about different members, the content of messages, and other situations, such as flame wars. My reflective field notes is where I recorded broad themes and patterns I saw emerging from the data. For example, my reflective log is where I began to notice a pattern that occurred in flame wars.

To learn more about the culture of NFL, I conducted field work outside of MDC. I watched movies that MDC members mentioned in the forums, such as The Business of Being Born, a movie that explores giving birth in the hospital and at home. I shopped at my local grocery store that sells natural, vegetarian, and organic goods to understand the products used in the NFL home. I paid attention to flyers aimed at NFL families, such as group family yoga and meditation workshops. I read synopsis of books frequently 
mentioned in the forums. All of these types of activities deepened my understanding about the beliefs and practices of NFL.

At the same time I was observing the forum activity at MDC, I went through each forum and printed out at least two threads from each group. Threads chosen to analyze had met the criteria of no longer receiving activity and having at least five threads (threads are members' replies to the first posted message). Altogether, I printed out over 200 messages total to analyze. The purpose of looking through archived messages was to learn more about the culture of NFL and MDC while also looking for evidence of members' learning.

I conducted semi-structured one-on-one interviews while I reviewed messages and conducted daily observations (Appendix A). The interviews allowed me to collect a more focused set of data about how women learn the culture of NFL through MDC. I asked women about their motivations for participating in MDC. They shared their experiences as community members at MDC, including things they had learned and taught others. The four interviews conducted in person lasted from one to two hours. The women picked the location for their interviews that were convenient and comfortable for them. Although I had anticipated the interviews would be shorter in length, the women were open and appeared eager to share their thoughts about learning NFL. Interviews conducted in person were tape recorded and transcribed for later analysis. Audio file recordings were erased in order to assure confidentiality.

The other eight interviews were conducted through emails. I sent each participant an initial set of questions. Follow up emails were sent to women who raised interesting points or included ambiguous information that needed to be clarified. For example, one 
participant wrote that she did not practice NFL before having her baby, but that she became heavily involved in NFL while pregnant. I asked questions to probe deeper into the meaning and motivation for her lifestyle change. To further assure confidentiality, the electronic versions of transcripts were kept on my secure, password protected computer, and hard copies were kept in my secure home office.

In addition to regular observations, reading archived messages, and interviews, I created four profiles of MDC members: Kathryn, Maisy, Wendy, and Joanna. I looked for members that posted actively in different forums in order to represent a varied group from MDC. I read through every one of each members' posts multiple times. I read once to learn the members' stories and gather my first impressions. I then read through to look for members' learning of the MDC and NFL culture. A third reading of the messages was conducted to look for members' relationships with others and the member role they played in the forums, such as a newcomer or a veteran.

\section{Data Analysis}

The purpose of analyzing the data was to (1) examine the beliefs and practices of NFL and (2) look for evidence of learning as demonstrated in the forums and as stated in interviews. Collected data were organized by type; I created separate files for interviews, archived messages, field notes, and reflective field notes. Interviews, field notes, and reflective notes were labeled with dates and page numbers. Transcriptions of interviews occurred within the week they occurred. Margins on typed notes were wide in order to accommodate a space for coding.

Data analysis was an iterative process, occurring both during and after data collection. Data were analyzed by the literature regarding communities of practice and 
the ideas framing NFL. While collecting the data, I recorded preliminary open codes on the pages of interviews and archived messages as well as memos regarding emerging themes in my reflective field work log. Familiarizing myself with the material during the collection process helped to find emerging themes and patterns regarding the learning of NFL at MDC.

When data collection ended, I did a more focused read through and coding of the data. I started with a set of open codes for evidence of learning at MDC. I began with the following codes for evidence of learning:

1. Basic question and answer format. A woman asks a question and receives answers from other members. EX: A mother asks members which doctors in town are non-vaccination friendly and members share what they know.

2. Applying gained knowledge to actions. A member writes that she tried out the advice provided on the forum and shares her experience. EX: Member shares that she went to the doctor recommended by the group.

3. Application of knowledge to ways of thinking. EX: Member writes "I always thought $\mathrm{X}$, but now I believe that $\mathrm{Y}$ is true..."

4. Demonstration of knowledge acquired through the MotheringDotCommunity. EX: A women writes "I read on here before that mothers should nurse on demand."

5. Sharing of knowledge. EX: A woman researches a topic and shares with other members.

6. Learning of the culture. EX: A woman moves from the periphery of the group to the center as demonstrated through increased involvement.

After an initial read through of archived messages and interviews, I added a seventh code based on what emerged from the data:

7. Pointing to resources. EX: A member asks if anyone has advice for how to get a baby to sleep better through the night, and another member shares a title of a book on the topic. 
Sentences that demonstrated evidence of learning were highlighted and marked with a corresponding number beside them. Another set of codes for identifying NFL traits, such as was used (Appenix B). As new aspects about NFL emerged, I reorganized old codes and created new codes as needed (Miles \& Huberman, 1994). I then created themes I saw emerging from the findings.

After the coding of data, I shared my impressions and emerging themes with a professor and peers. Discussing my initial themes and coding with others helped me to refine my codes and consider other perspectives and explanations. This type of member checking also increased the credibility of the study.

With the feedback from others, I returned to the data with the suggestions from others. I read through the data with more focused themes and patterns that had emerged as most significant. During this read through, I looked for direct quotations from subjects that would support the emergent themes. Afterwards, I looked at my data in order to begin answering the study's research questions. The triangulation of data helped to support the themes while answering the research questions, and again, helped to increase the credibility of the study. I considered how women learn the culture of NFL at MDC and used the collected data and literature to support these explanations. My next step was to consider alternative explanations to the answers I had created, as Marshall and Rossman (1999) claim that alternative explanations to research questions always exist. Finally, I began writing my report. I used the collected data, literature, and reflective field work notes to inform my writing.

The multiple data gathering methods of this study and the triangulation of the data strengthen the transferability of the findings from this study (Rossman \& Marshall, 
1999). Meeting the criteria for transferability helps to ensure the dependability of this study as well (Lincoln \& Guba, 1985). In addition, I recorded if I changed my interpretations of activity in the forums at MDC in order to ensure dependability.

\section{Ethical Considerations}

As virtual research is a fairly new methodology, I did not find clear guidance on how to conduct my study. At this time, the methods of online research are still being debated amongst researchers. However, there were general suggestions about how to ethically conduct online research which I followed.

To begin with, I introduced myself to MDC as a graduate student wanting to learn more about NFL. In order to avoid lurking (the often frowned upon act of just looking at a website and never contributing to the discussion), I commented and asked questions on around 50 messages. I tried to keep my comments and questions as value neutral as possible in order to prevent guiding subjects to certain responses. In addition, I did not include any information in my findings from forums with restricted access. My original findings section included a paragraph from the Partners as Parents forum. As interesting as the exchange in that forum was, I deleted it from my findings out of respect to the community. Finally, I provided women interviewed with pseudonyms as they shared personal, in-depth information. After much consideration, I also chose to change the names of the member profiles as they did not chose to be a part of the study. Although the information about the members profiled is accessible to the public, I still felt it was appropriate to change their names after condensing and analyzing their posts in one place. I did not, however, change the names of members quoted infrequently throughout the findings. 


\section{Terminology}

I originally began this study using the term "holistic mother." However, as my research progressed and I narrowed in on one website, I changed to the term natural family living mother to match the language at Mothering. The two terms, natural family living and holistic, signify the same practices and philosophies for mothering. Both are concerned with all aspects of a child's well being.

\section{Researcher Role and Study Limitations}

Although I started this study mostly unfamiliar with NFL, many of the practices were new and foreign to me. I recognize that my own subjectivity may have affected the analysis of the data. To help with this, I shared my coding and thoughts with colleagues so they could question my analysis and raise alternative explanations. I also used direct quotes from the interviews throughout my analysis in order to test my claims (Maxwell, 1996). The smaller sample size of this study is a limitation as it prevents me from applying the results to all MDC members. Still, while the small sample size limits generalizing results in the statistical sense, Marshall and Rossman (1999) argue that the findings from smaller-scale qualitative studies can be transferable (p. 43). 


\section{CHAPTER 4}

\section{FINDINGS}

Part I: Defining the Natural Family Living Mother

In part I of the findings, I analyze how women interviewed and other members of MDC construct the NFL mother. I share both the beliefs and practices of the NFL mother as described by MDC members. Data revealed that MDC members use similar terms and ideas to discuss NFL, but that there is also variation in the degree at which women practice this type of intensive mothering.

\section{Labels}

Women interviewed were asked what it means to be a Natural Family Living (NFL) mother in order to answer the research question "how do women construct NFL mothering?" Many of the MotheringDotCommunity (MDC) members interviewed found defining the NFL mother to be challenging. To begin with, some women used terms other than NFL to describe their parenting approach. Anna, for example, referred to her mothering approach as "thoughtful parenting," (personal communication, July 1, 2009), while Virginia called her style "mindful parenting," (personal communication, July 30, 2009). Other mothers disliked labeling their parenting style altogether. For example, although Blair practiced components of NFL, she would rather not give her mothering style one particular name. Blair explained "I'm not actually a person who gets too dressed up in labels. It's much more what made sense," (personal communication, June 26, 2009). 
In addition, the different terms used to describe mothering styles at MDC can be confusing. NFL, attachment parenting (AP), holistic mothering, crunchy, and granola were all labels placed on mothers at MDC. Adding to the misunderstanding of terms was the fact that a mother might have practiced both NFL and AP, or just AP and not NFL. In other words, some mothers believed in attachment parenting, so they did things such as wear their babies close to them, but they did not practice a green lifestyle, so were not concerned with composting or using solar power in their homes. To top it off, some women practiced NFL with their children, but not with themselves (e.g., Molly, personal communication, June 23, 2009). MDC members repeatedly had to ask what being crunchy means and which parenting practices fall under which labels.

Being crunchy refers to being a hippie, and many messages at MDC were dedicated to members proudly sharing how they are crunchy. To help women figure out their crunch factor, they could take the quiz "What's Your Granola Factor?" that was found in different MDC forums (e.g., Theoretica², 2009; Firstkid4me, 2006):

What's Your Granola Factor?

1. Do you have homebirths? 15 points for "yes" (unassisted), 10 points for "yes" (with a midwife in attendance), 5 points for alternative birthing center, 2 points for "thinking about/would like homebirth," 0 for "no" (wouldn't consider it).

2. Will you circumcise future sons? 5 points for "no," -5 points for "yes".

3. Do you use cloth diapers? 20 points if you do Elimination Communication (no diapers), 15 points if "yes" (wash and make your own), 10 points if "yes" (wash your own), 5 points if "yes" (diaper service), 2 points if "thinking about it," 0 points if "no" (wouldn’t consider it).

\section{Do you observe your fertility signals using Natural Family Planning/Fertility Awareness and use that for birth control/trying to conceive? 10 points for "yes" (observe and use for birth control/Trying to}

\footnotetext{
2 Theoretica is the name of a member at MDC. Members' names at MDC are often unique. Although some members do not capitalize their names, they have been capitalized in this study for ease of reading.
} 
conceive or you use ecological breastfeeding/lactational amenorrhea, 5 points for "yes" (observe for trying to conceive), 2 points "thinking about it," 0 points for "no" (wouldn't consider it).

5. Do you breastfeed exclusively for the first 6+ months? 10 points if "yes," 5 points for "no" (use occasional bottles of expressed breast milk), 2 points for "no" (use occasional bottles of formula), 0 for "no" (don't breastfeed by choice).

6. Do you co-sleep? 10 points for "yes" (all night every night), 5 points for "yes" (part/all of most nights), 2 points for "thinking about it," 0 points for "no".

7. Do you use a sling/soft carrier? 5 points for "yes," 2 points for "thinking about it," 0 points for "no" (wouldn't consider it).

8. Do you believe in/practice child-led weaning (even if that means breastfeeding for several years)? 15 points for "yes" (complete child-led weaning), 10 points for "yes" (up to 3 years), 5 points for "yes" (up to 2 years), 2 points for "thinking about it," 0 points for "no" (you'll wean the baby at 1 year or earlier).

9. Do you tandem nurse/nurse during your pregnancy? 10 points for "yes" (nurse during pregnancy and tandem nurse), 5 points for "yes" (nurse during pregnancy, but wean before birth), 2 points for "thinking about it," 0 points for "no"(wouldn't consider it).

10. Do you eat organic/whole/natural foods and limit your meat? 15 points for "yes" (grow own/buy organic, shop only at health food store, grind own wheat, vegetarian, etc.), 10 points for "yes" (grow some of own food, buy organic, use whole wheat flour, bake own bread, eat some meat occasionally), 5 points for "yes" (try to buy natural, whole grain foods, etc.), 2 points for "thinking about it." 0 points for "no" (wouldn't consider it).

11. Do you use herbal/homeopathic remedies? 10 points if "yes" (very rarely see a regular doctor), 5 points if "yes" (but use a doctor occasionally), 2 points if "thinking about it" (see a doc for now), 0 points for "no" (wouldn't consider it).

12. Do you homeschool? 10 points if "yes" (currently homeschool), 5 points for "yes" (will homeschool), 2 points for "thinking about it," 0 points for "no" (wouldn't consider it).

13. What's your take on childhood vaccinations? 15 points for no vaccines, 10 for delayed, selective vaccination, 5 points for selective, on schedule vaccination, 2 points for thinking about not vaccinating, 0 points for vaxing on schedule.

14. Would you/have you ever breastfeed/fed someone else's baby or have someone else breastfed your child? 10 points if yes (have or someone has bf 
your baby), 5 points if yes (would), 2 points if maybe, 0 if no (wouldn't consider it).

15. Do you use cloth/re-usable products for mom? 10 points if yes (make own), 5 points if yes (buy own), 2 points if thinking about it, 0 points if no.

Ratings: 120 - 140 Super Nutty, Ultra-Crunchy Granola Earth Mama/ 90 - 119 Mmm! Love that whole-grain crunch!/60 - 89 Pretty Crispy/20 - 59 Sprinkled with Granola /5 - 19 Instant Oatmeal/0 - 4 Jell-O

The granola factor quiz brought forth different reactions from members. After taking the quiz, MDC member Lolalola complained about the format of the quiz because it did not cover her crunchy activities, like belly dancing and yoga (2006). Some women were proud of their high crunch factor (Um Hanna, 2009), while others provided explanations for their low scores (Bmcneal, 2009).

MDC members discussed whether or not people are able to detect their crunchy identities based on their external appearances. Women shared how their clothing choices, whether or not they wear make-up, and the types of cars they drive helped people figure out their crunchy identities. In addition to personal appearances, members asked about other external signs that indicate they have NFL identities. For example, Daisymommy asked The Mindful Home forum how she could make her house look crunchier (2006). She explained that she already used natural cleaners, but that her home looked "... way too formal, mainstream, etc. This is because I only came across Mothering 1.5 years ago, so everything about it is from 'my former life'--life before MDC $\odot$ )" (2006). It was important to Daisy that people be able to identify her as being crunchy.

Amongst the extremely crunchy mothers at MDC were also the more moderate mothers. The moderate mothers created threads where they shared their non-crunchy ways, such as using disposable diapers and bottle feeding their babies. These threads 
were frequently locked and/or removed from the forums on the basis that MDC only hosts conversations that promote NFL. One thread, however, made it to almost 200 posts where women shared their non-crunchy ways. Throughout the thread, moderate mothers expressed how grateful they were to have found a place on MDC where they felt they belong. After confessing to her mainstream ways, Igraine exclaimed "I have cleansed my soul. I feel more like I belong. Thank you for this thread!" (2006) and Hajenkatt agreed that "It is nice to find a group that will accept varying degrees of crunchiness. Yay!” (2006).

Clearly, there is a wide range of what constitutes the MDC mother, and this diversity in parenting practices is encouraged O'Mara. O'Mara insists that NFL is not to be viewed as a checklist of practices (2000, p. 237). Instead of following a script, mothers should choose NFL practices that work for their families (O’Mara, p. 327). It does not seem, however, that all MDC members aligned with O'Mara's beliefs about picking and choosing NFL practices. When MDC members shared their parenting practices in bulleted lists, comparing their NFL practices versus their mainstream ways, the impression was that there were MDC members who perceived NFL to be, in fact, a checklist of activities.

Not completing the checklist of NFL activities caused some MDC members to feel inadequate. In a forum group of moderate mothers, EvansMomma shared how she felt inferior in comparison to the crunchy moms at MDC (2006). She wrote "... sometimes being on this board make me feel...I dunno...less than I could be, KWIM [know what I mean]?" (EvansMomma, 2006). For Kitty_Jo, her feelings of inadequacy have stymied her participation at MDC. She wrote "I thought I was the only semi- 
crunchy mom lurking around the boards. I never really wanted to post cause [sic] I didn't feel crunchy enough!! (I'm not worthy, I'm not worthy!!)” (Kitty_Jo, 2006).

Other members felt deep guilt for not completing the NFL checklist. BlueIrises (2006), a member who was pregnant with her first child, shared "I feel very overwhelmed sometimes by the decisions I have been making and will have to make. I feel very guilty about some of the things I don't want to choose to do." Finally, the checklist of NFL practices provided a point of comparison that women used to measure themselves against one another. For example, Familylove (2006) was proud that she breastfed her baby for a year. However, after Familylove (2006) spent time at MDC, she said “. . . I thought *that* was a major accomplishment. . . little did I know." Her sense of accomplishment for breastfeeding her daughter diminished when comparing herself to other MDC members who nursed their children well past a year.

Although the NFL label created a sense of camaraderie amongst MDC members, it ended up excluding other mothers in the process. As previously discussed, MDC members view themselves as challenging the status quo, while they perceive mainstream parents as blindly following the advice of conventional institutions. Parenting labels created division amongst mothers, forming an "us" versus "them" mentality. MDC members posted messages such as "What do you talk about with mainstream mothers?" (Mommyshoppinghabit, 2009) and "How annoyed do you get with mainstream baby thinkers?" (CarrieCo, 2009) and "Keeping your lips zipped around mainstream mamas SO HARD!" (MegBoz, 2009). In these messages, members discussed how to avoid being judgmental or upset over mainstream mothers' parenting decisions. Those 
practicing NFL felt they are greatly different than mainstream mothers, and many seemed unable to find a common ground with them.

The division did not stop at the mainstream - alternative level; even within MDC, there was a division in the community based on member's level of crunchiness. The division left some MDC members feeling unaccepted. Moderate mothers felt like outcasts from MDC for not being crunchy enough, yet in real life (IRL), they were considered to be extreme by their moderate friends. Parenting labels added another layer of stress onto the already challenging role of being a mother.

\section{Importance of Respect}

Since O'Mara, the main icon of NFL, consistently emphasizes the importance of respect, it is not surprising that out of twelve interviews, half of the MDC members interviewed spoke about respect when discussing their beliefs about mothering. Claire shared that with NFL, the major idea is “... respecting your child as a complete human being right from the start," (personal communication, July 28, 2009). Her statement is reflective of the NFL belief that children are equals to adults in terms of "emotional experience and personal integrity," (O'Mara, 2000, p. 328). In contrast, MDC mothers perceive that mainstream mothers try to control their children rather than respect them (e.g., Betsy, personal communication, 2009). Betsy wrote that mainstream mothers treat their children more like "objects and somehow 'less' than adults," (personal communication, July 6, 2009). Betsy touched on the NFL perception that mainstream parents are overly concerned with raising obedient children who comply with their rules (Danielle, 2009). When parents force their will upon children through strict authoritarian ways, NFL advocates believe children's simple rights are taken away (Danielle, 2009). 


\section{Mothering as Spiritual, Instinctual, Intuitive, and Natural}

Spiritual was another word to describe mothering. In MDC's forums, women used the idea of spirituality to explore the topics such as pregnancy (Indeospero, 2007), housecleaning (AutumWind, 2004), conception (KariM, 2007), infertility (OTMOmma, 2006), not vaccinating (Anewmama, 2007), and caesarean section (Yama, 2004).

DebraBaker explained that anything that is done with love and intent, from diapering to wiping runny noses, is a spiritual practice (2003).

Other high usage words MDC members used to describe NFL included instinctual, intuitive, and natural. In fact, Blair explained that listening to her instincts is the major defining element of NFL for her. She said "I think that is basically what is at the crux of holistic parenting to me. It's finding instincts and listening to it," (Blair, personal communication, June 26, 2009).

NFL's claim that mothering is natural and intuitive creates the impression that a woman only needs to listen to herself in order to do what is right for her child. If this claim is true, however, then, why is there a need for forums such as MDC in the first place? Why do thousands of women flock to MDC and post messages with titles filled with doubt, such as "is this (my child's development, my feelings, my experience) normal?" Based on NFL's claim that mothering is instinctual, it would seem these questions of uncertainty would not exist.

Some members expressed the belief that it is difficult for women to listen to their instincts because they have not been supported to do so in all aspects throughout their lives. Blair believed that children are not encouraged to trust their instincts and to be comfortable with making mistakes (Blair, personal communication, June 6, 2009). 
Consequently, Blair believed people are insecure about making decisions on their own, and this carries over into mothering (Blair, personal communication, June 6, 2009). She said “...if they've [mothers] never experienced success, it is overwhelming to try and figure which is going to be a successful option for your child. ."” (Blair, personal communication, June 6, 2009). Meemee (2009) also explained that because she has not been supported to listen to her intuition, she has had a hard time doing so as a mother. She wrote:

intuition - the small voice questioning inside of you - was never encouraged in my life. yet [sic] when i [sic] grew up and found out that that 'small voice' was mostly correct, $\mathrm{i}$ [sic] started believing in it more and letting it lead the way. (Meemee, 2009).

Seashells believed that schools are responsible for women not being attuned to their intuition as they teach children "there is only one right answer," (2009). From these members' perspectives, women posses the maternal knowledge of best mothering practices, but they have not been trained to listen to their instincts throughout their lives. Another reason women may have difficulty listening to their mothering intuition is because NFL is a new lifestyle for them. Mothers new to NFL may have family and friends criticize and challenge their parenting practices. This was the case for Anna, a woman raised by mainstream parents. Anna shared "I think that our mother's generation thinks we're crazy. They had Dr. Spock, and that was it! They think that we worry too much. They're like 'you turned out fine, and I didn't do any of this,"” (June 15, 2009, personal communication). SarahElizabeth found that criticism from others decreased her ability to listen to her intuition. She wrote "The main reason I doubted myself was that what i [sic] FELT was right was not what I was being TOLD was right," (SarahElizabeth, 2009). Barbie64g felt that people questioning her decisions “... have 
an uncanny ability to help me doubt myself," (2009). If others constantly question the logic of a mother's NFL parenting decisions, it is understandable that she might begin to question her own choices as well.

Ironically, the NFL label could be a factor that influences a mother to ignore her instincts. A mother preoccupied with meeting NFL expectations might not listen to her own instincts in the process. For example, a mother may feel that the family bed is not the best practice for her family, and that she should have her baby sleep in a separate room. However, she might ignore her instincts in order to meet the NFL ideal of the family bed. Heavenly explained that she once worried about meeting the perceived NFL/AP standards, and that it decreased her ability to listen to her instincts:

... they want to make sure they are doing everything right to fit in with the AP 'standards.' It was only after I let go of being the perfect AP parent and worrying about what people thought of me (including those on MDC) that I finally started listening $100 \%$ to my own intuition and doing what I knew was best for my family. (November 20, 2009).

Finally, the perceived high stakes involved with mothering may cause women to have difficulty trusting their intuition. NFL portrays mothering as the most important endeavor in existence, and the weight of responsibility placed on mothers is heavy. O'Mara poetically writes "Parenthood is worthy of our best efforts, and raising the heirs of our civilization well is the prerequisite for a healthy society," (2000, p. 2). Based on this point of view, not only does a woman influence the life of her child, but she shapes the future well-being of society as well. During an interview, Veronica talked about the pressure involved with mothering. She said "... people feel like this is your chance. Don't screw it up. This is your kid. It's high stakes," (Veronica, July 1, 2009, personal communication). For Claire, she believed that her mothering practices determine her 
child's future. She expressed her belief that mothering is “. . . about realizing that how you treat this little human being now will affect the adult they will become and who you want [italics added] that adult to be," (Claire, personal communication, July 28, 2009). In NFL, mothers are portrayed as having great power and influence over their children's outcomes in life. It is understandable, therefore, that mothers feel pressure to make the right decisions and that this might cause them to question their own intuition.

The emphasis mothers placed on their role in influencing their children's lives highlights an existing contradiction amongst MDC members. On one hand, there are MDC members who believe their babies are already equals to adults in many ways. They view the baby not as a lump of clay waiting to be crafted by its parents, but rather as a person with its own distinct personality that needs to be respected. At the same time, there are MDC mothers who believe they hold the ultimate influence in shaping their children's futures. These mothers view children as more of a blank slate, and therefore fear making mistakes since they are the ones determining their children's future. In other words, the MDC community seems unclear as to which they believed is more important and influential: nature or nurture. This difference demonstrated that although MDC members share an interest NFL, there is still a wide spectrum of beliefs and values in the community.

\section{Emphasis on Education and Challenging the Norm}

In the end, a mother having a hard time relying solely on her intuition can seek out parenting advice from other sources. Turning to others for advice, however, is not always a simple task. Mothers have to first decide who they trust as an expert. After finding a trustworthy expert, they are encouraged to pick and choose from the tips 
provided by experts according to what makes sense for their families. A new mother shared with MDC her troubles in figuring out how to make decisions that are good for her child without becoming obsessive, neurotic, or judgmental (Batsoup, 2006). The new mother, Batsoup, lamented:

As I'm working through the millions of decisions to make on my journey to be a super-conscious mom, where do I draw the line. . . .it seems like there are a million tiny little issues, and a million things that are BAD FOR BABY... AND, how do I remain open to all this information without overloading?? (2006).

Batsoup was not the only one MDC mother to have felt overwhelmed by all of the required parenting decisions to be made. NiteNicole summarized how many mothers struggle with decision making, writing "I do sometimes feel totally overwhelmed with information. I feel like everything from poop to sleep to food is SO COMPLICATED," (2006).

To guide their decision making, O’Mara encourages MDC mothers to research parenting issues and topics thoroughly (2000). Unquestionably, research and education are highly valued and ranked as top priorities for MDC mothers. O’Mara stresses that mothers need to "look at all sides of an issue before making a decision," (O'Mara, 2005). 3happygirls writes that for the MDC mother, "education is everything," (2006). Members implored one another in the forums to "believe in yourself and do your research," (BlueIrises, 2006) and "trust your instincts. And read, read, read!!!" (Sydnee, 2006). These statements highlighted another contradiction amongst the MDC community; although NFL is said to be instinctual and natural, it also requires mothers to conduct a large amount of research.

In NFL, researching parenting practices is not just about gathering information, but also about challenging the norm. Questioning the mainstream, in fact, was a trait 
MDC members felt set them apart from mainstream mothers. Unlike mainstream parents who are believed to "worship their pediatrician," (Erica, personal communication, June 30, 2009) the MDC mother challenges mainstream parenting conventions by "questioning their usefulness and appropriateness for the child and parent," (Sarah, personal communication, July 27, 2009). At MDC, criticism and skepticism of the medical community was apparent, and mothers posted their complaints about doctors along with smilies ${ }^{3}$ of grumbling, angry faces.

O’Mara has spent a great deal of her career challenging the medical community. In her editorial titled “The New Health Journalism: Challenging the Status Quo,” O’Mara shares a speech she gave at the National Vaccine Information Center (2010). In her speech, O’Mara starts off by stating how parents cannot trust society (2010, p. 12). In particular, O'Mara warns parents to be careful in placing trust in the medical community. She writes that health care in the United States is "fear-based, interventionist, and compromised by economic considerations," (p. 12). She writes that mothers who conclude vaccinations are what caused their child to be autistic are correct because "The mother always knows," (p. 14). The message from O’Mara's speech is clear: use great caution with the medical community.

Unlike MDC members who openly bashed doctors in the forums, Mothering articles are more subtle in their criticism. For example, author Lewars wrote "Follow your Heart," (2008) an article about her daughter being born with a heart defect. Lewars became uncomfortable, and sometimes angry, about her daughter's routine doctor visits that involved technicians, tests, and machines. In the beginning, she felt the medical care

\footnotetext{
${ }^{3}$ Smilies and emoticons are the names MDC uses for colorful symbols which are sometimes animated.
} 
was a necessary evil, but changed her mind after one particular visit. Lewars described the medical visit:

When I placed her on the cold metal table and saw the big X beamed down on her chest for the X-ray, I felt as if I had set her up for target practice. She kept crying, and the technician said I had to hold her still. It took every ounce of control I had not to get her off that table and run away as fast as I could. (para. 14).

The hospital was portrayed as uncaring, intrusive, and impersonal. Based on that hospital visit, Lewars decided to no longer take her daughter in for routine visits. The author granted the doctor some grace, sharing that he did not try to change her mind about ending the regular hospital visits. She asked her friend, a Reiki practioner, for advice:

She told me that pink and green were good colors for the heart and suggested I try to dress my daughter in these colors whenever possible. I followed her advice and supplemented it with my own ritual of holding my hand over Stella's heart every night while I nursed her to sleep. (Lewars, para. 18).

In this story, Leswars encompasses all three desirable mother traits promoted by NFL. First, Lewars questioned the medical norm. Next, she decided to listen to her instincts and no longer rely on the hospital for her daughter to be healed. Finally, she did her own research and practiced alternative, gentler, and more natural forms of care for her daughter. The end result? Her daughter's heart healed, and the doctor admired her efforts, saying “. . .feel free to call me if you have any questions or concerns, but I assume you won't," (Lewars, $\Phi[21)$.

By challenging doctors and mainstream childhood experts, the MDC mother feels empowered. Rather than implicitly trusting doctors as experts, MDC mothers discussed interviewing potential doctors to see if they align with their own NFL beliefs (e.g., MommyDOK, 2009). If a pediatrician did something that is strongly against NFL, like forcibly retracting the foreskin on an uncircumcised baby, mothers urged members to 
slap the doctor's hand (e.g., Kiara7, 2009). Women shared and critiqued their

pediatrician's advice, rolling their eyes through smilies and complaining about the medical communities' mainstream ways.

Doctors are not the only ones to be scorned by MDC mothers for their mainstream mentality. MDC mothers also expressed their displeasure with other mothers who they believed had not done any research of their own. In the eyes of MDC mothers, mainstream mothers actively choose not to educate themselves about parenting and childcare. MDC mothers vented:

My irritation stems from the fact that most of their "mainstream" decisions come from a lack of info. I just can't respect someone who isn't interested in educating themselves on issues as important as giving birth and raising children. (Elishveva, 2009).

Education is important and there is so much out there, you wonder why women don't know things, or why they don't WANT to know. (Akind1, 2009).

It's just blows my mind how uninformed parents can be. They'll spend HOURS on how to decorate the nursery, and making sure they have enough cutesy outfits and so much superficial doesn't really matter stuff. . . (Thefreckledmama, 2009).

If a mother does her research and decides to go with a more mainstream parenting approach, O'Mara insists that she will respect the woman's decision (2000). She empathizes with mothers, acknowledging that the research and decision making process is a lengthy one. O'Mara writes (2000):

With so much information coming to us from so many sources, we have to figure out how to discriminate among the sources, how to filter it, and how to recognize the sources of information that are the most reliable for us. (p. 327).

NFL encourages mothers to consider and research all sides of a topic in order to make an informed decision. 
Even if mainstream mothers' decisions are based on research, MDC members remain critical of their parenting practices. MDC members believe that educated mainstream mothers have used incorrect filters to sort through their information and are therefore misinformed about their decisions. For example, Moonfirefaery explained that educated mainstream parents:

... are ignorant, misinformed, and operating on outdated information without realizing it. It's not that they haven't done research at all, it's that they haven't found the right info or just cannot let go of mainstream mentality and embrace it. (2006).

Tattooed Hand believed that ingrained mainstream thinking and experiences in people and society make it very difficult for others to filter information (2009). Tattooed Hand wrote that in addition to these ingrained mainstream views, “. . . people don't want to entertain any notions that might challenge that," (2009). When mainstream parents' decisions are based on experts that widely differ from the philosophy of NFL, MDC members can have difficulty respecting the mainstream parents' decisions.

\section{Value of Community}

In 2008, MotheringdotCommunity was actually called MotheringdotCommune, demonstrating the value MDC places on close bonds in a community. Mothering has published articles about intentional cohousing, a new form of communes

(O’Mara, p. 10, 2009a). In the forums, members discussed their experiences living in communes (e.g., Ruthla, 2008) and their thoughts about what constitutes the ideal commune (e.g., Spughy, 2008). Member Yoga even formed a separate internet group for MDC members to gather and seriously explore creating their own commune. The idea of living and interacting closely with community members who believe in NFL appealed to many MDC members. 
Members discussed the concept of community in the forums at great length. To illustrate, Samy 23 felt that she would like to be a part of a community because she has heard it is fulfilling, but that she was not sure exactly what community means or where to find it (2009). CameronsMama explained that she believes community is when people come together to support one another and create lasting bonds (2009). Tigerchild agreed with CameronsMama, but added that while a community should share a core value or two, there should also be a good amount of diversity (2009). Many of the members recommended that Samy23 look for community in a church (e.g., Tradd, 2009). Doubledutch shared that her communities have changed over time; before children, her community was her local music scene, during pregnancy and early motherhood, it was a doula group, a prenatal yoga class, and a mamas and babies group, and now it is a weekly craft night community that she as started on her own (2009). May May felt that MDC serves as her community (2005). She shared that although she felt connected to mothers at MDC, she also felt isolated:

... when I'm on MDC, I imagine and feel a big room, with all of us in it, yapping and chatting away while our dc [dear children] play, too -- altogether. I imagine it as quite a loud but joyous commotion. But yet, when I get off MDC, I can only 'fantasize' about all of you, because you're not there, kwim? I have amazing irl [in real life] friends, too, but there's just no way for irl to compete with the smorgasboard of choices in friends that you get with the virtual neighborhood, here. (2005).

In another thread, Bluegoat started off by lamenting that although a village is needed to raise a child, the villages of today have eroded (2009). Her comment is based on the phrase "it takes a village to raise a child." She asked the community why the support from villages has eroded (2009). Softmama believed that becoming a mobile society has broken down family ties (2009). Riverscout's explained that America's ideal 
for independence made the village concept of relying on others for help undesirable

(2009). Suzukiaustin believed women in the workforce and technology are to blame

(2009). She started her post by saying she hopes she will not get flamed, and writes:

... I think our villages have been destroyed with the influence of modern technology and women moving out of the home and into the workforce (think Rosie the Riveter). I must say that I am for women's rights, rights to equal education, healthcare, equal pay when working, voting rights, but, if there is not an extenuating circumstance, a young mother should have the right to be at home with her new baby (not 3 months maternity leave...but years), a grandmother should have the right to nurture her daughter and the new grandchild, the husband should be out working (hunting), the children should be running around naked in the sun with their cousins, we should be dependent upon one another...we shouldn't carry the burden of a male when we clearly are more skilled in motherly things, like lactating. :) With modern technology we have slowly strayed from our natural roles in this world.

What can we do about it? Unplug from the Matrix and teach our children that we all need each other. Get back to the basics. Grow our own food. Buy food from the same farmers at farmer's markets. Teach our children to say hello to people, to call them Mr. and Mrs. Take on our natural role as nurturers. Become a domestic goddess. I really think it's up to our generation to start pushing the pendulum in the other direction. Our mothers and grandmothers (at least mine) were pushing things too far on the other side of the spectrum.

Suzukiaustin did not get flamed for her response, and Chipper26 and Averysmomma wrote that they agree with her (2009). EnviroBecca was the only one who gently challenged Suzukiaustin, writing that it is not women in the workplace that has destroyed the village, but work brought on by the Industrial Revolution in general (2009).

Tigerchild chimed in at the end of the conversation, writing that people think of the idea of villages in a too simplistic manner. She shared:

I think that we have become too accustomed to segregating ourselves and too spoiled about having to learn to get along with lots of different types of people. Yet I think our society right now has greater potential to do that than at any other time in our history (at least in the US).

But first we kind of have to give up the idea that there's one group of people who 
can be faulted and one group of people who is always right. Can we do it? I don't know. It's a pretty damned hard thing to do. (2009).

Finally, there were members who debated whether they truly agree with the concept of a village raising a child. Even though NFL promotes the practice of being part of communities, there were still MDC members who were unsure about the concept. Corvis said that she cannot trust the village as non-NFL members are likely to try to sneak her children ice cream and cookies (2005). Veteran member Choli believed that the NFL mother's fear of the mainstream's influence on her children is the reason why the village had eroded (2008). She shared:

I think the village got tired of the sort of mothers who have so many specifications about how their child must be treated, and who throw fits when anyone interacts with their child that is in any way different from how Mom does it. Plenty of Dads are included in the disaffected village. If you want help, don't have a fit when the helper is not a psychic clone of yourself. (2008).

USAmma worried that leaving her children with others might lead to them being kidnapped or molested (2005). Also, by remaining isolated as a family, USAmma writes that she does not have to justify her parenting decisions to others, nor does she have to worry that her children will pick up the view points of those who differ from her own (2005). Mama2Jesse explained that she did not need any help, and that she is not a village dweller, but a hermit with a stick (2009).

The discussion about community involvement in raising children touches upon topics raised in MDC's forums. First, MDC members believe they should be the primary caregivers for their children, and the idea of letting anyone else fulfill this role is difficult. The mothers viewed the village as unnecessary because they are the main nurturers. In addition, the mothers mistrust institutions and the mainstream. They fear that others will go against their NFL ways. In fact, a high number of threads involved MDC members 
complaining about their family members who challenged their parenting decisions. The main enemy was usually the mother-in-law. For example, KweenKrunch shared her frustrations about her mother-in-law giving her six month old son a plastic chainsaw (2009). She was offended about the gender-role implications of the present, and she did not appreciate that the toy was plastic and required batteries (KweenKrunch, 2009).

Furthermore, KweenKrunch was upset because a chainsaw cuts down trees, representing deforestation, the destruction of non-renewable resources, and the loss of animal habitat (2009). For MDC members concerned about not exposing their children to mainstream ways, it is easier for them to be the sole caregivers.

In addition, the discomfort mothers felt with having others around their children highlights the existing fear in the MDC community. In fact, O'Mara wrote an editorial about how to handle fear (2009b). She explained that people become fearful when life feels out of control, and that the sensationalist media can contribute to this as well (O’Mara, p. 12). At MDC, members spoke about their fear of uncontrollable things such as childbirth (e.g., CougBride07, 2008), unassisted childbirth (e.g., Hesperia, 2009), not vaccinating their children (e.g., Chloe'sMama, 2009), and having a baby that is not cute (e.g., Shakenbake, 2009).

NFL and Intensive Mothering Intensive Mother-Child Bond and Constant Close Proximity to Child O’Mara reminds us that no one, not "even Dad, can substitute for Mom," (2000, p. 116). Online discussions at MDC proved that members align with O'Mara's belief that mothers are the main source for nurturing. Members posted multiple messages about their children not liking their fathers, or their babies preferring to be comforted by them 
(e.g., Viviensmama, 2009; Chirp, 2008). Other mothers posted questions inquiring how they can help their husband learn to be nurturing and gentle fathers (e.g., MamaRuga, 2008). MDC discussions like these align with Hays' research that found many mothers believe fathers are incompetent caregivers for children due to lack of training or intuition (1996, p. 107). For many MDC members, not even the father can serve as a substitute for the mother as a source of comfort, placing the mothers in the role of primary caregiver.

The amount of time mothers spend with their children was a hot topic amongst MDC members. There were varying opinions as to what it takes for children to attach to their mothers. Erica, a working mother, was bothered by the MDC members who believe that working mothers are unable to truly be attached to their children as they are not physically with them the majority of the time (personal communication, June 30, 2009). MDC members also discussed their comfort levels with being away from their children. In one thread, some women shared that they are comfortable leaving their children for a night out or to run errands. Hempmama writes "I think people need varying amounts of time to themselves, to recharge, in order to be good parents," (2009). There were many moderate mothers who agreed with Hempmama and claimed to enjoy some time without children around. Other mothers, however, felt anxious when away from their children. In the same discussion, MDC members shared their feelings about being separated from their children:

I will say that I am very attached to DS, and I don't feel comfortable leaving him for more than a couple of hours or so at a time, with a few months in between each occasion. (Mama.Pajama, 2009).

I really enjoy my son and being with him. I am uncomfortable if I am away from him. I do not like it. It makes me nervous. (Angelchristin, 2009). 
I take my baby everywhere. . . I have never left her with someone. I don't feel comfortable leaving my baby with someone. She is 7 months old. Do you think that's [sic] wrong? (Sarhaj, 2009 ).

But, I have a hard time leaving my son...I wouldn't have much fun if baby was somewhere else. I'd worry. (UhOhWhatNow, 2009).

We're the weirdos who are all together at every lesson, camp, activity, school function, practice, game, wedding, birthday, Scout function, vacation, etc...Also, with them in school, I volunteer 2-5 times/week just to be near them. (SAHDS, 2009).

In this discussion, the tension ran high as mothers accused one another of judging how much or how little time they spend with their children.

MDC members who are uncomfortable being away from their children possibly are anxious people by nature. It is also possible, however, that these anxious women have learned and internalized the NFL message about the vital importance of a mother physically being with her children. With NFL's strong emphasis about the importance of attachment between mother and child, it is understandable that MDC mothers would be uncomfortable with being away from their children's side.

\section{Extensive Research and In-depth Knowledge}

Another aspect of intensive mothering is the amount of research MDC mothers conduct regarding pregnancy and child rearing. As previously discussed, research and education are valued endeavors of NFL that allow mothers to make informed decisions about parenting (O'Mara, 2005). The level at which the MDC mother researches topics is extensive and thorough. For example, BeckyBird told the group "I spend every minute of my free time reading and researching," (2009).

An example of a MDC mother's extensive research came with Meemee. In a discussion about baby door way jumpers, Meemee informed MDC members that they are dangerous (2009). Although the group was skeptical about the danger of jumpers, she 
assured them that they are unsafe and writes "I did a lot of research which talked about breaking bones," (2009). Meemee did not rely on just one resource to learn about the safety of jumpers, but rather read multiple studies that compelled her not to use them.

Due to their extensive research on parenting topics, MDC mothers are often the main decision makers regarding child care, trumping partners and husbands. While partners may chime in with their opinions, the MDC mother is frequently the ultimate authority regarding parenting decisions. To demonstrate, Averysmomma told the community:

I'm the one who does the "dirty work" of researching until my little eyes are bleeding, he [her husband] lets me steer the ship for the most part in making those choices. . . I summarize what I have researched and he nods his head and says things like "you're right". .. (2009).

Another member, Ashleedio, shared that in her relationship with her husband, she makes all of the decisions. She explained "He's let me call every shot there is in regards to parenting our dd - cosleeping, bf'ing, cd'ing, vax schedule, gentle discipline, etc completely takes my lead and does what I feel is best," (2009). Ashleedio was upset because along with the research she had done about circumcision, her instincts also told her that the practice is wrong. This is the desired NFL combination to inform parenting decisions: research plus instincts. However, Ashleedio's husband did not agree with her. She planned not to sign the hospital consent forms to circumcise their son, and she knew her actions would anger her husband. The MDC mothers assured Ashleedio that she was making the right decision. They applauded her for doing her research and letting her instincts guide her parenting decisions.

MDC serves as a resource of information for women researching mothering issues. Not only does the forum cover a wide breadth of topics, but members share great 
in-depth knowledge about parenting issues as well. The more specific the circumstance, the more in-depth knowledge the mothers have about a topic, such as premature babies or breastfeeding. Poetgirl, for example, tried to conceive for two years. She demonstrated her incredible in-depth knowledge about in-vitro fertilization by sharing her ritual when preparing for her in-vitro treatments. Poetgirl writes:

So, I am trying/tried to get 6-8 acup. [acupuncture] visits in before the ER. I began meditation daily and doing breathing exercises (I get a bit short of breat $[\mathrm{h}]$ on the injections, so this was important). When I wasn't told to avoid bending or twisting, I did yoga most days. I took my pre-natal, fish oil, Chlorella, royal jelly, extra vit D and E. I drank Kombucha every day, Kefir often and juiced some wheatgrass. I drank lots of nettle and red rasp.[berry] leaf tea. I did not drink caffeine or alcohol.

When I found out my kidney meridians were weak, I added fresh ginger and ginger tea. I was concerned about my lack of circulation and the uterus feeling cold from a TCM [traditional Chinese medicine] perspective, so I took baths and rubbed castor oil on my abdomen after and sometimes used heat after that. Above all, I tried to let go (not force) of the whole "story" of how my fertility struggles have gone. Through mediation, I was catching myself repeating the story of it over and over, creating this deep negative groove. Becoming aware of that and gently trying to redirect it (and I was grateful for the long protocol here) were important steps in my feeling ready to start. It's not perfect but it's better. (2009).

Clearly, Poetgirl demonstrated she possesses in-depth knowledge about how to prepare for in-vitro fertilization. She has researched both mainstream and alternative medical sources. Poetgirl also had extensive rituals for what she did after in-vitro fertilization treatments.

\section{Burn out and Rage}

Intensive mothering is not a sustainable parenting mode for all. NFL creates the expectation that mothers should spend their time researching, trying to be attuned to their intuition, respecting and responding to their child's needs, being with their children around the clock, and bettering their own selves, all while striving for simple, natural 
existences. For some mothers, the end result of intensive mothering was burn out. For example, Sparklefairy followed NFL's guidelines of keeping her children always by her side. The constant physical attachment to her children did not go well for her, and Sparklefairy shared:

I burned myself out badly doing the $24 / 7$ on duty thing for years on end. I missed weddings and other 'adults only' events. I couldn't spend 15 minutes browsing for a library book (reading is my great love) without somebody emptying one of the lower shelves. My husband coming home from work was no respite and there were times when he was working out of town for months. I would not choose to parent that way again. (2009).

A veteran member, Zinemama, believed that frazzled, burnt out mothers are common on MDC:

We see this sort of thing on MDC all the time. Mothers who are exhausted from wearing their babies all day long and nursing them all night - yet who refuse to take a break and recharge for a few hours, because that somehow equates to "leaving" their babies, even though the child would be with its own father. (2009).

MDC mothers attached to their children admitted to longing for space and time away.

Claire shared that she envied mainstream mothers at times:

Sometimes I fantasize about how much easier it would be to mother these ways, but then I realize that they'd only be easier on me and much, much harder on my daughter. She has a real need to be with me 24/7. (personal communication, July 28, 2009).

Goldingoddess shared how upset she was to discover her friend lets her baby cry it out $\left(\mathrm{CIO}^{4}\right)$ so she will sleep through the night. She writes "I'm angry but I am jealous too. I want my LO [loved one] to STTN [sleep through the night] so bad. Isn't this horrible?" (2009). By trying to meet the checklist of NFL expectations, some MDC mothers ended up being exhausted and feeling resentful of others.

\footnotetext{
${ }^{4}$ To let a child cry it out refers to not going to them at nighttime if they are crying. The idea is that children need to learn to soothe themselves back to sleep and not be dependent on their parents for comfort.
} 
In addition to feeling worn down, intensive mothering leads some MDC mothers to experience feelings of rage. Morgraine started a message discussing the rage she experiences while caring for her children in January of 2006. The thread was still active in January of 2009, totaling over 1,550 posts. Members shared that while they would never actually hurt their children, they have had intrusive thoughts about hitting them, throwing them across the room, or yelling. These thoughts often occurr when their children were needy, wanting to nurse, or crying (e.g., TeaBag, 2006). Members shared that there have been similar discussions on MDC about mothers feeling intense anger, and expressed that they were frightened, surprised, and ashamed by their feelings (e.g., WuWei, 2006).

Iverson and McPhee (2002) found that sharing frustrations is a common activity in communities of practice, and there are multiple messages on MDC dedicated to mothers venting about the sources of their aggravations. Members addressed the source of their annoyance (children, in-laws, husbands, strangers), and ranted about how angry and irritated they felt. Women were grateful to know other mothers experienced feelings of hostility towards family members, and they thanked others for sharing their emotions with the community.

Certainly, there are multiple factors that contribute to a mother feeling rage and exhaustion, and these feelings are not exclusive to those practicing NFL. The amount of work and dedication NFL asks from mothers, however, may well be a large contributing factor to this unhappiness. When speaking about parenting pressure and mothering rage, Iliex shared:

I have been thinking lately about our lives. Our lives as mothers in this culture. The pressures, the expectations, the guilt, the noise, the unceasing stimulation, the 
constant barrage of it all, never letting up. Even when we try to squeeze in that millisecond of time for ourselves, it is never what we need it to be. It is just catch up. and [sic] therefore we never get around to what we really need, which is to just be, without all of this. (2006).

While NFL can lead to a happy, healthy, and attached baby, it can also lead to a stressed out, depressed, and resentful mother.

Part II: MotheringDotCommunity as a Community of Practice

The second section covers the findings regarding MDC. The culture of MDC is examined and individual components, such as forum activities and symbols, are analyzed. Based on observations of forums, analyzed archived messages, and interviews with MDC members, MDC was identified as a community of practice. As such, a community-ofpractice lens is utilized to frame the findings of this study. Also in this section are member profiles that demonstrate learning and evolving at MDC. The section about MDC concludes with the disadvantages and advantages of being a part of an online community.

\section{Domain}

According to Wenger, an essential characteristic of a community of practice is that is has a domain (2001). MDC's domain is NFL, and it is clearly outlined in the online mission statement. Wenger explains that the domain of a community of practice might not be recognized as an area of expertise to others. Storm Bride believes that people do not view mothering in general as an area of expertise, and she wrote "There seems to be an attitude that even monkeys or dogs can have babies, so just anybody can do it," (2009). Due to the perception that others do not view mothering as an area of expertise, Storm Bride concluded that the practice is not valued. Sparkly agreed that mothering might not be valued, but this does not bother her. She said that mothering is ". 
.. my job, and I'm darn good at it, [I] am content and fulfilled with my job and family, and don't care if it isn't 'valued' by someone else," (2009).

In NFL, the domain of mothering is undoubtedly an area of expertise. Mothers are asked to conduct research on all topics regarding pregnancy and child rearing to inform their parenting decisions. They practice intensive mothering with the expectation that they will always respond to their child's needs. In addition, NFL is not just about mothering, but also about living a green lifestyle and working towards personal growth. Women are encouraged to support socially conscious organizations, lower their carbon footprints, and nurture their spiritual growth.

\section{Rules and Moderation}

Along with the user agreement, each forum has its own guidelines. A forum's guidelines and rules might be generic, simply reminding women to follow the user agreement, and many warn against providing medical advice. However, some forum guidelines are very specific, like in the adoptive forum. Members are told that they must not allude to or directly offer to adopt someone's baby. There are also guidelines on how to respond to others in a gentle tone:

I would like to stress that we need to be gentle with prospective adoptive/foster mamas. Even if they stumble and trip over their words and the terminology at first. It is essential that we are gentle. Everywhere on MDC and especially here. (Abimommy, 2009).

Also at the top of forums are posts referred to as "stickies." If a message is a sticky, that means it is always stuck to the top of the forum for easy access. Stickies are often a compilation of resources, such as books, articles, and websites. Other stickies are compilations of past posts. For example, the Homebirth forum has a sticky where women share insider tips for birthing at home. 
Moderation is a regular MDC practice that is intended to correct user agreement violations and to keep members safe. Alerts and warnings are given by moderators and administrators to members who are breaking the rules. A moderator reminder equals zero points, a moderator alert equals one point, and an administrative warning equals three points. All points are recorded, and when a member reaches nine points, their account is suspended for 30 days. After a suspension has ended, if a member reaches nine points again, the membership is removed.

MDC explains that members who have received warning or alerts " $d o$ have the right to have it reviewed and possibly reversed," (Fullofgrace, 2006). If a member receives a warning, she is to first email the moderator who issued the alert in order to discuss the situation. If that does not satisfy the offending member, she can move on to discuss the situation with the board administrator through an email. There is only one designated administrator who reviews the alerts and makes the final decision. Should a member still feel the warning or alert is unfair and deserves to be overruled, she can submit a request for review at The Kitchen Table. The Kitchen Table is an advisory board that works to resolve conflict and address members' complaints. Two moderators and three board members are appointed to The Kitchen Table, and the membership rotates. Finally, if The Kitchen table does not provide a prompt reply, a member can email the publisher or the web editor.

Moderators most commonly step in to remind members that they are not to discuss things that promote non-NFL practices, such as letting a baby cry it out. For example, in a thread discussing how much formula to feed a baby, Coffee.caugh shared 
how much formula she feeds her own baby. She then proceeded to overstep MDC's user agreement by writing:

while [sic] we are on topic of ffing [formula feeding] i [sic] get really irritated when people assume $\mathrm{i}$ [sic] do not have a great bond with my baby bc of ffing. and $\mathrm{i}$ [sic] would love to know how many ffeeders are on this board.. i'd [sic] love to have conversations with you too. $\mathrm{i}$ [sic] end up feeling sort of like an outcast sometimes and when $i$ [sic] see other mamas who ff $i$ [sic] don't feel so alone. $i$ [sic] know ffing is frowned upon here but $\mathrm{i}$ wish the mods would put a ff subforum for us too. (2009).

Lusa's Mom thanked Coffee.caugh for her post and wrote that she also feels the same way (2009). At this point, Annettemarie, the moderator, stepped in to remind the mothers that hosting a general forum about formula feeding would be outside the scope of MDC's purpose of promoting NFL. She told the women that when appropriate, formula feeding has been discussed in other forums, such as:

Breastfeeding Challenges and Adoptive and Foster Parenting, threads on formula for special needs children in the Special Needs forum, threads on supplementing preemies in the NICU forum, threads on homemade formula in Traditional Foods, threads on the nutritional aspects in Nutrition and Good Eating, threads on the health aspects in Health and Healing, threads on working through your feelings in Personal Growth, and threads on bottle nursing here in Life with a Babe. (2009).

Annettemarie attempted to redirect the conversation by telling the women they should email her or a moderator and/or raise the issue in the Questions and Suggestions forum for further discussion. She was unsuccessful, however, at shutting down the conversation. Other mothers chimed in that they would like to discuss formula feeding as well, and that they have felt nervous raising the topic on MDC. They shared that they feel judged for bottle feeding their babies, and that they are grateful to have found other mothers experiencing the same situation. Annettemarie stepped back in and wrote "I'm going to go ahead and close this, as it's turned into a variety of questions best asked in their own threads or in different forums (please see my post earlier in the thread)," 
(2009). In this thread, the members shared information and supported one another, desirable actions in a community of practice. However, the moderator felt they were deviating too far from MDC's purpose, and she ultimately has the last word about which conversations are allowed to continue.

Other times, moderating posts is done to protect the members of MDC. Blair shared that she has seen posts shut down when members reveal too much information or give advice that is dangerous (personal communication, June 26, 2009). For example, a thread was closed when a mother shared that her baby had died during her unassisted homebirth. The mother did not believe in receiving prenatal care, so she was unaware that her baby was in the breech position. Consequently, the baby presented first by a single foot, and it took her thirty minutes after she first saw his foot to deliver the rest of the baby. By that time, the infant had died. Normally, a moderator will lock a post, meaning the message can still be viewed by the public, but no one else can post a reply. This post, however, was quickly removed altogether from MDC. The moderators may have feared that the woman shared too much information about her unassisted childbirth, and feared that she could get in trouble for her actions.

Through moderation of posts, MDC's desired norms for online interactions can be enforced. Moderators remind women to be kind to one another, and that they are not supposed to speak poorly about other forums or members. When members do break this part of the user agreement, they will either receive a reminder or the moderator will delete their posts altogether while still keeping open the discussion thread. For example, a debate became very heated when members shared how they deal with people who do not practice attachment parenting. Two members become the predominant voices in the 
debate, arguing back and forth. The moderator, USAmma, deleted certain posts and sent private messages to the offending members. USAmma scolded the members, writing:

This thread turned very quickly from discussing and debating an issue, to debating back and forth between one member. Sometimes the best thing to do at that point, rather than making it a public spectacle, is to use your PM feature. (2005).

The moderator publicly shamed the members, letting them know that the tone of their conversations and the manner in which it was conducted was inappropriate. At the same time, she explained what members should do if they want to debate back and forth, which is to converse through private messages.

Although the moderation process and penalty points at MDC appear to be straight forward, even veteran members have been confused about the process. In the thread “Automated Suspension/UAV Tracking," senior members, administrators, and moderators discussed how the penalty system works (2009). Even after a lengthy discussion, members still remained unclear as to how MDC's penalty system works. Furthermore, many of the members did not know if they had any penalty points against them. Members discussed how others should be forgiven for their user agreement violations, and WuWei quoted O'Mara and Thich Nhat Hahn to support her beliefs about reconciliation (2009).

Other times members are unclear about individual forum's specific guidelines. This is seen on the forum Parenting Gifted Children. A mother asked the forum what classifies a child as gifted, and No5no5 responded "I think everyone has their own definition. And we're not really allowed to discuss," (2009). Joensally replied "I think we can say what we think giftedness is, we just can't say that we think someone else's 
definition is wrong or debatable (2009). The debate about what is allowed in the forum continued amongst members:

Soooo. . . a whole thread in which everyone lists their own personal definition would be fine, so long as nobody actually says that they disagree (though the disagreement would be obvious)? That seems a bit contrived, if it really is the rule. (No5no5, 2009).

Joensally replied:

Hey, I'm just sharing my short hand for how I read the forum rules $\odot$. I figure if I stay out of doing that, I'll avoid censure. Although, this post could be interpreted as debating the UA. . (2009).

Vaw jumped in to support No5no5's interpretation, writing:

I agree - I read the rules as saying we could poll or list our definition - just not go back and forth over and over again arguing why we are right and the previous poster is wrong .... (2009).

Members debating about the norms of the group is an identifying feature of a community of practice (Wenger, 1998). Together the members are trying to negotiate the meaning of the group. The negotiation of norms, such as goals and communication styles, is an important step in helping communities of practice move forward and grow (Palloff \& Pratt, 1999). In the example of members debating what they can say regarding the definition of gifted, however, the forum guidelines seemed to stifle lively conversation. Rather than challenge one another, members had to allow each person to state what they believe being gifted means. The process of a member defending her definition could cause her to be affirmed in her beliefs, or possibly to reexamine her arguments. In addition, as No5no5 pointed out, it feels contrived to have everyone accept each other's definition, even if they clearly differ from one another. So while the Parenting Gifted Children forum's guideline of not debating the definition of gifted is 
meant to prevent endless debating, it also seems to stifle sociability and gives conversations an artificial feel.

Members might also feel angry and confused when administrators edit their posts. For example, an administrator removed a thread where members shared their noncrunchy ways. JessC was confused as to where the post went to and why it was shut down, so she started a new message to let mothers continue sharing their non-NFL practices (2006). Multiple members were also confused and disappointed about why the thread was removed. The moderator, Annettemarie, told the group that they should email her if they have questions rather than complain to each other as it could be interpreted as criticizing the moderators' decisions, which is against the rules (2006). Annettemarie quoted the user agreement, writing that it is not allowed to:

... debate or criticize the MDC User Agreement, or to otherwise discuss the moderators, administrators, or their actions. Constructive criticism and questions for purposes of clarification may be sent through the Private Message feature or by email to the moderator or administrator. (2006).

The moderator's explanation was not enough to satisfy member RomanGoddess. She was still angry that the thread was shut down without an explanation. She complained:

Um, I think it is nevertheless appropriate and just plain good manners for the moderator to provide US a sincere explanation ON THE THREAD as to why the thread was closed. This is normally what is done. And the quote provided above is not an adequate explanation. (2006).

The moderator reminded her once again that members are not supposed to criticize moderator's decisions. After that, another moderator stepped in and wrote "speaking of closing, this thread is being locked for moderator review $\odot$ We will post a response as soon as possible. Thank you for your patience, *8. 
demonstrates how the moderators hold the power in deciding which posts stay open for discussion and which ones get shut down.

It can be difficult for the group of administrators and moderators to be consistent and thorough with their moderation practices. With 45 moderators and 11 administrators, it is understandable that there is variability in what is deemed appropriate for forum discussions. A moderator for the breastfeeding forum might find a particular thread to be in violation of the user agreement while a moderator for the parenting forum thinks the same message is fine. This happened with the thread where mothers shared the ways in which they are not crunchy; the thread was shut down in one forum, but it remained open in another.

In addition, some thread titles seem to be in direct violation of the user agreement, but they do not get locked down. For example, even though members are forbidden to provide medical advice, a message remained open titled "Wanna play doctor?" (JessicaTX, 2009). Another message titled "I hate breastfeeding" (MegBoz, 2008) also remained open, even though it is clearly against NFL practices. The moderators' actions of deciding which threads to lock down and which ones remain open are not always consistent with one another.

Members have different reactions and thoughts about MDC's moderation. Member Erica appreciated moderators working to reduce hostility in the forums, but she believed members find ways to skirt around the user agreement (personal communication, July 6, 2009). Erica was especially bothered by the conversations about mothers returning to work (personal communication, July 6, 2009). Erica explained that members will write that while they understand why some women go back to work, they 
could never do so themselves as they do not want to be away from their children. Erica said that these underhanded comments are "... downright snarky, especially when there are clearly working mothers participating in the thread (the implication being, sure I give lip service to respecting your decision, but ultimately I am clearly the more dedicated and loving parent)," (personal communication, July 6, 2009).

Other members felt that MDC's moderation is equivalent to censorship (Zjande, 2009). The moderation can be so off-putting that it lessens members' online participation, both in contributing to discussions and visiting the website altogether (Earthmama369, 2009). Some members appreciated the intent behind the moderation, but they felt wrong judgment calls are made. Claire called the moderation at MDC a “strange phenomenon" where moderators wrongly judge threads (personal communication, July 28, 2009). Claire explained:

Sometimes people learn from someone saying "I did cry it out with my first child and now realize how horrible it was for my child." That post was removed for being pro cry-it-out. I've seen/heard many women who have given up mdc in disgust because of over moderation when they generally agree with the ideas of the community and I believe many more probably never stick around long enough to really explore the ideas presented there. (personal communication, July 28, 2009).

Even though the user agreement and moderation is in place to protect MDC and its members, it clearly can cause confusion and frustration. Even worse, it can result in lowered member participation, or members leaving the community altogether.

Perhaps the most bewildering aspect of MDC's moderation and the user agreement is the fact they both go against O'Mara's own words on NFL. O'Mara tells mothers to use only the NFL ideas that that will work for their family, and ignore NFL practices that will not (2000, p. 2). O'Mara promotes that parents create an ethic of 
parenting based on the nature of their children, and not on the beliefs of the culture (p. 2). O’Mara tells mothers "If there is any advice I would give after twenty-five years of parenting, it is to be yourself. Go your own way," (p. 327). O'Mara insists that she is fine with mainstream parenting choices as long as they are informed ones (p. 327). However, MDC's user agreement and moderation convey a different message. By not allowing women to discuss, or sometimes even mention, the mainstream practices that they use, MDC sends a message that parenting differently than NFL is unacceptable. The moderation activity combine with the numerous critiques of mainstream parenting conveys a message that anything different than NFL practices are not valued at MDC. Women cannot reveal the mainstream aspects of their lives as parents, thus limiting the true openness and honesty of the community. The user agreement is intended to protect members, but it can actually hurt members by limiting what members can share with one another.

\section{Shared Repertoire}

The practice in MDC's community of practice, NFL mothering, involves a shared repertoire of resources. These resources include things such as language, symbols, tools, concepts, stories, and experiences (Wenger, 1998). Members learn the repertoire of MDC through participation.

Without having the insider knowledge regarding members' titles, language, rules, and smilies, a new MDC member can feel left out and confused. This was the case for Just Wondering. She shared that as a new MDC member, she felt like an outsider due to finding the language usage to be obscure (2002). After time, however, she began to feel 
like she belonged at MDC as she began to understand the insider jokes. Just Wondering wrote:

... and the thing is, once you have hung around here long enough, you won't feel left out. Maybe its [sic] like fitting into a new class at school, where all the others know each other from the previous years. (2002).

Not knowing the shared repertoire can make a new member feel like a novice, but it is also what helps members move to a veteran status.

\section{Language and Symbols}

Reading messages on MDC can be like learning a new language. Acronyms, abbreviations, smilies, and language pepper messages throughout the forums. Cynthia Mosher, an MDC administrator, empathized with new MDC users, acknowledging that "the use of acronyms, emoticons, and abbreviations on the net have become so commonplace that those new to all things internet are often lost in a sea of confusing caps, colons, dashes, and do-hickies," (2001). To help members out, there is a link in the Questions and Suggestions forum that explains hundreds of the popular acronyms. Mountaingirl3 referred to MDC member's different combinations of practices as the “APNFL alphabet soup,” (2006). Members can also view a code list for smilies. As there is no compiled list for language usage, it might take new members longer to learn. For example, mothers may use the slang terms used by their children for nursing, such as nummies or milkies. New members could be confused if a mother signs off quickly, writing that she needs to go "catch a pee" (a term used in elimination communication). An administrator also explained message typing etiquette. She wrote that using all caps is considered to be yelling online, while not capitalizing words at all might be perceived as either being lazy or preoccupied with her children (Cynthia Mosher, 2009). 
A practical benefit of using online acronyms is that it allows members to type out their messages at a faster rate, a bonus for busy mothers. Acronyms can also help others understand why a mother's message might be full of typos or disjointed in nature. For example, mothers starting messages with the acronym NAK informs members that she is Nursing At the Keyboard, thus limiting her typing ability.

Furthermore, smilies allow members to more accurately convey their emotions and sentiments. A member might start a post that sounds like she is frustrated, but by placing a smilie of a person shrugging their shoulders, she can show that she is not that bothered by the situation. When a mother shares a deeply sad story, such as losing her baby during childbirth, members can respond with an emoticon of hugging faces, rather than try to find words to sympathize. Thus smilies aid in communication, an important tool as the intended tone of messages can sometimes be misconstrued online.

Lastly, by correctly utilizing the smilies, language, and abbreviations, women boost their member status, showing that they are knowledgable of the shared repertoire of MDC. LaceyW. showed her knowledge of the smilies and language in the Trying to Conceive forum. After getting pregnant, she wrote ".... I found a wealth of support and information on these boards, so even though I always thought this was waaay cheese:

here is some baby dust for everyone : $\Theta$ IT $="(2008)$. Online, the pink face animated to move its arms and throw out good vibes and the fairy's wand sent out stars. By wishing others good luck through the use of smilies and NFL language like "baby dust," LaceyW. demonstrates her insider knowledge about the shared repertoire of the Trying to Conceive forum.

Inside Jokes 
Another way for members to prove their MDC insider status is through the use of inside jokes. One MDC inside joke are certain members' signatures lines that say they are banned for various silly reasons. This joke originated from a past April Fool's Day prank. The moderators and administrators changed well-known members' signature titles to say silly things. Even though the title change was a joke, many of the members asked to keep their banned titles. Justmama explained "Those of us who are still banned had begged to stay 'banned' because we felt a little special. I had no senior title before and I really really like mine now!” (2007). April Fool's Day jokes have proven to be a community building event for MDC. Veteran members know that the moderators and administrators will play a prank, so they watch for changes on the board. An additional insider joke for members to participate in is Dirty Deeds Done Dirty Cheap (DDDDC). DDDDCs are purchased for $\$ 2.50$ and allow a member to change another member's signature title for seven days. MDC explained that DDDDCs might be purchased for the following reasons:

Did a member post something particularly funny? A "running joke!" Someone coin a phrase or maybe you want to uplift a member after a particularly bad week/experience/day? Whenever you want, just send it on in! (http://www.mothering.com/mdc/ddddc).

The insider jokes not only serve as a source of fun, but they also create a feeling of belonging amongst members.

Netiquette

Although some of the community rules are spelled out for members, like the user agreement, there are other MDC etiquette rules that are only learned over time through reading and posting messages. These rules of conduct for internet behavior are referred to as netiquette. To begin with, lurking, the act of reading messages without ever 
commenting, is not actively discouraged, but lurkers are encouraged to participate. Since MDC tracks how many people are viewing a forum at a time, members might ask lurkers to come out and introduce themselves. If a woman has been a member for awhile without posting and finally decides to introduce herself, her title might say something like “Coming out of lurkdom!”

Another unspoken rule at MDC comes with the DDCs. When women post to DDCs that they are not members of, they often start with saying "sorry for crashing!" They acknowledge that they are not part of the club, but that they would like to comment anyway. An example of tension rising from DDC crashing occurred in Claire's club. Claire complained to her DDC about not being able to get into a bar on New Year's Eve with her baby, a minor (2009). While some members sympathize, other people who were not in her DDC told her that she should not try to get into a bar with a baby anyway. Claire grew angry, writing "I made this post in my DDC, to women who I feel I've gotten to know pretty well over the course of my pg [pregnancy], and who I felt safe venting to," (2009). The administrator originally locked the message when it began to turn into a flame war. However, the message was reopened when the administrator realized it was in a DDC and she backed Claire up, telling members to only write positive and supportive remarks in DDCs.

The Community and Activities

In addition to the domain, the actual community and the practice are vital components to a community of practice (Wenger, 1998). The community is formed by members interacting with each other through joint activities, such as sharing information and providing others support. The relationships built in the community are what allow 
members to learn from each other (Trentin, 2002). By interacting with one another through joint activities, the members expand their community repertoire. The following section covers the major activities of MDC.

\section{Creating Online Identities}

MDC members can display personal information such as birthdays, home page URLs, instant messaging names, biographical details, location, interests, occupation, and Momspace (a social online community for mothers) information in their profiles. Some members will provide exact locations, such as San Francisco, California. Other members will just include the state, like California, or the general region, such as the west coast. Some members strive for humour in their profiles, writing things such as "where are we?" for their location. Members can post as little or as much information as they like. Mothers' screen names often include information about their children, such as "Joanna'sMama." Other mothers may include information about their hobbies or their jobs, such as "VegamMommato3" or "TeachingKids."

In addition, members are able to provide personal information through their signature lines. Signature lines include animated icons that represent aspects of members' lives. While most icons are easy to understand, others require more investigation to reveal their meaning. For example, a maroon ribbon turned upside down stands for a caesarean section, which MDC views as the less ideal method of delivering a baby. A woman having three cesarean sections might choose to have three upside maroon ribbons with the birth date of each child next to them. There are a total of 26 colored ribbons, and some colors represent multiple causes. The pink and blue ribbon, for instance, represents pregnancy and infant loss, SIDS, male breast cancer, and genital 
integrity. Other examples of smilies include smiling faces with wings on them to represent children lost due to a miscarriage or stillbirth, and a mother whose child runs by her, lifts up her shirt, nurses, and runs off.

A signature line may read like the following: Wife (31)

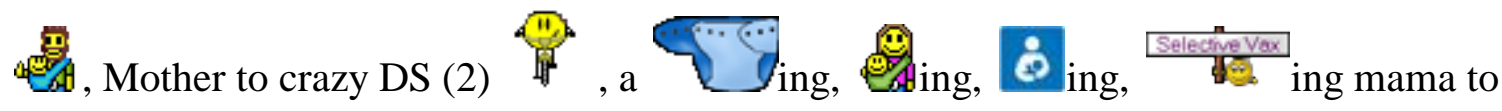
our $\overparen{F}$. On this animated signature line, the baby crawls and tumbles, the diaper flips around to reveal the letters CD for cloth diaper, and the bicycle boy pumps his legs. While the signature lines add a personal touch and an element of fun, they also serve another purpose: members share personal information about themselves, aiding in nurturing emotional connections with others (Boyd, 2002). The smilies represent the easily identifiable artifacts of the NFL, such as a baby sling and cloth diapers.

The smilies also create a common symbol system, strengthening MDC's shared repertoire of language and practices (Boyd, 2002). Artifacts that would not be found in the NFL home might include a lack of baby gates, baby crib, or play pen, all which are viewed as unnecessary and disrespectful methods of containing a child.

Through the creation of signature lines, members share unique information about their lives with the community. At the same time, the signature lines allow MDC members to show how they belong to the NFL community. As McDermott points out (1999), members of a community of practice are bound together by a sense of collective identity. A MDC member displaying the NFL practices she uses in her life shows that she understands and contributes to that collective MDC identity. 
Adding to MDC members' online identities are their displayed membership statuses. There are three different membership titles which are based upon participation: new member, member, and senior member. The title of senior member is for women with over 1,000 posts. Senior members can choose their own phrase to replace the title senior member, such as "Super Crunchy Mama to Three." The title of member is for women with 50 or more posts.

There are many threads where members inquire about post count totals. When Sunflower asked why people care about their total post count, veteran member Ruthla, who has made close to 47,000 posts since 2005 , explained that it is a way for longstanding members to have fun with one another. She explained about the inside joke, writing:

.... it's just a bunch of longtime MDC members being silly- we tease each other about "having no life" if the postcount is high, or "being a newbie" if the post count is lower. I've seen 2 members "race" to get to a certain post count first. (2006).

Along with being an inside joke, the post count total signifies status in the MDC community. Members have a sense of pride in their new member titles. When members' titles do not change after they reach 1,000 posts, they often write to the moderators to complain, eager to claim the new title that they have earned.

Along with their membership titles, members will also try to make clear their oldtimer status through their messages. One way members show that they are old-timers is through their relaxed attitudes with mothering. They exude a confident "been there, done that," attitude, and will tell newcomers that they need to relax. For example, OnTheFence wrote that while she might have been an uptight mother with her first child, she now has four children and has mellowed out considerably (2005). She wrote this to 
address the members who say they would not be comfortable letting others participate in raising their children due to their mainstream ways (2005). At the same time, members are clear about making their newcomer status known. They will introduce themselves to forums as a newcomer. If they make a mistake and trip over language of a group, the members might explain that they are newcomers, apologize, and write that they have a lot left to learn.

In addition to their membership titles, members can also have roles as an administrator, moderator, or granola ambassador. All three of these titles signify the role varying levels of power. Administrators are paid by Mothering, while moderators have been recruited due to their activity level or because they have asked to volunteer. Moderators have the power to lock down posts down and cite violations, and they are asked to dedicate at least five hours a week in the forums. Granola ambassadors are also volunteers who have been members for a year or more and have 500 posts. They help out the moderators and administrators by looking out for and reporting spam, trolls ${ }^{5}$, and signature and user agreement violations.

Leadership roles, such as administrators and moderators, are critical components of a successful community of practice (Stuckey, 2004). The leaders of the community of practice help to provide reassurance, continuity, and structure (Lai et al., 2005, p. 35). In an online community as large as MDC, granola ambassadors are helpful in catching user agreement violations.

Finding Your Tribe

\footnotetext{
${ }^{5}$ Trolls are people who post inflammatory remarks on discussion forums in hopes of causing disrupt in the community
} 
It can be difficult for members of an online community of practice to connect with others if they operate in different contexts with different constraints (Barab et al., 2004). One member's local experiences and insights may not be germane to another member's situation. For example, a stay-at-home mother in Alaska without immediate family living nearby deals with different situations than the working mother in Florida living near her large extended family. The ideal for online communities of practice is to allow for members to share local experiences in a large, diverse group of participants.

In order for members in a large online community of practice to find a place of belonging and to strengthen bonds amongst members, Wenger et al. (2002) suggests creating a structure that promotes both local variations and global connections. MDC has done just this by creating a forum called Finding Your Tribe. Formed in 2001, the Finding Your Tribe forum allows members to connect with others over a common interest that is not discussed in the other forums. It was first created to allow members to connect with people living in their local area, but expanded to include other interest over time. The Finding Your Tribe forum aligns with the NFL's belief in the importance of community.

Popular MDC tribes are created around race and ethnicity, such as Women of Color and Native American Mamas. Crunchy tribes include forums for mothers who do not wear bras, do not shave their legs, and like to hula-hoop. Some tribes are based upon religious beliefs. Some examples of unique tribes include mothers who live permanently in travel trailers, yurts, or consider themselves to be nomads. In addition, a popular tribe is for mothers who are lonely and do not have friends, while another popular tribe is for mothers who want to make online friends. A tribe that seems out of place, but is very 
popular at MDC, is the tribe for women who do not plan to have children. They still refer to themselves as "mamas" despite their childless status. There is also a tribe for women who want children but do not have them yet. In the tribes, women will occasionally request a roll-call to see who is participating. Members will respond by introducing themselves, writing "here!" and possibly providing biographical information.

Through the regional tribes, members meet mothers in their local area. Women will plan to meet together for a La Leche League meeting, or to attend a protest or lecture together. Play dates are set through MDC's local area forums. Play date sessions are social events, but they also provide learning opportunities for mothers. By meeting with other MDC members and their children, women can observe others practice NFL firsthand. In addition, members will arrange to help out other members who live nearby with child care. Although MDC is a large community, it serves as a place for others to make local connections.

Some MDC tribes can be considered communities of practice that exist within MDC's large community of practice. In tribes that are communities of practice, members spend time discussing and learning about topics specific to their group. For example, in the atheist/agnostic tribe, women share why they do not believe in God, and provide articles and books that back up their beliefs. The mothers share how they handle religious holidays and questions their children ask about religion. In addition, the atheist/agnostic tribe members will share their frustrations over certain situations, such as organized prayer at school athletic events.

However, not all tribes can be considered a community of practice. For example, in the Mama's Without Kids tribe, the discussion is more general. Members chat about 
their weekend plans and what they think they will make for dinner. They are not focused on creating and learning information, but have come together mainly to form social connections with others.

Certain forums serve as independent communities of practice as well. Some members are initially drawn to MDC for one specific topic, and that forum serves as their home tribe. For example, MCatLvrMom2A\&X came to MDC for the discussion on the Case Against Circumcision (CAC) forum. She wrote "I have visited the other parts of the board but my home is still CAC," (2009). Members come to know other members in specific forums. Like members in tribes, they may read messages from all over MDC, but they will only post in their home forum.

Strong connections are seen in forums centered on specific parenting contexts. For example, close bonds are seen in the forums for mothers with babies in the neonatal intensive care, women who are trying to conceive, and families trying to adopt. In instances like these, the women are working with a specific body of knowledge, and often have much to learn. Members grow to know one another, and refer to each other by their real names or nicknames. They check in to see how members are doing, remembering significant dates and events. Deeply personal information is shared with the group, and a large amount of information is consistently passed around. When joyous occasions occur, the members celebrate together, having online parties filled with smilies of champagne and dancing smiling faces. In times of grief and hardships, the members support one another and commiserate, giving cyber hugs through smilies of hugging faces, and candles for remembering those who have passed. 
Regardless if a tribe or forum involves focused conversations or general chit-chat, women express their gratitude for finding a niche at MDC where they feel like they are at home. Members get to know one another, and refer to each other by their real names rather than their screen names. A member may lurk in other forums, but actively post primarily in her small community of practice. The smaller communities of practice allow members to feel like they belong at MDC.

\section{Documentation Projects}

MDC has created a space for women to record to major rites of passages: pregnancy and motherhood. Mothers document their pregnancies through DDCs. In their DDCs, women share how they are growing and feeling throughout the months of their pregnancies. They compare their symptoms and cravings. Members will share also pictures and videos with one another.

After women deliver their babies, they often record their experiences in the Birth Stories forum. Recording birth stories is an activity that is part of MDC's shared repertoire of practices. There is an entire forum dedicated solely to members sharing their birth stories, proving that it is a valued MDC practice. Women will share in great detail their birth stories, sometimes providing pictures or links to videos of their labor and deliveries. The titles of birth stories usually include the name of the baby, whether they were born in a hospital or at home, and adjectives to describe the experience. Women will also tell if their stories are long, sad, or include pictures. For example, a title of a birth story might read like "First beautiful homebirth of Rosa May (Warning-Long! Pictures at End)." Some women choose to share every detail about the experience, including the thoughts they had during labor and what others were doing at the time. 
Others simply share a sentence or two. Mothers will often include the weight and height of the baby.

Women will embed NFL beliefs and practices throughout their birth stories. For example, MDC members might refer to their contractions as surges, or share mantras they chanted throughout their labor. In addition, mothers new to NFL might share how their natural delivery compared to their previous mainstream births; these comparisons paint natural births as superior to drugged births. Normally members only congratulate women on their births, but if a woman writes something that runs counter to NFL beliefs, members will step in to gently correct her. A 20 year old woman, for example, told the group that her pelvis is too small to naturally deliver babies (Carter'sMummy, 2009). Members give congratulations, but also encourage her to learn more about the delivery process, and inform her that she might not actually have to endure a caesarean section in the future.

\section{Exchanging Information}

A common MDC activity involves women requesting and exchanging information. Members post threads with titles such as "need information on 25 week old preemie" and "preservatives in vaccinations question." Other threads might come across as more urgent, with titles that cry "Help!" and "Don't know what to do!!" Although the amount of replies varies, members normally receive at least one to two responses to their questions. At times, a member will reply that she does not have any advice, but that she wanted to give a virtual hug and offer sympathy.

Additionally, members exchange information by discussing current news and events. They might share, dissect, and analyze recently released articles and books 
pertaining to child rearing. News that does not mesh with NFL receives criticism from MDC members. For example, Ann-Marita posted excerpts from a news report supporting circumcision (2009). Members expressed their disgust, and went on to cite their own facts that refuted the information from the news report (e.g., Brant31, 2009; Fellow Traveler, 2009). The mothers hashed out each point where they believed the author is incorrect. They discussed protest letters they planned to send to the publisher, and shared responses they had prepared if the article was brought up in conversations.

By sharing and exchanging knowledge, members possibly gain new perspectives. Discussions may raise points that members had never considered before. Through these exchanges of information, MDC members become less reliant on other sources of information, such as family members or pediatricians.

Other times, members will indicate in their titles that they are looking for members to share their been-there-done-that (BTDT) experiences. By explicitly asking for BTDT replies, the reader taps into community members' local knowledge and first hand experiences. For example, MissRubyandKen asked for practical BTDT advice about how to handle a bank error (2010). Other mothers searched for empathy and emotional support through their requests for BTDT. MynameisMom wrote in looking for BTDT stories about children going on nursing strikes (2009). She already had received practical advice from her lactation consultant, but she wanted to hear from other mothers about how they dealt with feelings of rejection, and to hear any nursing strike stories that had happy endings (2009). Greeba shared her nursing strike story with a happy ending, and encouraged MynameisMom by writing "Hang in there. You'll both be okay. I remember how hard it was. I was beside myself," (2009). 
When members share their BDTD stories, they occupy positions of agency in the production of knowledge (Blair \& Takayoshi, 1999). The women are therefore deciding what constitutes knowledge in their community (Madge \& O'Connor, 2006). As the information exchanges from the forums are archived, they become part of the sanctioned knowledge of MDC (Eble \& Breault, 2002). Archiving members' local knowledge places them in positions of authority (Eble \& Breault, 2002). Eble and Breault reference Michel Foucault in explaining that "power is inseparably linked to the creation and dissemination - the control - of knowledge," (p. 323).

Additionally, there is a forum where women can share the articles and features they like in the current issue of Mothering. Lighter topics are also discussed in the forums, such as movies and celebrity gossip. The discussions move quickly on MDC. Monarchgrrl said "I also just love that I can log in in the morning and read my favorite subforums and threads and then a few hours later so much has changed and conversations started. It's always moving and changing! 98 " (2009). The quick pace that some of the threads move at can make the online messages feel like a live conversation.

When women share their experiences and provide each other with information, the original poster is not the only one who benefits. It is possible that lurkers also have their questions answered or have new ideas about parenting sparked. Sometimes another member will write that she is also interested in the thread topic, and will add on questions of her own. If the responses become more directed towards someone other than the original poster, it is said that the thread as been hijacked; a moderator may step in to redirect the thread back towards the original poster's question.

Building Relationships and Community 
A strong community of practice has members who not only recognize each other, but who also have established relationships (Wenger, 1998). Members can become familiar with other members by regularly reading throughout the forums. Some members are recognizable because they post consistently in multiple forums. In other instances, a member might be well known in one specific forum.

In the DDCs, women try to build community by highlighting specific members. These threads are titled "Spotlight on (member's name)!" and women ask the spotlighted member questions. Some of the questions are personal, like asking what her greatest accomplishment is, while others are light-hearted, like asking about her favorite book. MDC administrators caught on to the popularity of these threads, and now MDC spotlights a new member and an administrator each month.

Another community building effort is recognizing members' birthdays. The bottom of the forum lists members' birthdays, and MDC sends members an email on that day. Members are also able to see which thread a member is currently viewing, giving them an idea as to what topics interest certain members. To start a more personal relationship, members can send each other private messages.

Members use MDC as a way to meet mothers in their local area. Women will plan to meet together for a La Leche League meeting, or to attend a protest or lecture together. Play dates are set through MDC's local area forums. Play date sessions are social events, but they also provide learning opportunities for mothers. By meeting with other MDC members and their children, women can observe others practice NFL firsthand. In addition, members will arrange to help out other members who live nearby with 
child care. Although MDC is a large community, it serves as a place for others to make local connections.

\section{Providing Support}

Support, both receiving and providing it, is a main activity for MDC members. This activity aligns with the findings of Ridings and Gefen (2004), researchers who discovered that members of online communities of practice log-on primarily to seek social support. In addition, other research has shown that female-dominated websites are more likely to be supportive (Miyata, 2002; Sharf, 1997). Without a doubt, MDC has pulled its members through difficult times. For Molly, MDC acted as an online therapy group when she suffered through three miscarriages. Molly referred to MDC as online therapy, and she provided support for others in similar situations (personal communication, June 23, 2009). For Poetgirl, MDC served acted as a place of refuge during the three years she was trying to conceive. Poetgirl shared:

MDC has been a life saver in a 3 yr span when no one in my life seemed to know the right thing to say. It also helped manage some of the invisibility I felt during the years of failed attempts. (personal communication, July 22, 2009).

JayJay, whose baby was stillborn, posted a thread of gratitude to the members of the Trying to Conceive After Loss forum. JayJay wrote:

I wanted to write this because every now and again I am overwhelmed with just such pure love for you all, and for the healing process that we are all going through so, so well together. . .

This is sincerely the best, most loving, most compassionate group of women I've ever met in my life. I feel honored to have met all of you and even more honored to share this healing journey with you. ...*HUGEST most ENORMOUS* hugs to my fellow, wise, beautiful and wonderfully full-of-life mamas $\odot$ XXXXX (2009). 
Twelve other mothers responded to JayJay's post by sharing how special MDC's group has been to them during their difficult times as well. There is also support for survivors of abuse and postpartum depression. While these examples involve intense situations of grief and loss, women receive support for lighter situations as well. A woman who has decided to nurse in public will receive a cyber high-five from other members, and those who switch to cloth diapers will be applauded.

Affirming that a mother has done the right thing is another form of support offered by MDC members. Women might directly seek this affirmation by asking "did I do the right thing?" or the affirmation might bubble up sans solicitation. To illustrate, Ahappymel received affirmation that she correctly handled a situation with her seven year old son. Noticing that he was angry and frustrated, Ahappymel asked him to write down his feelings. His letter included the following "You stupid motherf . You are a sh_tty a__hole. You are a f___ ing idiot! I want to kill you, you stupid wetbag!...." (2009). After reading the letter, the mother said her son felt ashamed, so she cuddled with him. Members virtually applauded her, told her she is an inspiration, and offered some other ideas for her to implement. Ahappymel responded "Ah...thanks Mamas "Q⿱艹 the insight and affirmation that I get here," (2009). A few mothers told her they would be uncomfortable with the intensity of the letter, but Ahappymel dismissed them and defended her son's actions.

Other times, members write that MDC unexpectedly affirmed their parenting decisions. Without reading any books, some women decided to mother the NFL way because it seemed intuitively correct to them. At MDC, they discovered that their 
parenting approach has a title and a large group of followers (e.g., Joy Seeker, 2009). Thus, MDC affirmed their mothering decisions while connecting them with others. Along with support, MDC serves as a place for women to vent about their frustrations. Women vent about various topics: their children, their significant others, their jobs, society, mainstream parenting, and the medical community, to name a few. Although this sounds like a negative activity, member Momtwice explained that knowing she has MDC to vent allows her to be polite in public. After an evening around people promoting mainstream parenting practices, she copes by biting her tongue and “.... composing internet threads in my mind rebutting their arguments. . ." (2003). She then shares her rebuttals and AP quotes with the MDC community. Momtwice has found that doing this prevents her from getting into arguments in person and allows her to be more compassionate (2003).

A long-running rant at MDC is where members share the worst/dumbest parenting advice they have ever received. Women also rant on threads where they pretend to yell at their children or their loved ones. The idea is that if members yell online, they will not have to yell in real life. After ranting, women often thank others, sharing that they feel better.

On MDC, there are times when the member support involves other topics besides childcare. For example, MCatLvrMom2A\&X started a thread in May asking for advice about her pregnant dog. She posted pictures of the puppies when they were born, and around message number 80 , members started to brainstorm about where the puppies could be placed. By August, and 530 posts later, half of the puppies were placed in MDC members' homes across the country. Mommyswen wrote "MCat, we can't thank you 
enough -- you got all these little guys off to such a great start, and it really shows!" (2008). Once the puppies were in their new homes, members provided training advice and continued to share pictures of the puppies. Placing the puppies in MDC members' homes required coordination amongst the members, and they sent each other private messages and made phone calls.

Another MDC activity of members supporting one another is the Holiday Helpers program. The Holiday Helpers program lets families explain their life and financial situations and list items that they would like and need. Families are assigned a number, and members can purchase the requested items for them. MDC members also help each other by coordinating to reuse their assets. There is the formal MDC trading post that allows mothers to swap items, or mothers simply give belongings away to other members. Informally, a mother might tell members that she will be selling an item, such as gently used diapers, on eBay.

\section{Fighting and Debating}

Wenger explains that the mutual engagements in communities of practice are not always kind and gentle. In communities of practice, there is also bound to be conflict amongst members:

In real life, mutual relationships among participants are complex mixtures of power and dependence, pleasure and pain, expertise and helplessness, success and failure, amassment and pain, expertise and helplessness, success and failure, amassment and deprivation, alliance and competition, ease and struggle, authority and collegiality, resistance and compliance, anger and tenderness, attraction and repugnance, fun and boredom, trust and suspicion, friendship and hatred. Communities of practice have it all. (Wenger, 1998, p. 77).

Despite Sharf's (1997) finding that woman dominated discussion groups are generally devoid of rude and abusive remarks (referred to as flaming), conflict still occurs at MDC. 
As previously discussed, differing ideas about how to parent can create friction amongst mothers. MittensKittens exclaimed "who knew that parenting was such a controversial issue, causing so many arguments, before we ever had kids?"(2009). When a member speculated as to why mainstream moms feel threatened by NFL moms, Snuzzmom told her that there is tension even amongst MDC mothers. She said "There is much dissention within the ranks, as it were, as you can see just be reading these boards," (2009). In other words, tension amongst mothers exists amongst all parenting circles.

Although it may seem desirable to avoid conflict, arguing can actually help push members towards mutually engaging with each other. Through debates, members can be forced to examine what their group is all about. This type of engagement is referred to as the negotiation of joint enterprise (Wenger, 1998, p. 77). Through the negotiation of joint enterprise, the community defines what is significant to their group and this shapes the practice (Wenger, 1998, p. 77).

An example of a constant debate amongst MDC members involves discussing AP and NFL. The discussions about NFL and AP can cause frustration and disagreements at MDC. In one heated thread, members argue about what the AP label stands for, the relationship between AP and NFL, if circumcision is an AP concern, what the wide spectrum of gentle discipline in NFL means in terms of AP, and the pros and cons of using labels to discuss parenting styles (Calynde, 2006). Members in various threads explain whether they are crunchy or just AP, demonstrating their awareness of mothering identities and where they fit in at MDC.

One source of tension in communities of practice is the clash of the old-timers against newcomers. When newcomers join a community of practice, they may clash with 
the old-timers as they are likely to have competing viewpoints (Lave \& Wenger, p. 115). Lave (1993) explains that since communities of practice are not homogenous in their makeup, “...conflict is a ubiquitous aspect of human existence,” (p. 15).

The tension amongst newcomers and old-timers is seen on MDC. In one thread, Trishy, an old-timer, grew tired of a conversation where she had been posting. She felt the newcomers were misconstruing the meaning of her message and were being overly sensitive. Trishy wrote "Sigh, I long for what MDC used to be," (2005). Tracymom agreed with Trishy, and she explained why she longed for the good old days on MDC:

I think it's because it's more mainstream here than it was in so many ways. It does have a different atmosphere, for better or for worse. One thing I know that hacks the old-timers off in a major way is the disrespecting and disdain expressed by some newbies who clearly don't know what the heck NFL is about and more, don't wanna hear it and don't want to shut up and listen to learn. That's really a hard one to swallow; I'm not that much of an old-timer and it bothers me sometimes. (2005).

Pickle It, a newcomer, was displeased with the old-timer's complaining. She responded by writing:

Here's an acronym: IYLFTODGRTA If you long for the old days, go read the archives.

There are several threads going on right now about how great the old days at MDC were, weren't we so smart, so special, so unique, it's not the same, these new so called NFL folks are clueless, blah blah blah. Well, ok, ya'll had babies first, so you got to be the founders club, paving the way for us wannabees. If people's QUESTIONS and OPINIONS are so wearying to you, why are you hanging out on a DISCUSSION board? (2005).

This conversation is evidence that tension between old timers and newcomers exists at MDC. The conflict between old-timers and newcomers in communities of practice eventually subsides. Through increased participation, newcomers gain more power, and 
members have time to get to know one another, helping to alleviate tension (Lave \& Wenger, 1991, p. 116).

A sure fire way for a member to cause friction at MDC is to post a message that comes across as judging other mothers. Isamama has felt that at times, there are MDC mothers who act superior to others (2009). She wrote "I admit, I have had a love-hate relationship with MDC. I have found some folks really holier than thou and offensive," (2009). The message titled "Is this common?" is an example of members negatively reacting to a perceived self-righteous attitude from the original poster, Not Now. Not Now explained that in her culture, mothers take their babies everywhere. She was unfamiliar with the idea of women wanting to leave their children at home in order to run errands or have time away from their babies, so she asked MDC if leaving children behind is a common activity. Many mothers said they like a little time away, explained why, and then told how they manage to do so. There were some mothers who said they just cannot do this, that being away from their children makes them anxious and sad. The discussion began on a civil note.

However, the thread took an ugly turn when Churndash got angry and wrote "You know what else is common? Mothers judging other mothers," (2009). Mamatoablessing was the next member to post, replying "No doubt. These 'I'm a better mom than you' threads are getting tiresome," (2009) and Snuzzmom agreed, writing “. . . I feel like this thread is a wolf in sheep's clothing. Obviously the OP already knows it's common enough, since so many of her co-irkers are doing it," (2009).

The replies continued to flood in with mothers explaining why or why not they take their children everywhere with them. Many of the mothers simply shared their point 
of view and omitted quoting other members or building upon previous comments, a pattern in long posts with lengthy replies. Another pattern in heated conversations is that there is often a member who tries to serve as the moderate voice of reason. In this instance, Tigerchild stepped in and tells Not Now:

Who cares if it's common or not. That has no relevance to what YOU or anyone else does. Just enjoy your family. If you need to have them all close by all the time, or you need some quiet time to yourself to make that happen, so be it. (2009).

Like many posts that receive a large amount of comments, the original poster, Not Now, was surprised by the strong responses. She wrote:

Huh, didn't know my question would spiral into a 'discussion.' I hate when this happens on MDC, people accusing others of not understanding where they are coming from bla, bla, bla. Accusations of judgement [sic]. This is also why I don't post often, I love the message of the community as a whole but man things get out of hand sometimes. (2009).

Despite Not Now bowing out of the conversation, the women continued to debate with one another. Five members end up dominating the thread, going back and forth with their arguments. It ended on civil note, however, with one member apologizing to Not Now, another member apologizing for being adversarial, and someone else congratulating another member on the upcoming birth of her baby (2009).

Unfortunately, not all tense threads end on a civil note. At times, members of online communities drop all decorum, directing incendiary comments and accusations towards one another. These hurtful threads are referred to as flame wars. Some members are careful not to participate in flame wars, while others members, such as Amy, delight in being a part of the drama (personal communication, June 18, 2009).

An example of a flame war is a post in the Parenting forum titled "If you got this email after a 'playdate', what would you do?" The original poster, StephandOwen, is a 
prolific writer on MDC, totaling over 5,000 posts in one year. She is not shy with confrontation, and directly challenges other members' comments. The start of the flame war began with StephandOwen shared an email she composed after a play date with her partner's family and her son. The email was lengthy and detailed the reasons she was upset (she believed that her partner's nephew bullied her son). StephandOwen acknowledged that the email would probably cause a rift in her family, but that she did not care. She also clarified for members that the toy mentioned in the email was not a toy gun, because unlike the nephew's family, she does not allow violent play. This clarification shows the StephandOwen knows the shared repertoire of NFL, which does not condone the usage of toy guns or other tools of violence.

Advice was provided by members. Mammal_mama suggested that StephandOwen shorten the long email (2009). Other mothers told her not to send the email at all, and explained how the email would make them feel. Betsy wrote "If I got an email like this I would be furious at the tone and embarrassed and hurt. ..”(2009). Empathy was also extended to StephandOwen, with messages like "I can understand your anger/frustration/mama bear feelings about this - I really can. But the email is much too long," (Kirsten, 2009) and “\$2 What a rough day!” (Mammal_mama, 2009).

Blame was pointed towards StephandOwen. Kidzaplenty wrote "I think, all in all, that the situation was a lot of your own making. . . you should honestly share the blame for the entire situation," (2009). At this point, StephandOwen wrote that she already sent the email, so suggestions not to do so are pointless. The members were upset, feeling that she mislead them into thinking she had not yet sent the email. Betsy responded "Well after that email I don't think you will need to worry about them playing together 
anymore,” (2009). StephandOwen replied again, getting progressively more defensive about her actions. Members began to quote other members to make their point, placing Q $\uparrow$ THMT empathy, the consensus was that StephandOwen has made a huge mistake. The tension was clear.

Tanibani stepped in to point StephandOwen to a book that teaches how to resolve conflict (2009). She explained the basic concept of the book, and concluded by writing 'Now, isn't that a more helpful response to the OP than berating he and calling her passive-aggressive a hundred different ways?" (Tanibani, 2009). StephandOwen was very angry at this point, and she lashed out with sarcasm, writing:

Yup, I'm a spineless whiny passive aggressive $b *$ itch because MY child was getting the crap beaten out of him while the other parents sat there and allowed it to happen. Huh. And to think I had higher thoughts of MDC parents. (2009).

Artgoddess responded "I didn't see anyone tell you are a bad parent, but the irony of you making this post after you sent the email to your SIL is not lost on me, WingonWing replied "So no one is saying what you want to hear - is that the problem, OP? When you post something like that, you aren't always going to get validated," (2009).

After more berating posts, StephandOwen told the group that she was out of the conversation. She wrote that the group could continue talking badly about her for what she had done, but she did not regret her actions. She ended by telling the group to have a good afternoon and posted a smiley face emoticon at the end. Even though StephandOwen left the conversation, the women continued to post their replies. Many 
are annoyed that StephandOwen left the conversation, believing she did so just because they gave her advice she did not want to hear.

A few members are upset by the tone of the thread. AniT wrote "She was probably looking for support. It's hard on here. I have had this happen before. . ." (2009). Whitneymum was also disheartened by the tough comments, and said “ 12 yea, I expected better responses from 'our' community too. *sigh* I see WAY too much negativity here, self righteousness etc...it's kind of sad," (2009). Trinity6232000 stood up for StephandOwen, explaining that she knew her and understood why she chose to leave the tense conversation (2009). Hey Mama!, however, was also familiar with StephandOwen, and she wrote "This has happened before with the op. Steph, you just dropped a huge bomb in the middles of you dp's family..." (2009). Teale directed the blame for the flame war at technology (2009). She wrote "Tone and intonation can easily get lost, and if someone wants to get their hackles up about something, they can because they are reading it how they wish to read it," (2009). The long thread concluded with Zinemama praising the community for the solidarity on the issue. She proudly wrote:

I've seen a lot of discussion on MDC and honestly, I'm having a hard time recalling even one where every singly response has been basically the same. We all, every one of us, agreed that the email was a bad idea. (2009).

Betsy was also pleased with the thread. She said "I am rather heartened by all the agreement in this thread. . I would argue that is exactly what MDC should be about," (2009).

After time passes, the thread was locked by the administrators, and members could no longer read the message. However, while the flame war was taking place, the moderators never stepped in to give members warning during the conversation. The 
thread grew quickly, and only lasted for two days, possibly making it difficult for moderators to catch. The flame war did not slow StephandOwen down from posting in the future. For other members, being the subject of a flame war could possibly be upsetting enough to cause them to leave the community.

StephandOwen's message has patterns typical of flame wars. First, they move very quickly, rapidly amassing messages. Once a flame war begins, it is hard to stop. Even if the original poster tries to explain her thoughts and actions, the fire has been ignited and is hard to smother. Next, people quote other members to build their arguments against each other and to tear each other down. At the same time, some members do not respond at all to other threads, simply throwing in their opinions without reading other messages. The original poster will either become defensive and stick to her view point, or she will try to appease the community, explaining her ideas as a way of regaining favor. Finally, there are often a few members who try to make peace, but they are usually in the minority and are ineffective.

\section{Sharing the Message of NFL}

MDC mothers have strong convictions and are passionate about NFL. For some mothers, NFL is more than a parenting choice. Amy explained that NFL let her ". . . feel like I'm part of a movement," (personal communication, June 18, 2009). Momtwice also felt like NFL is a movement, and she said that ". . .the grassroots power of the internet to spread the word that more and more people are parenting gently or in AP style is SO COOL!" (2003). With their deep beliefs that NFL is the best way to raise children, it may be hard for MDC mothers to watch other women do things differently. Spreading the word about NFL, therefore, is another activity of MDC members. While this activity 
takes place outside of MDC, member will come to the forums to share their methods, thoughts, and experiences with the community.

When evangelizing about NFL, MDC members may choose to focus on one issue alone, such as breastfeeding and circumcision. There are mothers, in fact, who refer to themselves as lactivists and intactivists. Through sharing information and their own experiences, women hope to convert other parents to NFL practices. Women share stories in the forums about their hopes and aspirations to convert other parents to NFL.

MDC members have differing ideas about how to share information with mainstream parents. One method it to simply present mothers with compelling information and hope that it will lead them to NFL. Typing "mainstream friends" into MDC's search engine pulls up multiple messages where women ask for information to share with their mainstream friends. They ask for information about topics such as pregnancy and labor for their pregnant friends, circumcision for women having boys, and gentle discipline for those with older children. MDC members will provide books, articles, and movies to recommend to others, sometimes rating how crunchy a book's content is. Books that promote NFL while remaining straightforward are seen as the ideal to share with mainstream friends (e.g., Lilysmama1124, 2009).

In terms of the preferred method of delivering the information, MDC mothers differ in their approaches. Some like to share information through emails. Elanorh wrote that when a woman she knows becomes pregnant, she sends an email with a list of NFL books that she likes regarding labor, breastfeeding, and child care for the first few years (2009). She shared:

I usually say something like "Well, now that you're becoming a parent, you'll be getting all sorts of unsolicited advice. It bugged me to no end. But allow me to 
pile on with this advice! ;)". . . I'm known as a bit of a 'wonk,' and I say upfront in the email that I just hope the information is helpful for them ... that I read a lot of stuff that wasn't useful or helpful or accurate, and these were the ones which I liked the most in the end, if they're interested.

And call if you have questions about any of it. I always say too that we have had natural births, and if they have any questions about it, I would be happy to discuss with them, if they're wondering about it. ....I've had several friends thank me for the email, some more than once. (2009).

Email allows women to share large amounts of information at one time and avoid having face to face interactions that may be uncomfortable.

At a more extreme level are mothers who choose to keep mainstream information away from the public. DaisyRose shared with MDC that she and her friends regularly check out mainstream parenting books from the library to keep them out of circulation from "vulnerable" moms (2005). While the majority of MDC mothers who replied disagreed with this tactic, a few thought it was a good idea. MDC members also shared alternatives to keeping the books permanently checked out, such as donating AP and NFL books, asking the librarian to purchase other books, or sticking a note sharing NFL information in the mainstream books (2005).

In order to effectively reach other mothers, MDC members discuss how to use language in a convincing way. Angelamariebee shared that she learned how to use fear to convince other mothers to breastfeed. She wrote "Part of my lactivist indoctrination, heh, when I was pregnant and first learning about the subject was the importance of the language you use. You aren't supposed to talk about the BENEFITS of breastfeeding, but the RISKS of formula," (2009). Angelamariebee has been taught how to effectively use language to convince women to breastfeed. Other mothers strive to sound nonjudgmental in their tone. By using neutral language, MDC mothers hope to attract, rather 
than repel, mainstream mothers. Moonfirefaery (2006) explained that when correcting other mothers, it is important to be polite and not to come across as preachy:

Educate as if you're sharing a tip of just something interesting you read. Don't preach it. If you see a mom spanking a toddler, you can say "You know, when my child ___, we ___ and it works pretty well. You could try that. It's a little easier on everyone than a spanking!"

Other members provide the scripts they use to approach mainstream mothers.

Instead of trying to convince mainstream mothers about NFL through words, some MDC mothers advocate doing so through their actions. For example, rather than explaining all the benefits of breastfeeding, a mother could simply breastfeed in front of others. Dentmom3 said that she had a friend who did not plan to breastfeed her baby (2006). She wrote that she hoped modeling breastfeeding in public would convince her friend that breastfeeding is easy and convenient (Dentmom3, 2006). She believed that approaching her friend directly would appear confrontational and would only serve to alienate her (Dentmom3, 2006).

Being subtle and polite are other ways MDC mothers share the message of NFL. For example, some members do not believe in directly confronting mothers who have chosen to bottle feed their babies. A mother can, however, be subtle in discussing breastfeeding and its benefits. This is the belief of Moonfirefaery, who told the group that you can politely inquire why someone chose to formula feed, and if it is an answer you can "combat," you can subtly raise alternative solutions (2006). Other mothers believe in the power of subtle messages. Zjande remembers reading Parenting, a mainstream parenting magazine, and finding a subscription tear out to Mothering magazine stuck inside. She began reading Mothering and subscribed to the magazine for 
the next decade, learning and altering her parenting choices, and ultimately changing her life (Zjande, 2009).

Mothers who have been on the receiving end of what are intended to be subtle suggestions shared that people are not always as polite as they think. Lula, a more moderate mother, wrote that women at her play-group tried to educate her about parenting by "casually" throwing out suggestions to her during conversations (2006). Rather than feel enlightened or encouraged, Lula felt judged by others. She wrote "None of this judgment helps," (2006).

Opposite of the gentle mothers are MDC members who believe in being bold when sharing the message of NFL. Regardless is she has been asked to, Tattooed Hand shares her NFL experiences and knowledge with others, writing that if mothers get offended, "that's their problem," (2009). Sweetpea_119 also believes in being direct with mothers, writing that she wishes someone had been bold and told her about NFL (2009). She urged MDC mothers to be direct, writing "I will be one who says it! I wish someone who really cared \& KNEW facts would have intercepted me during my first pregnancy to tell me about midwives \& homebirth," (2009). Sweetpea_119 wrote that she believes that it is vitally important for other women to hear the message of NFL (2009). In her eyes, mainstream parenting victimizes women who are uneducated about their options.

To be clear, not every MDC mother shares in the belief of evangelizing NFL. Gertie wrote that she believes parenting choices cannot be forced upon others (2009). She wrote that pushing the ideas of NFL onto others only brings negative results and that if someone is interested in NFL, they will ask. In the meantime, Gerite encouraged MDC 
mothers by writing "You just live your life, proudly, loudly, don't let anyone think you did/do anything different. ..” (2009). Other MDC mothers feel it is futile to try to change the mind of mainstream mothers. Doulanichole wrote that she sometimes posts on a mainstream parenting forum, sharing NFL information when she can. She said "I try to help out where I can, but sometimes it isn't worth the frustration and headache," (Doulanichole, 2009).

As previously discussed, there are MDC mothers who struggle when interacting with mainstream parents. Some MDC mothers choose to avoid having mainstream mothers as friends altogether, erasing this from being an issue. Amy explained that she tried not judging mainstream mothers, but she could not do so (2005). When around her one mainstream mother friend, Amy said that she found it "emotionally wrenching" to watch her parenting techniques, and that she did not want to be her friend anymore (2005). "We had a big fight about parenting stuff, and we haven't spoken since. I don't miss her," (Amy, 2005). For women like Amy, their identity as mothers practicing NFL is too much of who they are to compromise being around other mother types.

O'Mara writes that NFL is growing in popularity. She believes that old-fashioned beliefs and practices have become appealing once again to the public. Publications like Mothering magazine are certain to be responsible for spreading information about NFL. Judging from the numerous discussions of how to spread the word about NFL on MDC, it is possible that other MDC mothers have played a role in the growing NFL parenting movement. 
Another set of research questions for this study pertained to MDC members and their learning of NFL. This section examines evidence of members' learning at MDC as demonstrated in the forums and described in interviews. In addition, this section answers the question regarding MDC members' experiences with learning, including their motivation for coming to MDC, and what they assert to have learned from the community.

\section{Evidence of Learning NFL}

Through MDC, members have learned about various NFL practices, such as elimination communication, co-sleeping, gentle discipline, homeschooling, sign language for pre-verbal children, pregnancy and birthing information, baby-wearing, unassisted childbirth, food allergies, and circumcision (Claire, personal communication, July 28, 2009; Blair, personal communication, June 26, 2009; Caroline, personal communication, July 6, 2009; Erica, personal communication, June 30, 2009; Virginia, personal communication, July 30, 2009; Betsy, July 6, 2009). There are various ways in which members demonstrate what they have learned from MDC. These methods include members writing about applying gained knowledge from the forums to their actions and ways of thinking, engaging in a basic question and answer format, sharing resources and information, and citing MDC as a source of information.

The most basic demonstration of learning in MDC's forums comes in the question and answer format. Members can post a question mark emoticon beside their message title to notify the community that they have a question. For example, Just_Lily used the question mark emoticon and asked members for ideas about how to stay intellectually stimulated as a stay at home mom (2009). Ideas from the community included learning a 
new language, running a website or an online business, taking free online courses from universities, bloggin about the books she reads, getting a career outside of the home, listening to National Public Radio and podcasts, becoming a breastfeeding counselor or a baby carrier consultant, starting a daycare, doing freelance writing, joining Mensa, having intellectual debates with others, volunteering, taking up hobbies, becoming a doula, deciding on a career once she no longer is a stay at home mom, making friends who can converse at a high level of intellect, renting videos from Netflix, and writing a novel. Just_Lily dismissed some of the ideas, such as returning to the work force, but she thanked others for their thoughts (2009).

Other questions are more complex. Olliepop, for example, asked members when they planned an introducing the concept of race to their children (2009). Members had to ask her questions to clarify what she meant by race; RasJi7 asked "Do you mean how other people might classify them based on their looks or about where their ancestors originated?" (2009). The members continued to ask Olliepop questions, and she clarified her thoughts for the group. Other mothers shared their own experiences of teaching their children about race. Women shared book titles about how to discuss race with children, and others went on to discuss their viewpoints.

A clear indicator that members have learned from MDC is when they share about how they have applied gained knowledge to their actions. For example, Grace24 told the Toddlers forum that her son as not doing well transitioning from a mini-bathtub in a sink to a large bathtub (2009). Members offered possible solutions, like putting the mini-tub in the large bathtub to ease the transition. Grace 24 reported back "today we did the big tub inside the little tub and he didn't scream the whole time. .." (2009). Grace24 took the 
suggestions of members, applied them to her own actions, and experienced success. An additional example of a member applying knowledge gained from MDC to her actions came from member Virginia. After learning about unassisted childbirth from MDC, Virginia took the step of having her baby at home without any assistance or interventions from others (personal communication, July 30, 2009). A final example is with a longrunning thread where women share veteran advice regarding homebirths. Mothers will read the thread, then come back to forum to thank the community for the tips they used, and provide their own pieces of advice as well (e.g., RubyOrganique, 2008).

A powerful example of how gained knowledge from MDC has changed a person's actions comes from Joy_seeker. In the Gentle Discipline forum, she shared the things she used to do with her children that she has changed due to what she has learned from MDC. Joy_seeker shared (2009):

I used to be a yeller, but now I am a listener. I used to be a punisher, but now I am a behavioral guide. I used to be an authority figure, but now I am someone who offers advice and the wisdom of experience. I used to be a teacher of knowledge, but now I am a facilitator of learning. I used to get frustrated with behaviors, but now I look for the causes of the behaviors. I used to make decisions based on who my children would become, but now I see them for who they are right now. I used to sometimes spank, but now I only hug. I used to demand respect, but now I give respect and enjoy seeing it easily returned. I used to worry what others thought of my children, but now I only worry about what they think of themselves. I used to be so stressed, but now I am at peace.

Joy_seeker's changes align with the philosophy of gentle discipline. Joy_seeker shared that she came to MDC to learn about unschooling (a form of homeschooling), and she found the Gentle Discipline forum that helped her fine tune her instincts to do what she knew was right in terms of discipline (2009).

Not all mothers are successful when they implement the practices and advice they learned from MDC. Claire learned about elimination communication through MDC and 
tried it with her infant (Claire, personal communication, July 28, 2009). She gave up the practice, however, when is became too stressful and controlling of her life (Claire, personal communication, July 28, 2009). Other moms choose not to implement pieces of advice at all. For example, Dentmom3 wrote that although she has learned and evolved through MDC, she is “. . . consciously *not* changing some things as I know they won't work for me/us," (2006). As previously discussed, NFL promotes picking and choosing parenting practices that fit with women's families (O’Mara, 2000). Not all mothers, however, share Dentmom3's ease with adapting only certain NFL practices (e.g., BlueIrises, 2006).

Women also learn about other topics besides mothering at MDC. Frogautum shared that she lived a semi-green life before joining MDC, but that the community "... has given me courage to do things I never thought 'I had in me' like cloth diapering. . . I owe this place a lot!" (2009). Kangal622 said that MDC has really changed how she runs her household, with her “. . ' crazy' need to recycle and use of better cleaning products. . ." (2009). Women have also learned about non-NFL practices, like how to handle a buyer's complaint on eBay and how to cope with internal conflict over publishing a book (Erica, personal communication, July 6, 2009).

The information acquired from MDC can also change members' ways of thinking and feeling. The change might be broad, impacting a mother in many ways. Hopefulfaith, for example, writes that MDC has helped her to be a better human being in general (2006). For Caroline, reading a diverse range of perspectives from other members helped her to be more compassionate for those who are different from her (personal communication, July 6, 2009). She explained "I am in a world everyday that 
deals in black and white answers in my discipline, and Mothering.com helps me fill in the many shades of grey that I may encounter in my life," (Caroline, personal communication, July 6, 2009). Veronica wrote that she has applied information from MDC more to her own philosophies than anything else. In particular, she has absorbed from MDC the idea that children can be internally motivated to learn (personal communication, July 1, 2009).

In addition, a member might come to view a specific situation differently through discussions on MDC. For example, Wtg4Miracle shared with an infertility tribe that she interpreted her husband's desire for her to stop infertility treatments as being unsupportive (2009). Other members pointed out that the husband was probably concerned about her well-being during the exhausting in-vitro fertilization process. Wtg4miracle replied "I never thought of him being worried about me. This might be what is thinking...thanks for helping me," (2009). The members were able to bring up a perspective that Wtg4miracle had not thought of by herself.

Finally, members may come to MDC to learn and be reassured that what they and their children are doing is normal. As Blair explained, when you parent differently from others, it can be lonely (personal communication, June 26, 2009). Mothers can feel isolated in their beliefs, and MDC serves as a place where they are reassured that what they are doing is beneficial to their child's well being. A mother deciding to do homebirths, for example, can receive positive reinforcement about her decision by reading the homebirth success stories at MDC (Ms. Cellaneous, 2009).

Another way of detecting that members have learned from MDC is when they cite the community as a reference. Members will often write things such as "I read on this 
forum that this is normal." When Nattymom's son's uncircumcised penis turned red and purple, she did not panic because she had read on MDC that this is normal (2009). When Halfasianmomma askd for advice on how to help her daughter adjust to daycare, $\sim \mathrm{Pi}$ shared a routine that another MDC mother in the same situation had earlier shared with the community (2009). Finally, JSerene continued to breastfeed her child into toddlerhood because she read on MDC that it would not hurt her daughter's teeth (2007). Another sign that learning might be taking place at MDC is when members share resources and information with each other. In the forums, research studies are supplied to support arguments during intense debates. For example, LTK asked the I'm Pregnant forum if it would be okay to smoke marijuana during her labor. Women argued about the safety of this practice, and Baby_baby_mommy shared an article about the dangers of exposing babies to any kind of smoke to make her point (2008). Members constantly share books, articles, and internet sites with one another, creating an online annotated bibliography of sorts throughout the forums.

MDC members try to contribute to other's learning by sharing information, resources, and support. Caroline said she hopes that through sharing breastfeeding information and encouraging nursing stories, she has helped mothers struggling with breastfeeding (personal communication, July 6, 2009). Caroline has also given other mothers in higher education information about scholarships and jobs (personal communication, July 6, 2009). As Claire feels doulas are an important part of the birthing experience, she has shared with women information about low cost/free doulas (personal communication, July 28, 2009). Virginia, who suffered from what she calls a “traumatic birth experience," provides information and support to help others through 
their own negative delivery experiences (personal communication, July 30, 2009). Betsy has a daughter who suffers from constipation, so she shares what she has learned about this topic with the community (personal communication, July 6, 2009). Blair provides information for getting pregnant through a sperm donor and caring for children with allergies (personal communication, June 26, 2009).

MDC members share information and their expertise with the community about topics that are personal and important to them. With the large size of MDC, there are enough members to contribute to multiple topics, creating a rich pool of information for mothers learning about NFL. As Ivymae said "Mothering.com, where you learn something new every day. .." (2009).

\section{Members' History with NFL and MDC}

Researching parenting issues is a common way that women learn about and begin to practice NFL. Many mothers did not lead a NFL lifestyle before having children. In fact, before having children of their own, some women confessed that they mocked mothers practicing NFL. When asked if she practiced NFL before having children, Shelly said "No, and in fact, I rejected it. I had some friends who were holistic mothers and I thought there [sic] mothering style was too indulgent," (personal communication, July 8, 2009). It was not until Shelly had her own child and did her own research that she started to practice NFL.

Other women raised in mainstream families had never been exposed to NFL beliefs and practices. This is the case for Hopefulfaith, who has been raised in a very mainstream family. She said "I came upon AP and NFL entirely by accident. Here I was, a few months pregnant with ds1, and googling online to try to find out pregnancy 
stuff. .." (2006). Hopefulfaith wrote that her online research brought her to MDC, and that the rest “. . . is history. I'm a newbie APer, I use CDs, I make baby food, I sling, I swear by Hylands ${ }^{6}$, I'm a budding lactivist, and I'm learning a lot all over this place! I am edging toward NFL. . . I have learned so much here. ..”(2006).

Other MDC members were familiar with and practiced NFL before having children, but they became more dedicated to the lifestyle after starting a family. Caroline read the book "An Ecologist's Journey through Motherhood," which prompted her to think about:

... my journey through motherhood and how it should be connected to things I believe in. I had always been a bit holistic before, but it never was a priority, and this time I had someone else who was counting on me to make it a priority. (personal communication, July 6, 2009).

Some mothers, like Betsy, already followed NFL practices before having children, such as eating organic foods and using natural cleaning products (personal communication, July 6, 2009). Other women were familiar and comfortable with the NFL practice of challenging the norm. Veronica, for example, was raised in New York City by vegetarian parents who practiced eastern philosophy and mediation. She shared:

I think they've always been the type to kind of question things and do things in a kind of unconventional way. So when it came time for me to be a parent, I didn't feel pressure to sort of fit in any kind of mold. I felt comfortable doing things my own way and just kind of questioning things. (personal communication, July 1, 2009).

Veronica's research and involvement at MDC helped her discover more about the already familiar NFL lifestyle.

For Molly, the only part of her life where she currently practices NFL is with her baby. She considers herself to be mainstream in all other aspects of her life. When asked

\footnotetext{
${ }^{6}$ Hylands is a homeopathic brand of medicine
} 
why she chooses to follow NFL with her son, she explained "... . a lot of it really is reading. The more you read, the more you realize that just because that is what everybody does, doesn't mean it is the right thing to do," (personal communication, July $15,2009)$.

Many members learned about MDC through mainstream parenting sites or blogs; some members heard about MDC on parenting websites that actually criticized the community. Frogautum shared her story of discovering MDC:

I was a member of a DDC on another message board and someone actually posted a thread about 'Do you think MDC is too extreme/crazy/crunchy?' I had never heard of MDC, so I naturally had to check it out. I found that I related much, much more to you ladies. . (2009).

For other mothers, internet searches for specific information, like homebirths, midwives, doulas, and breastfeeding led them to MDC. In fact, Brown Lioness discovered MDC by simply typing "mothering" into her search engine (2009).

Members have had different reactions upon discovering MDC. Some instantly felt like they were at home and were happy to find others who share similar parenting philosophies (e.g., Kirstenb, 2009; MittensKittens, 2009). Other women felt intimidated by MDC's NFL intensity. Kangal1622 felt intimidated at first, but she found that over time, her thinking about issues changed and aligned with MDC (2009).

When members begin participating in a community of practice, they are often unaware of the group's values, norms, and resources (Atalib, 2002). Participation in the community, including lurking and actively posting, allows members to learn about the community from core members, who are experts of the field (Atalib, 2002). Participation at MDC not only produces learning of NFL, but it also involves an identity change (Brosnan \& Burgess, 2003). Women become mothers through the birth of their children, 
and if they choose to, they can become NFL mothers. MDC serves as a place for women to try out their identities as new mothers (Madge \& O’Connor, 2005).

Below are member profiles that are illustrative of different learning trajectories at MDC. The members' online participation is analyzed to document their history of learning the culture of MDC and NFL, noting if they move from the periphery to the core of the group. Each woman's experience in the MDC community is unique, and each woman derives different benefits through her participation. As the community's membership at 136,000 is large, these member profiles are not meant to generalize members' experiences, but rather provide a brief glimpse into the learning that takes place at MDC.

Member Profile: Kathryn

Kathryn joined MDC on August 27, 2009. Her signature line has a symbol with a graph that represents how she charts her fertility cycle. In her signature line, she invites MDC members to stalk her chart on www.fertilityfriend.com, which means people are welcome to look at her chart and provide feedback as to when Kathryn appears to be ready to conceive. The chart in her signature line is an immediate and constant request for information from community members. Her member profile shows that she does not have MDC friends or public messages, another piece of evidence about her newcomer status.

Kathryn postd her first thread to the Trying to Conceive forum on August 28, 2009. This means that once Kathryn joined MDC, she jumped right into posting. It is possible, however, that Kathryn lurked before deciding to join and post to the forums. Her first post asked people to read her fertility chart, and she provided all of the 
necessary information to decipher it (2009). She also let the community know that she is a newcomer by writing "This is my first post here," (2009). She wrote that she is new in her second posts and again shared her fertility chart information (2009). By posting her online fertility chart, Kathryn shared personal information about herself with others. She engaged other members by asking for their feedback, and showed that she is willing to learn from others. Kathryn placed herself close to the center of activity in the forum.

Although Kathryn immediately used the language and acronyms involved in the Trying to Conceive forum, she admitted that she had "a lot more reading to do on charting (-)" (2009). When a member provided her information about her chart, Kathryn wrote "Please tell me why you think I didn't O [ovulate] then....trying to learn the whole charting process...." (2009). She made it known to the group that she as in the Trying to Conceive forum to learn and was willing to learn from others.

Based on her initial posts, it appeared that Kathryn grasped the basics about trying to conceive, but still was overwhelmed with all of the information. She wrote "This is our first time trying and I am so confused 8 " and "Hmm looks like I have a lot more reading to do on charting $(2009)$. By telling the other members that she was new to trying to conceive and is confused with all the information, she made her newcomer status clear to the group.

By her tenth post, Kathryn had begun to congratulate other women who had gotten pregnant. Her community role, therefore, changed from being a member who solely asked questions to being a member who supported others. Still, like other community members, Kathryn did not branch out to posting in other forums, limiting her position in the MDC community. 
When a member explained another member's ovulation chart, Kathryn was confused. She asked questions, explaining her thought process in charting ovulation. This allowed member HulaJenn to directly address Kathryn's misunderstanding about charting. Kathryn thanked HulaJenn, and told her that she now understood the process (2009). Kathryn posted a smiley face, a common practice in her messages. Kathryn consistently thankd members by their names when they answered her questions, and she repeated back information that members provide. She also told the group that she would report back what she learned and provide updates, which she followed through with doing.

Kathryn began to contribute to the trying to conceive pool of knowledge by sharing information about the cervix (2009). She shared a link to an internet site that has pictures of cervixes, summarized what she has learned from the internet site, and ended by asking clarification questions (2009). Kathryn's post about the cervix was the first time she has researched information on her own and shared it with the community. She was actively working towards moving away from being a newcomer in the trying to conceive world, educating herself and others about women's bodies.

Kathryn tried to incorporate NFL practices into her life. She told the Trying to Conceive forum that she wanted to find a form of natural form of lubrication to use for sexual intercourse. Her rationale for switching lubrication was that natural products are less expensive (being frugal is part of NFL), and that "natural is better," (2009). She did not seem confident in her decision, and followed up her statement of "natural is better" with "(or is it in this case?)" (2009). It is unknown as to whether Kathryn practiced NFL in other areas of her life. Kathryn had considered using either ripe bananas or okra for 
lubrication. Ammaarah wrote that ripe bananas will either lead to a terrible yeast infection or fruit flies, and Lisoula responded by posting an emoticon of a face taking a drink of water and spitting it out due to laughing (2009). Kathryn was not offended at what could be perceived as teasing, and she replied with a winking emoticon, laughing along with the group. She told the group that she was moving onto trying water. MaerynPearl asked her to clarify, writing "hopefully you dont [sic] mean water as a lubricant," (2009). Kathryn replied "Arrghh I am so dumb," (2009), making it clear once again that she was a newcomer. She was still learning about the details of trying to conceive, and relied heavily on the group to guide her.

Another way that Kathryn centered herself at the core of the group was by quickly using the language of the Trying to Conceive forum. She wished baby dust on all the members, and used the emoticon of a fairy waving a wand of baby dust around. Her sentences were filled with trying to conceive abbreviations and acronyms, such as AF for Aunt Flo, a slang term for a woman's menstrual cycle, and BD for baby dancing, slang for sexual intercourse. In using the language of the group, she was able to converse about the details of trying to conceive, as well as participate in inside jokes.

MaerynPearl, an old-timer, was an active poster on the Trying to Conceive forum. She answered many of Kathryn's questions, and Kathryn began to refer to her as Mae, demonstrating that she had begun to form a relationship with her. Forming relationships with other members was another way for people to move away from their newcomer status in a community of practice. When MaerynPearl answered a question for Kathryn, Kathryn replied "Thanks MaerynPearl, can't tell you how much your replies help. You are the best 2009 " (2009). MaerynPearl also explained a new MDC rule to Kathryn, 
telling her that she is not allowed to place her chart link in her signature, but that she can place it in her member profile. MaerynPearl served as the old-timer mentor for Kathryn, and Kathryn thanked her for telling her the community rules. Kathryn changed her signature line that day, adhering to MDC's norms.

During September, Kathryn continued to ask questions about trying to conceive. She also welcomes new members to the Trying to Conceive forum, and congratulated those who get pregnant. When members shared their troubling situations, Kathryn offered empathy and asked members to check back with the group to provide updates, continuing her role as a supportive member. When members worried and stressed about trying to get pregnant, Kathryn offered virtual hugs or told members not to worry. When a member shared that she thought she is having a miscarriage, Kathryn wrote "I am sorry hun! Don't feel alone, we all are here for you. I would say go to doctor ASAP. Take care and keep us posted," (2009). She often used terms of endearment to address members, such as "hun." She still asked more questions than she provided answers, but she always thanked members for sharing information.

At the beginning of October, Kathryn believed that she might be pregnant and shared her physical symptoms with the rest of the group (2009). Someone said that MaerynPearl would be the right member to give her advice, and Kathryn responded "Oh yeah!! She is the first one that comes to my mind if I am in doubt $\mathbb{9}$, (2009). Kathryn had come to know and trust MaerynPearl. In fact, Kathryn felt close to many of the forum members. She wrote "It's just amazing how the internet and these forums bring us together..I can't imagine going through the TTC time period and pregnancy without the support I get here!” (2009). 
When Kathryn knew she is pregnant, her postings to the forum dwindled. She wrapped up her postings by sharing with the group the things she did in order to get pregnant, including charting her ovulation cycle and making changes to her diet. In doing so, Kathryn served as an old-timer, a woman successful in her trying to conceive quest. She returned to the Trying to Conceive forum to write "Hi Ladies. Just wanted to drop in and say hi! :- I still come to this forum often and miss you all $\$$ Good luck and lots of baby dust to everyone!" (2009).

It is not clear if Kathryn was actually pregnant. She wrote that the doctor did not see the baby in the first sonogram, and he warned her that it might be an ectopic pregnancy (2009). She wrote that she would change her signature line to include her pregnancy ticker, a counter that tracks her due date in her signature line, but she never added it. Kathryn's last posting and login date was on October 12, 2009.

Kathryn is an example of a woman who came to MDC for a specific reason, which was to learn about trying to conceive a baby. Her pattern of activity involved regularly posting in the Trying to Conceive forum in order to reach her goal of becoming pregnant. All of her questions were pointed towards the topic of trying to conceive.

Besides her post about wanting to use a natural form of lubrication, Kathryn did not demonstrate interest in other areas of NFL. She used the language involved with trying to conceive, but she did not show that she was knowledgeable or interested in other NFL practices, thus limiting her participation at MDC. The only shared interest Kathryn seemed to share with the other members was her desire to get pregnant.

Kathryn's first post at MDC included information about her age and her ovulation cycle, but she did not supply more personal information past that. Although Kathryn 
praised the forum for being supportive and claims to miss the members, she did not continue to communicate with them. In fact, even when she was regularly posting, there were no signs that she wanted to form deep relationships with others. She was always kind, but she did not give the impression that she hoped to form friendships with group members. Once she did get pregnant, she did not join a due date club, nor did she post in other pregnancy forums. The only community, therefore, it seemed Kathryn desired to be a part of was the Trying to Conceive forum, and not any other part of MDC. Once Kathryn got pregnant, she quickly left the group.

When Kathryn shared the steps she took to get pregnant, she acted like an accomplished old-timer. She was happy to share the information with the group. In actuality, Kathryn never was an old-timer at MDC. She did not form strong relationships with others, and she took more from the community than she contributed. While she learned about trying to conceive, she did not show any other interest in NFL, thus limiting her chance to connect with other members. Although it appeared Kathryn moved quickly to the core by asking questions and providing support to others, her role at MDC was never cemented in the community. Member Profile: Maisy

Maisy's signature reads "Mama to 4..student midwife..home birth activist..and now pregnant with twins for friends as their gestational surrogate due 8/10 0 (2009). She joined MDC on June 25, 2006. Her first post as in the Birth and Beyond forum on June 26, 2006. She told the group that she had been lurking in the forum for awhile (2006). She was uncomfortable in telling the group about herself, and she was not confident with opening up to the forum. At the end of one of her first posts, she wrote 
“did any of that make sense? I think I'll go back to " (2006). The popcorn emoticon is for lurkers, and it represents just sitting and observing. She posted the lurking emoticon in her third post as well, proving that she was not yet confident in participating in the conversations. At this point, Maisy was more comfortable participating on the periphery of MDC.

Maisy did not wait too long to post again, however, and she posted responses to two questions in the Breastfeeding and Homebirth forums. As a doula and a mother, she had experience and is familiar with both of these domains, conceivably adding to her confidence in posting. She used the symbols of MDC by posting smilies in her messages, demonstrating her growing knowledge of MDC's shared repertoire.

In addition, Maisy demonstrated her NFL knowledge in a thread about placentas. In the Birth and Beyond forum, Debrown asked what people had done with their placentas after childbirth (2006). Maisy shared with the group that the hospitals where she works do not allow women to do anything with their placentas. She wrote "Funny though how some of them come up missing when certain nurses are working! (2006). Maisy showed the community that she is on board with doing something with the placenta after labor (eating it, buying it, or using it to make art), a practice of MDC mothers. She was playful in her tone, using a laughing smilie. She did not come right out and confess to stealing placentas, but presented the information liked a shared secret for MDC mothers. Maisy also wrote "I don't think that there is a person big enough to tell me that I am not *allowed* to keep my own placenta!” (2006). Her statement demonstrated that she agrees with NFL in questioning medical authorities and being 
assertive. Through sharing information, both educational and personal, and making jokes, Maisy started to move away from the periphery of MDC.

Maisy posted several times to a message titled "Fellow alldoulas ladies..." (2006). Alldoulas is a separate online message board for doulas, and the server of the group crashed. Without their internet home, Alldoulas relocated to MDC and chatted in the Find Your Tribes forum. Maisy was at ease with her doula friends, called them by name, and signed off with her real name, showing that Maisy had experience with being part of an online community.

An Alldoula member told the board that their relocation goes against MDC's user agreement, and that it is rude for them to come to MDC just to talk about their group. Although Maisy did not reply, the conversation allows her to learn more about MDC's user agreement. She was the last one to post to the Alldoulas thread, writing "Bump," (2006). Bumping a thread moves the message to the top of active threads, increasing the thread's profile. Maisy wrote bump because she wishes for more members to reply, but they did not do so. In some web forums, bumping a thread is against netiquette. This does not seem to be the case at MDC, however, as even the moderators participate in bumping threads.

Maisy's first lengthy reply was in the Birth and Beyond forum. Women are asked to share their epiphany moments about natural birth/drugs/interventions. Maisy shared the stories of giving birth to her two children, which included an epidural and pitocin for the first. She had reduced amounts of medical interventions with the second baby, and she writes that the baby was much more alert than her first. Maisy told the group that she now knows she did not need to be induced with her second baby, demonstrating that she 
has done her research about natural childbirth. She ended her message by telling the group that she was trying to get pregnant, and hoped to have a homebirth (2006). Through this message, Maisy showd that she is a believer in natural child birth, and that she researches parenting issues. Maisy was demonstrating that she belongs at MDC. She used smiling, winking, and sad smilies throughout her message, conveying that the topic of childbirth is an emotional one for her. Feeling passionate about natural childbirth is a trait of MDC mothers, and using the smilies shows that Maisy is familiar with the repertoire of MDC. As Maisy tried to get pregnant for a third time, she began to feel connected to members in the Trying to Conceive forum. She told the group that she lurked in the forum, keeping up with everyone and their stories. She wrote:

You guys are really giving me an emotional rollarcoaster [sic] ride. I keep hoping to lurk and see lots of BFP [big fat positive] and I get so excited everytime [sic] that I do! - And I really get sad when each of you gets your AF. Kinda crazy since I've just been hanging around and haven't had any interaction with ya. (2006).

She then shared with the group the bodily position she puts herself into post-coitus to aid in getting pregnant, revealing intimate details about her life. Maisy began to post regularly in different Trying to Conceive threads, such as TTC in our 20s, TTTC newbies $-1+$ months, and The One Thread. She became familiar with the members of in the groups.

At the end of August 2006, Maisy discovered the Frugality and Finances forum. She was excited and wrote "I am soooo late coming to this section! I always go straight to the birthy stuff! How did I not know that this was here until today and I've been 


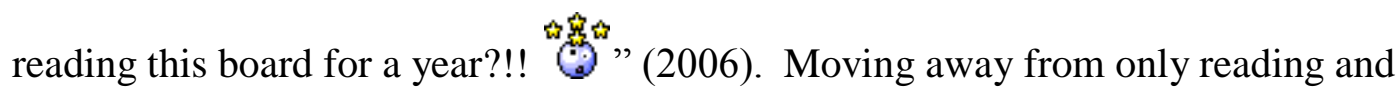
responding in childbirth forums placed Maisy closer to the core of MDC.

Maisy wrote in the Finances and Frugality forum that she did not have a lot of debt compared to the average American, yet when she wrote out the details of what her family owes, she as overwhelmed. She told the group that she is going to return to lurking so she will not have to dwell on all the money her family owes. Maisy did not do this, however, and began posting more regularly in the Frugality and Finances section. She asked about how to can peaches and other ways to stretch her food budget. She also shared her success in reducing her grocery shopping bill, proving to the group that she was actively practicing being frugal. By moving out of just reading threads about birthing, Maisy expanded her knowledge of NFL and made connections with more MDC members, deepening her role as an active community member.

Maisy formed relationships with other MDC mothers. She acknowledged when she received private messages from other members, showing that she was connecting with members past the just posting in the forums. When Jillian, another MDC member, told the Trying to Conceive forum that she was pregnant, Maisy congratulated her and wrote "Love ya girl!!" (2006). She encouraged others and offered advice. At the end of September, Maisy began to participate in the Trading Post, a forum that is restricted to members with fewer than 50 posts. Maisy had moved from lurking and being nervous to participate to regularly posting and forming relationships with other members.

In 2006, without even knowing she had been pregnant, Maisy had a miscarriage. She read about miscarriages on the Pregnancy and Loss forum to learn more information about pregnancy loss; her posts reveal that she was more interested in understanding why 
this happened rather than receive sympathy from other members. At the end of October 2006, Maisy was pregnant again. She shared the news with MDC before telling her friends and family. In fact, MDC members were the first to hear about her pregnancy news. Maisy wrote (2006):

I don't want to sound like a bad beauty contestant, but honest to God, I could not have done this without you guys. . .I feel so blessed to have spent this time with you guys. It's time to move on, and I will see you guys in July '07 club soon.

She quickly joined her Due Date Club and introduced herself to the group, telling them that this was her third baby and that she was planning a homebirth. Women from Maisy's Trying to Conceive tribe also moved to Maisy's DDC, and she expressed her great joy when they do. She checked in with the Trying to Conceive group for about another month, and then ceased to post in the forum. Although she made connections with the women in the Trying to Conceive forum, she was ready to put more energy into her DDC.

Maisy began to post primarily to her DDC, and sometimes at the I'm Pregnant forum. Maisy became chatty in her tone, sharing details not pertaining to being pregnant with other members. For example, she told her DDC about her difficult night, which involved an asthma attack from her son and eating a sub sandwich. They shared pictures each week of their growing, stretching bellies, assuring women that they are not fat, that they look cute, and that the baby is dropping. The DDC started their own cookbook thread, sharing recipes with one another.

The members in her DDC also shared technical information with one another, including articles and information from their doctors. As a mother to two children, Maisy was able to share BTDT stories. However, she is was to drug-free homebirths. It 
appeared that Maisy's DDC had become her tribe, a community of practice within MDC's large community of practice.

Maisy was one of the last people in her DDC to deliver her baby. She shared her birthing experience as it was happening with her DDC. She first told the group that she has lost her mucous plug, and she believed her labor will soon begin. The next day, she told the group that her midwives were coming over to her house and that she has been having contractions every four to five minutes. Later that evening, she shared with the group when she was dilated at seven centimeters and that her contractions were "... really starting to suck," (Maisy, 2007). Her DDC was amazed with her updates during labor, and Ahdoula wrote "Wow. . talk about a play by play! Are you going to type while you are pushing too?!!" (2007). The next day, at 9:30 in the morning, Maisy wrote: "WOW!!! That was amazing!! I'll type up the birth story later. . . Thank you guys so much for going on this journey with me. Best labor wishes for you all!" (2007). Typing while in labor in order to share her experiences with her DDC clearly shows the connection and dedication that Maisy had towards her group.

About a month after she delivered her baby, Maisy kept up with the DDC. They discussed NFL baby practices, such as baby wearing and breastfeeding. As designed by MDC, her DDC served as a temporary tribe meant to connect her with mothers through their pregnancy and a month afterwards. After that, a DDC no longer has a dedicated space in the DDC forum, although their messages are archived and members can form their own tribe in the Finding your Tribe forum. Maisy returned to posting primarily in the Trading Post and Frugality and Finances forums, and continued building relationships with other members. 
Two months after her homebirth, Maisy posted for the first time in the Vaccinations forum. She begian by writing "I've never been over to this part of the board before, so forgive me if I do/say something wrong,” (2007). Although Maisy was well established in other forums, she still recognized herself as a newcomer to the Vaccination group. She explained that she took her baby for a check-up appointment, and the doctor tried to convince her to have him fully vaccinated at that time. Maisy refused some of the vaccinations, and asked for her son only to receive the required vaccinations. When she returned home, she was upset to learn that the vaccinations administered by the doctor were not necessary. She asked the members for advice, and told them that she would not vaccinate her son any further. She also shared that while her first children were fully vaccinated, she now knows better. Maisy fit into the role as a mother who once was mainstream and uneducated, trusting her doctor, but had now seen the NFL light and had changed her ways.

The members in the Vaccinations forum wrote that Maisy needed to have a backbone to stand up to doctors, research all she can, and file a complaint against the doctor. Maisy did not ask any further questions or provide updates as to what she has decided to do. Her venture into posting in the Vaccination forum was a short-lived one.

In July of 2008, Maisy stepped into another forum for the first time, the Surro Moms and Parents by Surrogacy Support Tribe. She wrote "I used to be on here religiously while awaiting my home birth. . I'm ready to get back to my 'roots' and get into the swing of things here!!” (2008). Even though Maisy considered the surrogacy support tribe to be her roots, she had not previously posted to the forum. This demonstrates that through acts of legitimate peripheral participation, such as regularly 
lurking on a forum, a member can grow to feel connected to a group (Altalib, 2002).

Also, by sharing with the group that she had a homebirth, Maisy let others know that she practiced NFL, that she belonged at MDC.

In November 2008, Maisy shared a video of her son's homebirth in both the Birth Stories and Homebirth forums. The video was a slideshow of pictures, set to music and complete with captions, and she talked about feeling empowered through her birth.

Maisy told the group that she will write out her birth story one day, but that she was not ready for the closure that it will bring just yet. Maisy writes (2008):

I was able to have my home birth partly because of seeing so many inspiring videos and hearing so many of you describe how normal and beautiful your births were. I literally read every single birth story here and in the UC part. (I think I really took more interest in the UCs, but only because I knew that if they could do it w/out any help, then surely I could do it with my 2 midwives... and their overwhelming confidence really rubbed off on me while reading their stories). It was really difficult to make, but only because I could NOT decide which pictures to put on it! lol. (2008).

It was evident that Maisy was proud of her accomplishment of having her third child at home without any interventions. Each picture in her slideshow had a caption, many of them explaining her NFL practices. Maisy's post demonstrated that she practiced intensive mothering through her extensive research about NFL practices. For example, a picture of her having a contraction while smiling had a caption that explained how she wanted to smile and talk through each contraction. In NFL, women like to reframe the idea of contractions, referring to them instead as surges that can be pleasurable. In addition, sharing the story of birth is part of the group's shared practice. While she had not fully completed the practice of sharing her birth story, she had taken the first step by sharing her pictures. 
Over the next months, Maisy journeyed into many different MDC forums. She posted in her local tribe forum where she offered her opinions about health care providers and arranged to meet members in person. Through her local tribe, Maisy made MDC friends in real life, bringing the MDC community closer to home for her (2008). Maisy also rang in with her opinion on the Question and Answer forum about having a standing forum on preparedness (2009). In doing so, Maisy made an effort to have her feedback positively shape MDC. She also posted once in Mindful Home, a few times in Health and Healing, and in the Television forum. Once posting and lurking in only birth related forums, Maisy had diversified her activity at MDC. By posting in several forums, Maisy continued to connect with more MDC members and learn more about different aspects of NFL. Through her frequent activity, responding to and asking questions, and exploration of many forums, Maisy was at the core of MDC's community of practice.

On January 20, 2009, Maisy shared her thoughts about being an egg donor surrogate on the Adoptive and Fostering forum. She did not, however, indicate that she was thinking about having or being a surrogate mother. Then, in February 2009, Maisy posted that she was pregnant with someone's baby as a surrogate mother. This came as a surprise as Maisy had never spoken about this big decision to be a surrogate mother. The history of her steps to becoming a surrogate had not been shared in the forums. In March, she discovered that she was going to have a miscarriage. She did another transfer on May 27, 2009. Although she was very open in other forums about her life, she had decided to keep this occurrence more private.

On July 2, 2009, Maisy finally posted the birth story of her son. She had shared the story in bits and pieces over the years at MDC, and had finally condensed it into one 
long post. She wrote "I decided that it was finally time to sit and write out his birth story, MY birth story," (2009). Maisy put herself as the central figure in the birthing process, a main idea of natural birth. She shared that through a natural childbirth, she had been transformed (2009). Additionally, although Maisy had researched and prepared for the birth, she wrote that she let Jacob, her son, decide how he wanted to be born (2009). This demonstrates the ideal balance of education and instincts in NFL: Maisy educated herself extensively about having a natural childbirth, yet she still let her instincts and nature lead the way during the delivery.

In August of 2009, Maisy returned to the Vaccination forum, distressed because she had discovered her daughter is not immune to Pertussis, which means she will have to be vaccinated in order to attend kindergarten. Maisy wrote "DD had all of the recommended shots until she was 16 months old (you know the drill \& I was totally uneducated)," (2009). She asked the Vaccination forum what Pertussis was and what their opinions were about the topic. She told the Vaccination forum that her daughter was in the hospital due to vaccinations, showing that Maisy had come to believe vaccinations can be dangerous. She also told the group that she was considering finding someone with Pertussis in order to expose her daughter to it, another practice of NFL mothers. She trusted the advice of the forum, and made disparaging remarks about medical institutions.

At the end of November 2009, Maisy joined her DDC for August 2010. She introducedherself to her group, writing:

Unfortunately since this isn't my baby and we did use IVF [in-vitro fertilization], I have to have a few u/s [ultra sounds] in the beginning and I agreed to having a hospital birth. The parents are all for me staying home until the last second with my hb mw [home birth midwife] here and then she'll be my doula at the hospital. 
After I have the baby, I'm grabbing the placenta and getting the heck out of there! Lol. And then my mw will come home with me and monitor me just as if I had a home birth. (2009).

Maisy's introduction to her second DDC shows just how fully she had come to embrace NFL living and the MDC community. Maisy did not want to have ultra sounds during her pregnancy. NFL believes pregnancy is a natural occurrence, making ultrasounds unnecessary procedures that often only serve to cause fear in pregnant women. In her post, Maisy used acronyms for birthing and the language of MDC. Maisy planned on having a doula, a practice promoted by NFL. She did not want to birth at the hospital, and planned to stay at home as long as possible during her labor; she did not believe babies need to be born at hospitals, and hoped to create as much of a homebirth experience as possible. Maisy planned on taking her placenta with her, possibly to consume afterwards, and leaving the hospital as soon as possible. She enjoyed talking to other mothers in her DDC, and appeared happy to be a part of the community. Maisy was truly versed in NFL, and was firmly planted in the MDC community. She was a MDC veteran.

Maisy's pattern of activity revealed a woman who once was new to NFL. She lurked in the forums, lacking confidence to participate. When Maisy began to post messages, they were in forums where she had first-hand experience, such as breastfeeding and giving birth. Her pattern of activity involves decreased posting around busy times, like having a new baby and the holidays. Over time, Maisy began to explore non-child related NFL topics, such as the Finances and Frugality forum. She had a spike of activity in the Finances and Frugality forum, and her messages conveyed a sense of excitement about the news things she was learning. Maisy played the role of a reformed 
mainstream mother, sharing with the community the things she used to do before becoming educated about NFL. Member Profile: Wendy

Wendy is a 36 year old first time mom. She is a lawyer living in California bay area. Wendy joined MDC in July of 2008 and started posting to the forums right away, never formally introducing herself. She posted for the first time to the Breastfeeding forum, explaining the feeding challenges she was experiencing with her daughter. Leerypolyp replied that Wendy’s daughter might have allergies (2008). She received only one more reply from the Breastfeeding forum. Wendy posted the same question in the Allergies forum, and she received a total of 14 replies. Later that day, Wendy told the Allergies forum that she suspected her daughter had allergies, and that she was supposed to have her vaccinated that day. The members urged her not to do so, and Wendy reported back that they decided to not give her the shots. She also told the group that they were switching to a more holistic doctor. The Allergies forum cheered her for her decision. This was Wendy's first experience in a forum that will grow to be her tribe, her community of practice.

Over the next months, Wendy posted primarily to the Allergies forum. As she was solely breastfeeding her child, she has changed her diet to figure out what food intolerances her daughter has. She shareda great amount of information with the group, telling them all of the research that she has done. She did not use the language of MDC, but did refer to her husband as DH and her daughter as DD. She shared personal information with the Allergies forum October, telling them that her daughter, Isabel, was 
a happy five-month old baby. She wrote "I waited a long time to have her and she was worth the wait. "Q." (2008).

Wendy began to address members directly, thanking them for their words of encouragement. She also reached out to members, telling them that they were not alone in their trials of having children with allergies. Wendy responded to a Finding Your Tribe forum request for mothers in peninsula area. She wrote "I would love to hear if you have found a good group or PM me if you want to meet up," (2008). Although Wendy was opening up the channels to have direct communication with other mothers, it was not known whether her posting led her to meeting people in real life. Through sharing information and working to make connections with other MDC members, Wendy was working at moving from the periphery of the group to the core.

While the trials of having a child with food allergies seem overwhelming, Wendy told the Allergies forum that she was actually grateful for her situation. Due to allergies, she had become very focused on her daughter and had changed many of her former conventional ways. She wrote:

I'm sure I would have ended up vaxing DD, putting her in daycare, and following standard dr orders if none of this had happened. But thanks to this forum, and the many hours of research, I won't vax her, I hired a nanny to watch her so she gets 1:1 attention (and I can nurse her when I work at home), and I see a holistic pediatrician.

And it introduced me to homeopathy. I don't care so much about money anymore, it's about DD and my family and being healthy and happy. I am hopeful that we will all heal and DD will grow up knowing the truth about nutrition and health and lead a better life because of it.

Even DH is coming around and starting to realize some of his health issues are likely food/nutrition related. I really think all things happen for a reason and I'm just so happy that I have all the mamas in this forum to help guide me! 
Wendy's daughter's allergies led her to MDC, and MDC had played a part in changing her lifestyle. Wendy had obviously become educated in the NFL ideas about health care and attachment parenting.

Every now and then Wendy ventured into other forums, but it was usually for allergy related topics. She shared a great deal of information, such as facts about allergies she had learned from books and articles. She did post in the Traditional Foods forum to reply to a woman wanting a walnut yogurt recipe. Wendy had researched nut yogurt recipes as an allergy safe food for her daughter. She provided an internet link to the recipe and invites feedback, writing "I would be interested to hear how it turn out!" (2008). Even though Wendy did not regularly post in other forums, this post demonstrated that she does lurk in them.

At the beginning of December, Wendy wrote similar posts in the Allergies Forum and in the Florida, Georgia, and Alabama forum (2008). She was in search of an alternative practitioner in Florida who can help with digestive and auto immune diseases. In the Allergies forum, Wendy told the group that she was doing this for her mother-inlaw. She shared more information with her tribe, and also told them about a book she gave her mother-in-law. At this point, Wendy was using MDC not as a resource just for herself, but for extended family members as well.

Wendy ventured into another forum, The Family Bed and Nighttime Parenting. She was having a hard time getting her seventh month old to sleep, and she shared the details of her dilemma with the group. Wendy was trying to follow the advice from the book No Cry Sleep Solution, but it did not seem to be helping. Trillian11 offered Wendy advice, but Wendy told her that she had already tried that and it did not work with her 
daughter (2008). Another member, Dreamy, empathized and told Wendy to just keep trying the No Cry Sleep Solution book advice (2008). Wendy received no further feedback. With the small amount of responses, it was understandable why Wendy may have felt discouraged and only continue posting in the Allergies forum. In addition, it shows that although most of her attention at MDC was focused on allergies, she did read books involving other parenting issues as well.

On New Year's Eve, Wendy posted to the Allergies forum to celebrate with the members. She wrote "Happy new year everyone! I am also really thankful for all the mamas here. I would be so lost without all of you. Here's to a new year and lots of healing!" (2008). Members told the group that they love one another, and they wished each other blessings of good health. This post made it clear that for Wendy, the Allergies forum had become her tribe, her community of practice within a community of practice. Not only had she been learning a great deal of information through the Allergies forum, but she had formed a personal connection with the other members. She posted a picture of a champagne glass to toast to the mothers as they celebrated surviving 2008 .

As for flame wars, Wendy had stayed away from them. Members had not criticized her postings, and she had been kind to others. She did, however, post a reply to a flame war. Wendy begab her reply by writing "Wow, there are some harsh responses here!" (2009). While acknowledging that the replies had been unkind, she still did not directly shame the members for what they have said. Wendy encouraged the original poster not to beat herself up, and pointed her to the Allergies forum as a place of support and information (2009). 
In January of 2009, Wendy reported to the Allergies forum about her daughter's doctor's appointment. Her message demonstrated how much she had come to learn in the allergies community of practice. Her post was filled with abbreviations and allergies language. Although she seemed to trust the doctor, she still asked the group to evaluate his advice, showing that she had a lot of trust in the knowledge and opinions of the Allergies community. A member asked a question and Wendy told her that she would refer back to the notes she took during the doctor's visit, illustrating that she is a highly attentive mother (2009). That same month, Wendy also shared with the group that she was considering going to a medical intuitive, a psychic who would give her advice about her daughter's allergies. She told the group that she knew it seems "out there" and she wondered if she is wasting her time (2009). The Allergies forum encourages her to do so, and she reported back to them with the advice she received. Wendy had become willing to seek out alternative forms of medicine, a trait of NFL. By asking for her tribe members' opinions about an alternative medical practice, Wendy demonstrated that she trusted and valued their opinions.

Wendy shared with the Allergies forum her journal that tracked her daughter's food reactions. The journal was intense and in-depth. Wendy wrote:

I use an Excel spreadsheet and start a new column for each day. I write down everything DD eats and everything I eat (including supplements), her poops, naps, reactions, and anything out of the ordinary. I record the time and put it in chronological order and include a summary at the end of each day. I highlight her entries in red and what I eat is in black. I also highlight her poops according to color (so green background if she had a green poop) Her poops are her clearest symptoms so then I can look at a glance at how she has been doing based on her poops. I also put at the top if I'm trialing anything. (2009). 
Kjbrown92, also shared with the group what she records. Wendy addressed Kjbrown92 by her real name, Kathy, and asked her to share her charts (2009). Wendy had come to know members by their real names, and felt comfortable asking members to share personal information. Her journal also showed just how focused she was on ameliorating her daughter's allergies.

The stress of Wendy trying to solve her daughter's allergies had begun to wear on her marriage. She told the group that she and her husband had begun seeing a counselor (2009). Her posts became less intense, meaning that she did not respond to every person's questions or comments. She wrote "I haven't caught up on other posts. I don't know why, but this board has been overwhelming me lately. I just don't have time to keep up!" (2009). She told the group that she felt overwhelmed with information and was exhausted (2009). Wendy was starting to feel the burn out that MDC mothers are prone to experiencing.

In March 2009, Wendy posted a message about going out to eat that illustrates how her daughter's allergies had greatly restricted her own lifestyle. As she still was breastfeeding her daughter, Wendy had drastically changed her diet. Due to her diet changes, Wendy felt she could not go out to eat at the majority of restaurants. There was, however, one expensive restaurant in her town that served salmon made only with sea salt that she felt she could safely eat without causing an allergic reaction in her daughter. When she went on a rare evening out with her husband to the fancy restaurant, they did not have the salmon she had planned on ordering. She ordered chicken instead, and worried about how her daughter would react to the meal (2009).

In April, Wendy posted in a different forum, NICU \& Preemie Parenting, to seek 
advice for her sister who had a baby at 25 weeks (2009). It was evident that Wendy was out of her normal community at MDC, and she did not know any of the acronyms or language involved in talking about premature babies. She returned to the Allergies forum to pray for her nephew, and worried that her sister has not bonded to the baby. She again tried to utilize MDC as a resource for others besides herself, looking for an inexpensive apartment for her sister to stay at while at the hospital.

Wendy's worries for her daughter expanded past allergies. She posted to the Special Needs forum to describe details about her daughter's behavior because she worries she might have some kind of developmental delay (2009). Based on Wendy's descriptions, members told her that her daughter might be autistic. She was also worried because her daughter sometimes walked on her tip-toes, a possible sign of high calcium. In both instances, Wendy turned out to be worried over nothing. Regarding walking on her toes, Wendy wrote "I drive myself crazy looking for what's meaningful and what is just normal toddler behavior," (2009). After a doctor evaluated her daughter and cleared her anxiety about autism, Wendy wrote:

To be honest, my instinct tells me she does not have autism but I got so worked up with some of the information I got on the internet and from MDC that I couldn't even see what my instinct was telling me. (2009).

For Wendy, being a first time mom meant that she did not have previous children to serve as a reference as to what kind of behavior is normal. She questioned everything, and although MDC served as a place of great support for her, all of the information also caused Wendy to be anxious and unable to be confident in listening to her instincts. Wendy continued to post regularly to her tribe, the Allergies forum. If time passed without posting for a week, Wendy apologized and explained what had been 
happening in her life that has kept her away. She continued to share information and ask a lot of questions. She also set dates to meet with MDC mothers in the San Francisco area. On December 1, 2009, Wendy told the Allergies forum that her husband was unhappy with the amount of time she spent researching things. Wendy wrote about the therapy session:

In last week's counseling session with $\mathrm{DH}$, he said he thinks I am obsessing over the allergies and I need to stop researching (which I have been doing little of because I don't have time and he complains whenever I'm on the computer). Instead I should just find a doctor I trust and can listen to (which as we all know is so easy to do). The counselor suggested I have mommy burnout and I need some support, and I am now going to counseling by myself the next few weeks. It will be interesting to hear what she has to say tonight. I'm hoping it will be helpful. With respect to homeopathy and alternatives, I'm not sure DH believes in it, but I do it anyway and don't ask for his permission. Sometimes he complains about the cost but I ignore it (well, sometimes it starts an argument). Originally I wanted him to help me research and figure out the puzzle, but now I just want him to not complain when I do it and to support me emotionally in what I am doing. But we aren't quite there yet. (2009).

Wendy was experiencing the burnout that many MDC mothers endure. She used sarcasm when she said it is easy to find a doctor to trust, knowing the MDC mothers would agree with her that a good doctor is hard to find. She had the "mother knows best" attitude that NFL promotes, and she considered herself the ultimate authority regarding the care her daughter receives. Wendy also listened to her instincts to do what she felt was best for her daughter. Her posting frequency began to slow down after her therapy session with her husband.

Wendy is an example of a woman who, like Kathryn, came to MDC for a specific reason. Unlike Kathryn, however, Wendy has formed relationships with other members and has stayed on MDC for years. This could be because Wendy's daughter's allergies 
have not been cured. At the same time, it could be because Wendy feels a connection to the members of MDC.

Although Wendy remained primarily in one community, the Allergies Forum, she does read and post replies in other forums from time to time. Wendy also incorporates NFL practices into her life, such as promoting a strong attachment with her daughter. She has become passionate about health and well being, and explores alternative medicine for solutions. Her pattern of activity consists of regularly posting to the Allergies forum, not going more than a few weeks at a time without posting. Wendy is an old-timer in the Allergies forum and is always sharing information, but she continues to ask plenty of questions as well. When having to reach out to the other MDC communities, Wendy makes clear her newcomer status. At times, Wendy will use smilies, and she always uses proper grammar and correct spelling. She arranges to meet members in real life and exchanges private emails with them. When people share their email addresses, blogs, and Facebook profiles, Wendy tells the group that she does not like to share that kind of information online. So while she spends a great deal of her own time sharing personal information with her online community of practice, she still has boundaries regarding what she would like to keep private.

\section{Member Profile: Joanna}

Joanna has lived in North Carolina her entire life, but she writes in her member profile that she is an avid traveler. Her interests include running, music, her husband, cooking and eating vegan food. Joanna is a registered nurse. Her signature line reads "Melanie, vegan mommy to twin girls born Dec. 2007, and another little girl born Sept. 25 ${ }^{\text {th }}, 2009, "$ (2009). She joined MDC on April 14, 2002. 
Joanna's first post was in the Diggin in the Earth forum, titled "HELP! My basil is all shriveled up," (2002). She asked for advice on how to save her dying basil plant, and thanked members in advance for any advice they can provide. She ended the thread writing "Thanks everyone!" Joanna did not post for almost another year.

Joanna's second post in 2003 was in the Nutrition and Good Eating forum, and she asked how she could give up drinking soda so she could be healthy for getting pregnant in a year. Joanna described her addiction to diet soda and ended her message by signing “Love, Melanie,” an uncommon way to end posts (2003). Then Joanna was quiet on MDC for almost two years. She returned in 2005 to post in the Nutrition and Good Eating Forum, where she posted twice in June and once in November.

In December of 2006, Joanna posted once in order to ask about vaccinations and pregnancy. She ended her message writing “I'm new here but been a lurker for a while. I subscribe to the magazine. I'm about to be 31 and VERY excited about being pregnant (having kids)! I love this forum and website $\ddot{*}), "(2006)$. For her start at MDC, Joanna has had long periods of either inactivity or lurking. Since she subscribed to Mothering magazine, Joanna had been exposed to the ideas of NFL. Joanna had been on the periphery of MDC for years.

On May 19, 2007, Joanna discovered she was pregnant and she posted to the January DDC with the title "Yes!" and a smiley face. She wrote that this was the happiest day, and she was glad to no longer have to lurk on the forums (2007). She already shared a concern, however, which was that she dyed her hair before she knew she was pregnant. She asked the DDC for their thoughts (2007). No one addresses her concern about dyeing her hair, but she received four responses welcoming her to the club. 
Joanna introduced herself again to the DDC in a more lengthy email on June 1, 2007. She wrote about her ailments she was already experiencing: lethargy, constipation, forgetful, breaking out in acne, and having a belly pooch. She was not experiencing morning sickness, but did have strong aversions to wine and coffee, things she usually enjoyed. She wrote "I am trying not be negative and just enjoy this pregnancy but I'm SO FATIGUED!" (Joanna, 2007). At this point, the she did not respond very much to others' threads, but she just shared what was happening to her. Besides her DDC, Joanna posted regularly to Vegetarian and Vegan Living forum, usually sharing recipes.

Joanna experienced many negative emotions during her pregnancy. She was sad because her active imagination was no longer working in high gear (2007). She felt very lazy and guilty about her lack of motivation. She constantly felt nauseous, and missed cooking and eating her favorite foods. She worried that the charred food she ate would hurt her baby. She felt self conscious because she had gained weight already at seven weeks. She had guilt because she ate M\&M candies at a conference and it made her sick. She would cry easily. During a doctor's visit, Joanna shared that she was so unhappy. "I mentioned to my doc how unstable I've been feeling and she reassured me it's normal. God I hope so $2, "$ (2007).

Through sharing her worries and anxieties, Joanna connected with other members, learned about pregnancy and the culture of MDC, and felt supported. When she shared that she was no longer feeling creative, there were seven other mothers who felt the same way (2007). Joanna was sad that this part of her identity, being creative, had been sapped away through her pregnancy. Through her DDC, however, she realized that she was not alone with this loss. Members assured her that eating charred greens for one meal did not 
hurt her baby, and Joanna replied "I'm gonna try and relax a little bit heh " (2007). Others pregnant women commiserated about weight gain, but assured her that it is normal. Joanna's DDC members made jokes and shared their stories about having to frequently urinate. Finch, a veteran mother, told Joanna to make sure to buy a baby sling. Even though baby wearing was off topic from frequent urination, Joanna asked Finch what kind of sling she recommended. Finch was quick to tell her sling preferences, and told Joanna that mothers at NINO, LLL, or API meetings can help her figure out how to use them. Joanna had to ask what the acronyms mean, writing "VERY new to all this. . ." (2007). She was clear in letting others know that she is a newcomer in the pregnancy and child rearing world.

After sharing her guilt for eating candy, To-Fu told her that they have a lot in common. They added each other to their friends list on another social website. Joanna was happy to make the connection, and she wrote "SOO EXCITING ALL WE HAVE IN COMMOM!!!!” (2007). Joanna had begun making connections with members of her DDC, another step in moving toward a central location in a community of practice.

On another DDC thread, a member asked what books people are reading. Members shared their novel choices, and some included books about giving birth and raising children. Joanna was reading all novels, but she replied a second time to say that maybe she should read a book about babies like the other members (2007). Like other mothers at MDC, Joanna began to doubt herself with even the simplest activities, such as reading for pleasure, when comparing herself to other members.

Joanna expressed gratitude for having a DDC. She wrote “. . . I can't seem to keep up with all the other threads and groups elsewhere here $\overbrace{}^{2}:$ it's nice having a 
'home' $:$,', (2007). Joanna had finally found her community of practice within MDC's community of practice. Her DDC had become her tribe. By limiting the forums she visited, she did not have to feel overwhelmed.

Joanna received big news that she was pregnant with fraternal twins. The message titled "I'm so confused (I'm pregnant with fraternal twins)" conveyed her fear and displeasure about being pregnant with twins. Joanna shared with the Parenting Multiples forum an article that explained factors as to why women get pregnant with multiples. The members' replies were mixed. Some were confused as to why she is was upset, some assured her that it will be okay, and some told her to take this as a blessing. Joanna explained that she was really scared and insecure about her ability to mother twins. She used a lot of smilies to help convey her feelings, and she also thanked the group for sending positive vibes, a popular phrase on MDC. On August 18, 2007, she wrote:

thanks [sic] everyone! You all are really really amazing people. I've been lurking this board for YEARS (I used to be a doula and labor \& delivery RN VERY passionate about natural birth and CHOICES and so I guess I am also mourning the fact I will likely not get that. The midwives now aren't allowed to deal with me cause [sic] I am considered a "high risk" pregnancy just because they are twins $\Theta$

The thread ended up being 54 responses long, the highest amount of replies Joanna hadever received. Members offeedr her advice, told her books to read, and assured her that it will be okay.

Joanna posted in the Homebirth forum to ask what her delivery options were with having twins. People offered her solutions, such as driving to Virginia to a midwife, or having a UC or a CPM. She had to ask what the acronyms UC and CPM stand for, and wrote "sorry I am really stupid with all this!" (2007). Members told her that she was not 
stupid, and explained what everything means. Joanna had been a MDC member for years at this point and had posted regularly to non-child related forums. When it came to pregnancy and childcare, however, Joanna was still a newcomer.

Joanna delivered her twins at the end of December. Joanna's husband wrote the birth story and shared it with the group. The story was full of NFL practices. He discussed their desire to have privacy in the hospital, to delay cutting the umbilical cord, and to bathe their daughters for the first time themselves. They were dismayed when these things did not happen. Joanna's husband shared pictures of himself with his shirt off, holding his daughters close to his chest, a NFL practice to promote bonding and to soothe infants.

Joanna and her husband were smiling in the pictures, but Joanna shared with her DDC that she was struggling. Breastfeeding was not going well, and Joanna said it was a nightmare. She felt devastated that she could not properly nurse her babies, and she joined the Breastfeeding Challenges forum. She wrote "This is the most stressful time of my life," (2008). People gave her advice and support, and she thanked everyone for their responses, writing:

This board is such a godsend. . again I can't thank you enough for your advice. This is one of the most important things to me in the universe (to be close with my babies and breastfeed) so much appreciation to everyone of you. I cried reading these responses cause [sic] I've been feeling in the twilight zone. (2008).

Joanna checked back in with her DDC in February, telling them that she was really busy and that mothering twins as the hardest thing she has ever done (2008).

After giving birth, Joanna did not post for three more months. In May, she posted to the Exclusive Pumpers Tribe, sharing that she had been lurking for awhile on the forum (2008). She told her story about her breastfeeding challenges, and that she had 
unexpected post-partum depression due to not being able to breast feed. She said that she never knew there were other mothers exclusively pumping in order to feed their babies, and she was happy to have found others like her. Once again, a negative situation had allowed Joanna to make connections with other MDC members.

Joanna discovered she was pregnant again and in January of 2009, she joined the DDC for September 2009. She introduced herself to her new DDC, and told them that she was going to have an ultrasound to see if she was pregnant with twins again. She said she would accept it if she was pregnant with twins again, and that she was excited to be back in a DDC (2009). At this point, Joanna was an old-timer. She had gone through the experience of pregnancy and labor, and had been a member of MDC for years.

On February 12, 2009, Joanna started a thread titled "scared" on the Parenting Multiples forum. She had found out that she was nine weeks pregnant with twins. She was low in energy, unsure as to where twins would fit in their house, and depressed at not getting to have the normal experience of being pregnant and having only one baby at a time. She was so despondent that she had called an abortion clinic to explore terminating the pregnancy. Joanna received replies of support, including two people who offered to stop by to talk to her in person. Time passed, and Freethinker started a thread on the Parenting Multiples forum to follow up on Joanna (2009). Joanna shared that she lost one of the twins, but was still pregnant with one healthy baby. She felt guilty that she was happy not to be pregnant with twins. She wrote "'thank you' to the baby who went

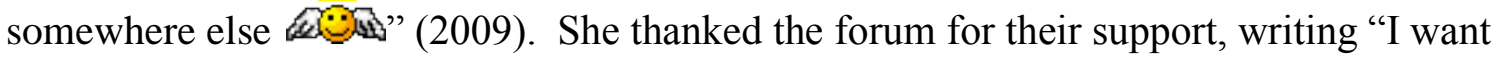
you all to KNOW how much I love and appreciate you. This board really saved me in my darkest hour," (2009). 
Joanna posted to different boards throughout her second pregnancy. She wrote in her DDC as well as in the tribe for pregnant vegans. Throughout September, Joanna congratulated her DDC members on the birth of their babies, using smilies of happy, jumping faces. She joined a support thread for women who are overdue when she went past her delivery date. When Joanna finally had her baby, she shared her birth story on her blog, but never posted it in the Birth Stories forum.

Joanna's last post in 2009 was in the Exclusive Pumpers Tribe. She shared her BTDT story of exclusively pumping breast milk for her twins. She encouraged the women and told them not to feel guilty for being unable to breastfeed their babies. She wrote "I am simply saying this to you all because I am someone who has BEEN there and done it. ..”(2009). Joanna acted as an old-timer, sharing her experiences and reassuring the newcomers that they can get through pumping for their babies. She used the language of breastfeeding throughout her post. In January 2010, Joanna had resumed posting in the Vegetarian and Vegan living forum, the one place she had consistently posted in such she became a member.

Joanna is a woman who was already involved in aspects of NFL before becoming a member of MDC. While Joanna learned a lot about NFL through MDC, she was already open and even practicing parts of the philosophy. Her pattern of posting activity has been sporadic. Joanna remained on the periphery of MDC for years, lurking and only posting a few times. Joanna felt being a mother was a requisite for posting regularly on the boards. However, even after she had babies, she continued to consistently share recipes and talk about food with other members, topics unrelated to having children. Her 
posting activity takes a dip after having babies, although it is possible that she is still reading messages during those times.

Joanna has benefited from MDC through receiving answers to her many questions about NFL childcare. However, the main benefit of MDC for Joanna appears to be the support she has received from other members. As an anxious new mom, she constantly sought reassurance from other members. Even when asking a straightforward question, Joanna seemed more grateful for members' support than for supplied answers. For example, she asked how to she could keep up her breast-milk supply when pregnant. Members gave her advice and words of encouragement. Joanna ends the thread by writing "Again I appreciate you all being here when I freak out! "Bi";" (2009). After the birth of her second child, Joanna continues to post messages asking members for their empathy, to motivate her, to give her support. MDC served as a life line for Joanna during her challenging life moments, and a source of constant reassurance about her parenting.

Advantages and Disadvantages of MotheringDotCommunity

As previously mentioned, there are differing opinions as to whether a community of practice can truly exist online. Some feel a major drawback to a community being online is that people are limited as to how much they can actually view a practice take place (Palloff \& Pratt, 1999). Even though women can access a large amount of information and resources on MDC, they do not actually witness the practice of mothering take place in person. However, both MDC and Mothering.com have features that help to ameliorate the limited availability of being able to observe mothering practices first-hand. On the main Mothering website, people can watch webinars, 
streaming videos, about various topics, such as the family bed. In addition, mothers at MDC share links to videos that shows them doing things like giving birth and nursing in public. Finally, if a woman needs assistance or simply to connect with other mothers in real life, members will point her in the direction of experienced professionals, or offer to meet with her themselves. While being online can be limiting when trying to learn a practice such as mothering, MDC does provide features that help with this challenge.

Not being able to witness first-hand the lives of others raises other challenges for MDC members. Veronica believes it is easy to feel inadequate when reading about other mothers and their lives. She said that it is easy to believe others have the perfect life, while your own life might have much room for improvement. Veronica shared:

But we all, reading these forums, have to remember that we're only reading what people are putting out there. ... the person who is posting how great things are might just keep it to herself when she's having a rough day. She might not put warts and all out there. . s some people find it really important to put out there this perfect image and I think a lot of moms do this. . . meanwhile, you don't know what they're saying and what they're doing, maybe everything is not so perfect. . . (personal communication, July 1, 2009).

At the same time, it is not just online that people distort their truth in order to present an ideal image about their lives. A mother describing her perfect life with a new friend at a coffee shop may actually have a messy home, financial troubles, and a not so happy marriage. Hiding the reality of a situation online might be easier to do than in real life.

It has been suggested that being online creates a tendency for people to feel more open with others (Wellman \& Gulia, 1999). Indeed, many women cited being anonymous as a big benefit to being part of MDC. Women felt they can be vocal about topics that they might not be comfortable discussing with their friends in real life (Claire, personal communication, July 28, 2009). This was the case for Amy, who practiced 
extended breastfeeding. She shared "I nursed my first for over 5 years, and there is no way I could have psychologically dealt with being such a weirdo compared to the norm around me, were it not for MDC," (Amy, personal communication, June 18, 2009). MDC members can ask questions online that they be too embarrassed to ask others in real life (Monarchgrrl, 2009). They share very personal information with other MDC members. Members describe in great detail their bodily functions, sexual activity, and relationship challenges with their significant others. Some mothers will even announce their pregnancies to MDC before they tell their friends in real life.

The internet, however, is not always as anonymous as women may assume. For example, Blueridgewoman started a thread to vent about her needy, clingy daughter. Her vent was 13 paragraphs long, and while she wrote that she really loves her daughter, she spends most of her time wanting "to run away," (Blueridgewoman, 2009).

Readytobedone responded by telling her that based on her username and her mention of a certain museum, she believed they live in the same town. She wrote "do i [sic] know you from LLL [La Leche League]? hmmm....” (Readytobedone, 2009). She did not criticize, and in fact, offered to babysit the fussy child so Blueridgewoman could have some time to herself. Still, Bluedridgewoman felt very embarrassed. A few posts later, an additional mother wrote that she believed she knew Blueridgewoman as well, and she also extended an offer of help. Blueridgewoman responded "Oh wow, I'm going to go crawl under a rock," (2009). The members assured her again that she did not need to be embarrassed. Blueridgewoman assumed no one knew who she was, but two different people easily figured out her identity through the content of her message. 
At times, there are more serious consequences for mothers whose online identity is figured out by others. In MDC's user agreement, members are warned "please be cautious in posting information of a personal nature or anything that might create legal concerns for you or other," (http://www.mothering.com/motheringdotcommunity-useragreement). An MDC old-timer explained that members' posts have been used as evidence in custody battles and with child protective services (Blair, personal communication, June 26, 2009). To avoid getting into trouble, women will change their user names in order to protect their identities. At times, messages are removed altogether. Blair shared that the moderators will shut down messages where women have revealed too much or if they believe things could be harmful. She feels that although MDC is about being empowered and making your own choices, the moderation and altering of members' posts seems to go against this belief (Blair, personal communication, June 26, 2009).

Another downside to members being anonymous online is that it makes it difficult to know who is a credible source of information. Erica explained ". . . basically anyone can post any nonsense they want and you have no idea if they really know what they're talking about. ..” (personal communication, June 30, 2009). Mischievium, an MDC oldtimer, has seen misinformation be stated as the truth on the forums. She corrected a newcomer, Thefreckledmama, who believed mainstream parents are the only ones guilty of following the advice of strangers online rather than conduct their own research. Mischevium wrote:

.... they just offer what they would do in the situation and don't cite any sources, or they refer to another thread here about the same issue that doesn't cite any sources. Obviously, not every response to every post requires a bibliography, but 
there are some situations where opinions on very serious, real life issues are given without any backup about what the true risks and benefits are (2009).

The large size of MDC also makes it difficult to discern who is a trustworthy source as it takes time to get to know other members, and it would be impossible to know the credentials of every member. Blair believes that asking for advice on MDC would be like stopping a stranger on the street for their opinion (personal communication, June 26, 2009). This is not to say that she does not value MDC as a source of information. Blair found that MDC serves as a springboard into researching other topics more in depth at different websites (personal communication, June 26, 2009). She said:

I find it's a good way to get information, to maybe have something sparked so that you can then go find more information because you might have never thought of that as a possibility, but not necessarily to say "oh, well somebody on mothering.com said I should do this so I'm going to do it. . . (personal communication, June 26, 2009).

Although it may be difficult to decide who is a credible source in a large online community, it can be just as challenging to decide who to trust in real life as well. Mothers may put a lot of time researching which pediatrician they should use, or wondering which friend's advice to follow. People presenting incorrect information as fact is not a unique situation to being online, but one that happens in real life as well.

A benefit to being online at MDC is that there is an enormous amount of information that is shared and learned by members. Momtwice spoke about her satisfaction of being able to provide information as well as debate with others:

When I can offer accurate support and info to a nursing mom it is emotionally satisfying. When I can have a vigorous debate about the science that says cosleeping is safer than a crib, when our culture says it is dangerous, I feel emotionally and intellectually satisfied. As a mom by profession, the intellectual value of the 'net is very valuable to me when I feel my brain cells dying off. (2003). 
Although MDC members share an interest in NFL, there are varying views on issues. One mother shared "I find it intersting [sic] to read the thoughts of a wide variety of mothers. .." (Mamaoui, 2003). The information flow is rapid on MDC, so there is constantly new information to read (Monarchgrrl, 2009).

The amount of information on MDC, however, may feel overwhelming to mothers. There is in-depth information on every topic about childcare. A mother posting a question online may receive many responses with different suggestions. Take the case of ScootchsMom, the mother of a six month old baby. She told MDC members that he does not sleep for long, screams frequently, refuses to nap, has reflux, and does not like to be held or make eye contact. The responses from mothers included: 1) he may need more sleep; 2) try soy formula; 3) do not feed soy formula; 4) he sounds like he is high needs; 5) take Hyland's colic tablets before bed; 6) he might have a lactose sensitivity or allergy; 7) try having him nap in a swing or your bed; 8) babywear your son and give him a pacifier; 9) take him to a chiropractor; 10) use Boiron's homeopathic colic treatment; 11) take him outside because fresh air can do wonders; 12) consider massages or baths; 13) trust your instinct because it is always right (told this several times); 14) hang in there because it will get better; 15) block feed and cut out diary; 16) do an elimination diet; 17) get reflux medications (told this several times); 18) read Dr. Sears' fussy baby book; 19) give him an infant probiotic; 20) get your health care provider to take you seriously because a friend's doctor did not take her seriously and her baby was having seizures; 21) try to find a naturalpathic doctor because pediatricians can be very wrong; 22) pediatricians can be very caring and attentive, so give them a chance; 23) daughter had these symptoms and she has sensory processing disorder, anxiety, and Raynaud's, 
but that does not mean that is what her son has; 25) take care of yourself and recharge (told this several times); 26) video tape the behavior to show the doctor (recommended more than once); 27) self refer for early intervention; 28) find a calming tool, like singing, snapping, or humming; 29) look to attachmentparenting.org for resources on creating a calm family environment; 30) smile and laugh because it is good for the constitution, and set a timer if you need to remember to do so; 31 ) see a cranial sacral therapist.

Due to members' pieces of advice, Scootchsmom had a multitude of options to explore to help improve her situation. With so much information, however, how did she know where to begin? Whose advice should she listen to? It is possible that Scootchsmom may have felt more overwhelmed and disheartened after reading all the possibilities and solutions to explore given by MDC members.

At the same time that advice and opinions can greatly vary on MDC, a complaint from mothers is that too many of the members actually think alike. On one hand, this is comforting for mothers looking to converse with other like-minded mothers, as MayBaby pointed out in a post:

You know, I was just thinking, I am SOOO happy that I found this site because the values, philosophies, ideas (whatever you want to call them) you ladies have are very similar to my own. (2009).

While interacting with others who have similar ideals can be gratifying, it may not challenge a person to really examine their own thinking, or to question if information being provided is actually correct. When discussing printing information against vaccinations, O’Mara writes that because she owns and edits Mothering, she does not have to answer to anyone; in fact, O'Mara writes that she seldom has to negotiate her 
point of view amongst her staff $(2010$, p. 16). The main leader of NFL is surrounded by a staff that rarely challenges her thoughts. Claire elaborates on MDC members thinking alike, writing:

There is a false sense of reality on that website in that everyone who posts there shares the same world-view. That must mean that sometimes that world-view could be skewed a bit and no one would be able to say 'Hey, that's a little skewed!' I wonder sometimes how much misinformation, or just heavily prejudiced information, gets passed around on MDC as gospel. (personal communication, July 28, 2009).

In order to deal with what she also perceived to be biased views, another member, Caroline, shared that she uses MDC as just one out of many resources for information and potential solutions to problems (personal communication, June 30, 2009).

Convenience is a big draw for members to go online at MDC when seeking support and information. No matter what the time of day, a woman can log on to get information and support. Answers to posted questions are "nearly instantaneous," (Caroline, personal communication, June 30, 2009), which is good for mothers wanting quick answers to ease a worrying mind. For mothers with newborn babies that are constantly nursing or sleeping, getting out of the house can be challenging. If a mother has a computer and internet access, she can be on MDC to interact with others and easily gather information. Mamaoui wrote "it is easy for me to spend the time I do here because ds\#2 still nurses tons and likes to sleep on me,” (2003). Blair also agreed that being online is highly convenient for the new mother. She talked about the need the internet filled for her:

... I've always been somebody who has liked to wrestle with the issues. And you can't, with a screaming baby, you can't do that in the public sphere, so the internet provides a way to do that at any hour of the day. And you can be in your pajamas, you can have a kid who is refusing to sleep because he has a bad ear infection so he's watching something on TV or he's engaged in whatever he is 
engaged in, even though it's 3:00 in the morning and you can find the support you need. Or the escape, the mental exercise that you need at that moment. (personal communication, June 26, 2009).

A lack of distractions is another factor that adds to the convenience level of being online. When Virginia uses MDC for finding solutions, she enjoys not having to "referee" children's arguments like she would in real life (personal communication, July 30, 2009). In addition, Virginia appreciates how online conversations can be more focused in nature and devoid of the small talk that occurs in real life. She finds that online conversations "... can be more focused and in depth online rather than following the natural flow of verbal conversation which generally gets on tangents pretty easily. Online isn't small talk, while in person frequently is," (Virginia, personal communication, July 30, 2009). In fact, Sometimes Virginia skips chatting with other mothers online altogether. Instead, she uses MDC's search function to find answers. She thinks of MDC as being essentially an online database of other mothers' experiences. By being able to access the database at any time with fewer distractions than those of real life, she finds that she is able to "learn more faster [sic]" (Virginia, personal communication, July 30, 2009).

For many mothers, MDC fulfills their need for socializing with others. By logging on, reading new posts, and sharing information, women feel they are connected to others. Mamaoui explained that "sometimes it's fun just to make small talk and joke," (2003). Lucky Charm also likes to hang out online. She shared:

Often times i make a pot of coffee, pour myself a cup, and log on and hang out. Not only do i find MDC a learning experience (including what i dont [sic] want to be like!) i [sic] also find it an emotional experience.....interacting and engaging in online conversations with women who, if they lived close by, i would hopefull [sic] be friends with in 'real life.' (2003). 
For Amy, MDC provided a sense of escape from her small town. She revealed that because of MDC, "my life feels a lot larger than it should," (personal communication, June 18, 2009). Women can talk to other mothers from all over the world. For some mothers, the connections made through MDC lead to real life friendships. Amy wrote ". . . many people who make up my social network, I met online. My doula and both the friends who attended my baby's birth I met online," (personal communication, June 18, 2009). Not only does MDC serve as a source of information, but it is a place to form friendships and socialize as well.

At the same time that MDC serves as a place for socializing, other members feel left out. Some members struggle in finding a place at MDC. In the message titled "What 'must' you do to fit in at MDC?" members talked about feeling left out or misplaced at MDC, either due to the community's large size or not feeling popular enough. Other members shared tips for how to feel included at MDC.

The amount of time members can easily pass in the forums is a drawback to MDC for several mothers. Shelly referred to MDC as a time waster (Shelly, personal communication, July 8, 2009). Ironically, while mothers search online for solutions to their parenting issues, they can end up ignoring their children in the process. To demonstrate, after replying to several threads in a message, Karamom asked other mothers to make her get offline, writing "someone tell me to get off MDC and go actually spend time with my kids. I need a kick in the butt," (2009). In addition, Amy admitted "Sometimes I'm learning all this great stuff about mothering while I am ignoring my children!” (personal communication, June 18, 2009). Although MDC 
members sometimes feel guilty for the amount of time they spend online, they also find it hard to resist the temptation of logging on.

Some mothers feel spending time online at MDC negatively impacts their personal growth. For Weetzie, a Buddhist mother, being online detracts from her ability to live in the moment. She said " $i$ [sic[ try to live with the buddhist [sic] thought of what is happening in *this* moment, but end up spending way to [sic] much time worrying about how other people will take my comment, and what they will think etc.” (2003). For other mothers, logging onto MDC keeps them from trying to make friends in real life or tackling areas of personal growth. Momtwice shared:

But other times if I rely on the net for emotional support too much or get addicted to how much fun it is, it is not so satisfying....if I am online to AVOID personal growth work, my feelings, getting out and trying to make friends IRL, the dishes. . . (2003).

While many mothers log on to connect with other mothers, spending time online can actually result in feelings of isolation. Claire believes that humans are wired to need face to face interaction. Claire said ". . .having to turn to your computer to talk to your friends can feel very weird to a species that is primed for face to face contact," (personal communication, July 28, 2009). On the other hand, some members make true connections with others, and it is distressing when a member suddenly stops posting. Erica has experienced this before:

. . people can just disappear into thin air. I can think of some members whose posts I REALLY enjoyed reading - they were insightful, witty, interesting in some way, etc. And then one day, they just vanished, never to return. I always feel a little sadness when that happens. (personal communication, June 30, 20009). 
Members will post questions to try to draw out missing members, asking "Are you there?" If a member who has not posted in some time comes back online, other members will write messages like "there you are! I was wondering where you went to!"

Finally, a large drawback to being online is that members sometimes give mean, snarky comments. Despite the user agreement that requires members to be respectful of each other, discussions still get heated on MDC. Claire believes that being anonymous is what causes mothers to be snarky towards one another. She said "you also can get all sorts of strange advice of hurtful comments from others enjoying the anonymous freedom to post as they really feel!” (Claire, personal communication, July 28, 2009). Other mothers feel that the conflicts arise due to the absence of face to face contact and the fragmented nature of online communication. Blair explained:

. . you can't tell what somebody's intent is the same way you can face to face. And because somebody may say something and then leave because the phone rang or they had to take their kid to school, or whatever, so it's very fragmented. Whereas if you're having a conversation, if you said something that offended me, we would work out until it was done, but you can't do that in the same way," (personal communication, June 26, 2009).

Indeed, the intent of a member's tone is sometimes misconstrued. Time is often spent with members clarifying their messages. Some members try to make their tone very clear from the beginning. In a tense conversation, one mother wrote "let me preface this with saying that if we were sitting across from each other and you could see my face and hear my voice you would see nothing but concern and an eagerness to help you. . .,"

(SashaBreeze, 2009). While most mothers try to avoid tense conversations, others are fine with the blunt nature of conversations that occur online. As Momtwice said "sometimes the anonymity of the net, and the bluntness of other posters, are good for my personal growth," (2003). 


\section{CHAPTER 5}

\section{CONCLUSION}

This study has examined and increased our understanding of three topics that have been identified as areas needing further research: women's own accounts of their experiences as mothers (Arendell, 2000), mothers who practice NFL (Bobel, 2002), and online communities (Livingstone, 2000; Wenger, McDermott, \& Snyder, 2000). In this chapter, I address the study's guiding research questions while presenting the major themes that emerged from the findings. I have suggested that MDC is a community of practice that significantly contributes to women's learning of NFL and toward their identification as NFL mothers. I end this section by suggesting areas for future research and concluding remarks about MDC.

Themes from Findings

\section{Empowerment}

A main activity at MDC is for members to share information with one another. At times, information shared is formal in nature, based on research from books and articles. When presenting information, members cite statistics to support their claims. Members also spend time discussing why mainstream studies are incorrect (e.g., Brant31, 2009; Fellow Traveler, 2009). MDC members request research studies and facts regarding NFL topics in their message titles. Requested information is sometimes for the 
original poster's own personal learning, and at other times it is needed in order to convince a family member or friend about a topic.

Informal information is also passed along in the forums at MDC. This type of information stems from MDC members' personal beliefs and their BTDT experiences. MDC members will specify in their message titles that they are looking for BTDT information, and others will respond by sharing what has or has not worked for them with different situations. They might also pass along advice they have received from others. The sharing of BDTD stories is empowering for members as they are deciding what constitutes knowledge for their community (Madge \& O'Connor, 2006).

The finding that women at MDC create and share knowledge within the community is significant. As research has demonstrated, the process of sharing and creating knowledge in women's websites is empowering for women (Drentea \& MorenCross, 2005; Eble \& Breault, 2002; Madge \& O’Connor, 2006). By obtaining advice from MDC members, women no longer have to rely solely on childcare experts, such as pediatricians, for guidance. MDC therefore decreases the role of scientific motherhood (Apple, 2006) and shifts the power towards mothers (Drentea \& Moren-Cross, 2005). Another activity of MDC members is providing support to others. Members empathize with one another and share their similar stories (e.g., Joanna, 2009). Members reassure each other that they will be okay, and write that they understand what the other person is going through. A member may respond with no words, but instead use hugging smilies in her message to show support. For example, when a member loses a baby through a miscarriage or stillbirth, members will post pictures of hugs, peaceful vibes, and lighted candles. In addition, members look to have their parenting choices validated 
(e.g., Ahappymel, 2009). Finally, members are supported by knowing they are not alone in their parenting practices and beliefs. Members will share their situations, such as raising a child with special needs, and ask if they are alone in their experiences. Mothers will assure one another that they are not alone, and that MDC is a place where they can receive support.

The finding that MDC is a place of support for women is an important one. While motherhood can be a rewarding experience, it can also be a challenging time. Women interviewed for this study spoke about feeling isolated and overwhelmed as mothers (e.g., Blair, June 26, 2009; Molly, personal communication, July 15, 2009). Titles of books in popular literature reveal that motherhood is perceived as being hazardous to women's intelligence, sex appeal, and happiness. Given that motherhood is charged with emotion and can be highly stressful, it is important to study how mothers can be supported (Madge \& O'Connor, 2006). This research shows that MDC serves as a community that both empowers and provides support to mothers who are learning NFL.

The support and information members receive at MDC can help women in challenging the norm. In terms of medicine, MDC is a community where women can learn about not vaccinating their children, using eastern medicine and homeopathic remedies, having drug free childbirths, and not circumcising their sons. Women can be supported in their decisions to have a water birth, a homebirth, and an unassisted birth. With education, MDC members can learn and be supported in homeschooling their children, or even practicing unschooling. They can learn about education alternatives like Waldorf schools. MDC members can also learn about why and how they should fight and resist the institutions of consumerism, work, and daycare (Bobel, 2002). MDC 
provides the building blocks of information about these types of alternatives along with the support from members to encourage women to do things the NFL way.

While it is evident that MDC is a place of learning, empowerment, and support, caution must be used to avoid hyperbole when discussing the community. To begin with, MDC does not serve as a community of practice for all; this point is further discussed later in this chapter. Additionally, there are arguments that women's websites such as MDC perpetuate unequal stereotypes through the promotion of traditional gender roles (Drentea \& Moren-Cross, 2005; Genusa, 2001, Madge \& O’Connor, 2004; Madge \& O'Connor, 2006). Bobel (2002) argues that NFL is oppressive to women through its promotion of having women stay at home with their children. Although there are MDC members who do work, the NFL expectation is that women should be close to their children at least for the first three years of their lives (O’Mara, 2000).

\section{Identity}

Conversations in MDC's forums reveal that indeed, there is a broad sense as to what it means to be a mother practicing NFL. Figuring out what it means not only to practice NFL, but to be a good NFL mother, is what drives most of the activity at MDC. Through their participation at MDC, women are working to learn, practice, and clarify their identities as NFL mothers.

One word is often asked about and discussed in MDC's forums: crunchy. Crunchy is seen as being a key part of the NFL identity, and multiple threads revolve around members asking what it means to be crunchy. Quizzes are posted to help women figure out how crunchy they are and familiarize them with NFL practices. After taking these quizzes, mothers share their scores with the community, allowing mothers to share 
their NFL identities and compare themselves to others. MDC members will argue about the content of the quizzes, pointing out questions that are missing or are not valid. During the process of analyzing the content of the granola factor quizzes, MDC members are defining the identity of the good NFL mother.

In multiple threads, women also share their crunchy versus mainstream practices, another way that MDC members create their NFL identities. There is a range in the intensity at which mothers practice NFL, and they share the MDC acronyms and abbreviations they use in their lives, such as no CIO (cry-it-out), GD (gentle discipline), $\mathrm{CD}$ (cloth diaper), no vax (vaccinations), no circ (circumcision) BF (breastfeed), CLW (child-led weaning). These threads are more than just a recitation of practices. Women explain the meaning behind their practices, and others will ask members to clarify their thoughts, implying that learning is taking place about NFL. MDC members can compare themselves to others and read what it means to be a NFL mother. These threads are additional acts of members defining their NFL identity.

Typing this one word, crunchy, into MDC's search engine reveals how popular the word is in influencing the NFL identity for MDC mothers. MDC members discuss items that are crunchy, including baby care products, personal hygiene products, clothes, house items, books, magazine, and websites. They also talk about crunchy versus noncrunchy events, like weddings, baby showers, and holidays. MDC members will ask which cities are crunchy, and how to tap into crunchy resources in specific areas. There is talk about crunchy issues involving others, like wanting to make more crunchy friends, run-ins with mainstream family members and friends, their spouse's crunch factor, and looking for crunchy doctors/therapists/dentists. Finally, MDC members discuss their 
feelings about crunchy issues, like wishing they were more or less crunchy, the challenges of being crunchy, the expense of being crunchy, and how it feels to be misunderstood or not appreciated as a crunchy mother. In the case of Daisymommy (2006), she wanted to make sure people could identify her as crunchy. Her identity had changed from mainstream to crunchy through MDC, and she wanted her house to reflect her identity as someone who practices NFL.

Through their messages at MDC, members collaborate on deciding what makes up the identity of a NFL mother. They discuss which practices are non-negotiable for the NFL mother. For example, MDC members agree that they should not let their babies cry-it-out (CIO) when trying to fall asleep. Still, members will debate about the length of time a baby can cry before it is considered to be crying it out. They debate whether a mother is letting her baby $\mathrm{CIO}$ if she allows her baby cry for five minutes to fuss and fall asleep.

Additionally, MDC members debate which practices belong to NFL and which practices belong to attachment parenting (AP). As previously mentioned in the findings chapter, the answer normally supplied is that AP is an integral part of NFL. However, a mother can choose to practice AP and not NFL. Some of the practices overlap, as both NFL and AP promote babywearing, cosleeping, and breastfeeding on demand. There are MDC members who practice AP more than they practice NFL.

MDC serves as a place for women to practice and try out their identities as NFL mothers (Madge \& O’Connor, 2005). When a mother writes to ask MDC members for advice, she is looking for more than just answers; she is trying to learn about how she should parent as a mother who practices NFL. Thus, members at MDC expand their 
identities as not only mothers, but as mothers who practice NFL. At the same time, MDC members limit themselves by narrowing the set of practices and beliefs to adhere to in their parenting. The activity of learning at MDC shapes women's' identities as NFL mothers.

In addition, women can read and practice the language of NFL at MDC. Reading messages influences members' perceptions about what makes a good NFL mother. For example, in the message where Ahappymel shares her response to the angry letter her son wrote, MDC members applaud her, point out how her actions aligned with NFL, and share that they are going to try her technique in the future (2009).

\section{The Role of MDC in Members' Lives}

At the time of her study, Bobel found that although natural mothers operated independently, some of them longed for a NFL community (2002, p. 167). The women of her study wondered where their NFL companions were, and some felt alone in their parenting endeavors (Bobel, 2002). My study has demonstrated that MDC acts as the type of community for NFL mothers that Bobel asserts is necessary. I have showed how MDC serves as a significant site as a community of practice for NFL mothers, providing members with information and support. This research has highlighted the strong impact MDC has had on many women's lives by helping them learn the culture of NFL and shaping their parenting practices and philosophies.

However, as previously mentioned, caution must be used to avoid hyperbole when discussing MDC as an online community of practice. To begin with, MDC does not serve as the only resource of information for mothers (e.g., Blair, personal communication, June 26, 2009; Caroline, personal communication, July 6, 2009). 
Members still rely on books, articles, and the advice from their family and friends to guide their parenting practices. Furthermore, MDC is not without its flaws. Members discuss their difficulty feeling included in the community (e.g., the thread titled "What 'must' you do to fit at MDC?'), and their dissatisfaction with their online interactions (e.g., the thread titled "Do you find your online experiences to be fulfilling?). Snarky replies, misinformation, holier than thou attitudes, and poor moderation are also deterrents to participation at MDC.

Different members value different aspects of MDC. For some members, the community support from MDC is the most significant aspect of the community. Joanna, for example, consistently seeks support from the forums, sharing her concerns and struggles with being a NFL mother. For others, MDC is most valuable as a source for information. As Virginia shared, MDC for her is only one of many resources for information about NFL (personal communication, July 30, 2009). For other members, such as Amy (personal communication, June 18, 2009), MDC allows them to feel like they are part of a social movement, and they enjoy connecting with a diverse group of people. Without a doubt, MDC is a diverse community. One can lurk in the Quiverful Tribe, a community of women who believe in conceiving many children for the glory of God, and then skip over to the Polyamorous/Non-monogamous tribe, where women speak about being married while also having a lover. In addition, MDC serves as a social outlet for some members. Blair, for example, speaks about her need to connect with other mothers, and she enjoys discussing current events at MDC (personal communication, June 26, 2009). Finally, there are members for which MDC serves as a strong community of practice, such as Maisy. Maisy asks questions, socializes with 
others, shows her passion for NFL issues such as natural childbirth, and provides and receives support to others. As Madge and O’Connor explain, MDC plays “... different roles for different women," (2004, p. 29).

Directions for Future Study

NFL Demographics

In her book published in 2002, Bobel asserts that NFL is for women who enjoy "a secure economic status, solidified by their racial, educational, and class status. ..” (p. 151). Bobel's study on NFL mothers, who she claimed were representative of the movement as a whole, were white, heterosexual, married, college educated, and well traveled (p. 150). However, MDC's forums reveal that Bobel's classification of NFL mothers may no longer be correct. MDC forums are created for single mothers, students, and professionals. There are forums and tribes for women from all racial and ethnic backgrounds, as well as sexual orientation. Was Bobel correct in her original assessment of the NFL population, and is MDC representative of the NFL population today?

Provided that the answers to these two questions are yes, research should examine what has caused such a radical demographic change of the community in such a short amount of time. Why and how has NFL spread to attract such a diverse group of people?

\section{Gradations in NFL Practices}

MDC has strict guidelines that only topics supporting NFL are to be discussed in the forums. However, as demonstrated in the forums, there are gradations in the levels of NFL intensities with MDC members. How do women negotiate when and when not to follow MDC's advice? Women interviewed expressed their ease in taking what works for them from NFL and leaving other pieces of the lifestyle behind. Anna, for example, said that she takes the many pieces of parenting advice, allows them to sit in her mind, 
and blends them together to create what works for her (personal communication, July 1 , 2009). The conversations at MDC, however, paint a different picture about women's comfort with picking and choosing NFL practices. In the forums, women express their guilt over not meeting the NFL expectations, and they labor over making parenting decisions. Further research can investigate how women negotiate finding what works and what does not work for them with NFL, and the role MDC plays in the process. More broadly, what are the effects of any mother not following the parenting advice of her community?

\section{Subgroups at $M D C$}

There are subgroups of women at MDC deserving of further investigation. For example, why are there so many women at MDC who do not plan on having children, or are currently childless? While there are certainly plenty of non-child related topics to explore at MDC, what drew them to a natural family living community titled MotheringdotCommunity in the first place? As motherhood is described as being a spiritual experience that is the most worthy of endeavors, how do the childless members feel as community members at MDC?

In addition, what about the Lonely Mamas Tribe? What makes this tribe one of the most popular groups at MDC? Are the women lonely because motherhood can be isolating? Is this simply a personality trait, or does the time spent on the computer take away from the efforts making friends in real life? Furthermore, there are a large amount of registered users who never posted to MDC. Do they continue to lurk, or did they join once and decide not to make MDC their home? At the opposite end of the spectrum, there are members who were active posters who suddenly stopped. What caused their 
departure from MDC? Studying these types of groups at MDC could reveal more about the community, helping MDC to better know their audience. In addition, it could highlight patterns about communities of practice in general.

\section{Fathers, Partners, and Children}

NFL emphasizes the importance of mothers being children's primary caregivers and calls for intensive mothering. Future research should investigate how the intensive nature of NFL mothering affects marital relationships. Two women in the member profiles mentioned experiencing marital strain. Marital problems are certainly not unique to NFL families. It is worth investigating, however, how intensive mothering practices involved with NFL impact marital relations. Are there examples of where NFL has drawn couples closer together? Examples of NFL practices and their impact on relationships could include topics such as mothers constantly being close to a child, breastfeeding on demand and for an extended length of time, answering a child's cries at any time, and sleeping in a family bed.

In addition, fathers at MDC deserve to be studied. How did they discover NFL? What has been their role in raising their children? For the male members of MDC, what has their experiences been like at the online community of practice? Do they feel marginalized, or special due to the minority status? Are what level of intensity do the fathers operate with their NFL practices? What are their beliefs and practices?

Finally, the products of MDC mothers, their children, should be studied. How does the promotion of strong attachment between mother and child affect children? How do children raised in a NFL home perform in school and other settings? In the absence of their mothers, how do the children fare? What are their thoughts and experiences with 
growing up in a NFL home? Are they healthier and more secure than other children? Will they plan on continuing their NFL practices once out on their own?

\section{Concluding Remarks}

What started out as a very broad area of interest, mothers, eventually narrowed to a very specific research group: NFL mothers at MDC. I have spent countless hours growing bleary eyed in front of my laptop reading through the forums, learning the culture of MDC and becoming engrossed in what I was learning about the community and NFL. I will end this study by sharing my personal thoughts and reflections about the online community of practice that I devoted so much of my time to during the dissertation process.

For my research, I took on the position of a participant-observer (with more focus on observing). I lurked in forums on a daily basis, and contributed my own thoughts and advice from time to time. I only posted advice in forums where I felt knowledgeable, such as the forums for pet owners and education related topics. I experienced my own taste of frustration when my posts were misconstrued. For example, in a post inquiring about how much homework a first grader should have, I commented about how I have discussed in a seminar the role that schools have in students' lives outside of the school setting. A woman became upset with my post and asked why I thought schools had the right to be involved in students' family life at all, and ended her message writing "the road to hell is paved with good intentions," (EFMom, 2009). I felt annoyed with the member for using what I interpreted as being a condescending tone. While I was polite in my reply (although I mentally composed more than one snarky reply), I was intent on clarifying my statement, not only to that one member, but for the benefit of the entire 
community. In other forums, I derived satisfaction in seeing a message I started receive many replies and provoke thoughtful responses from members. In addition, I was surprised at the disappointment I felt when I posted a pet related question and received no responses. It felt like a personal rejection.

Therefore, my participation at MDC helped me to better understand and empathize with other members' feelings. I had experienced what it was like to feel left out of the group, and I could understand how a message could burst into a flame war. I experienced the excitement in seeing a notification email that someone had replied to my message, and the eagerness for hoping more people would jump in to participate. Experiencing that level of satisfaction helped me to understand how members can rack up such high post totals.

In the beginning, I admittedly enjoyed sharing things I read at MDC that I knew would shock family and friends. "Mothers discuss how to consume their placentas, like frying them in a pan, or blending them into smoothies." That statement always got a terrific reaction from friends. Other topics with shock value included exposing children to illnesses in lieu of having them vaccinated, having homebirths without the assistance of any professional help, and mothers breastfeeding their children at the age of five years and beyond. In addition, messages where MDC members expressed their annoyance with the mainstream provoked anger from others.

Over time, I lessened the amount of findings that I shared with companions, and when I did share information, it was no longer done so for shock value. First, I came to respect many of the members at MDC, and I felt guilty if people made fun of the community. In addition, some of the ideas that had once seemed radical and strange to 
me, like having a home water birth, became so common for me to read about that I no longer had a reaction myself. In fact, some of the ideas began to seem rational, such as having a homebirth.

Finally, I realized that what I was doing, presenting information about a cultural group as peculiar, was "othering" MDC members. Othering involves looking at markers of differences and using them to shape the meaning of "them" and "us." I was looking at how MDC mothers were different from the ones I knew. I realized that rather than focus on the differences, I needed to examine what those things stood for.

For example, I found that MDC members believe in eating their placentas for a variety of reasons, such as its supposed ability to help contract the uterus, prevent postpartum depression, and bring in a mother's breast milk. Eating placentas fits into NFL's ideals in many ways. First, people argue for eating the placenta based on the biological fact that many animals do so as well, and NFL favors natural practices. Also, eating the placenta is not a mainstream practice, and women may have to fight to be given their placentas (some hospitals categorize the placenta as medical waste). Therefore, demanding the right to eat a placenta challenges the authority of the medical institution and looks outside of the mainstream for mothering practices. Getting over my surprise at certain practices discussed in MDC's forums allowed me to have a deeper understanding about the culture of NFL.

Through my time in the forums, I found myself drawn to the stories of different members at MDC. One member that stands out is Poetgirl. She was a long standing member in the Trying to Conceive forum. I was amazed at her in-depth knowledge involving trying to get pregnant, and impressed with her compassion for others. I once 
took a thread from the Trying to Conceive forum that totaled over 300 posts. It read like a novel. Poetgirl was anxiously preparing for an in vitro fertilization treatment. After she had her procedure, she reported back how she felt and I held my breath. I really wanted Poetgirl to be pregnant, but she was not. The disappointment was deep, and I was touched by the empathy that came from other mothers to comfort her. Months passed, and I continued to check in on Poetgirl from time to time. Finally, she was pregnant. I had been rooting for her, and although she was a virtual stranger, I was so happy to hear of her news. She began posting in her DDC, but continues to check in regularly with the Trying To Conceive and Infertility forums.

The large amount of time I spent at MDC created opportunities for moments of self reflection. Not yet a mother, I have wondered about which of the NFL practices might work for me. At a practical level, I can imagine trying out baby slings and cloth diapers. Some of the ideas from the gentle discipline approach appeal to me as well. More of what I have thought about, however, is how I will approach the learning of becoming a mother, and what role I want communities to play in that process. A researcher at heart, I can imagine participating at forums like MDC to soak up information, and clearing the library's shelves of every child-related book they have. I am comforted by knowledge, especially when preparing for the unknown. I read at least five different books, watched a DVD, and participated in online forums just to prepare for getting a puppy, so I can easily imagine the intensity at which I would approach learning to mother.

I worry, however, about what the intentional and intense process of learning to mother could cause, such as confusion with conflicting advice, and expectations for 
myself as a mother and my baby. Might I worry about things I would not have thought about if I did not conduct extensive research? Furthermore, the process of intentionally learning to mother seems to potentially lessen the joy of motherhood. Is there not value in delighting in surprises along the way? Are there not humbling lessons to be learned from making mistakes as well? Learning to mother should involve a balance between education and simply experiencing life, and finding that balance seems challenging. Finally, although I would participate in an online community of practice such as MDC, I still want to foster connections with people in my in real life community. This is not a judgment call from me on whether online or in real life communities of practice are more valuable. Rather my desire to connect with people in real life comes from who I am as a person, and my needs to leave my house and interact with others.

MDC can serve as a strong community of practice for NFL mothers, and it is a valuable resource for information and support. For some women, their participation at MDC has transformed their lives. For others, MDC has changed a few of their practices or their thoughts about certain issues. And for others yet, MDC is simply a place to lurk for entertainment, or to pick up a piece of information every now and then. MDC can be accessed at any time to meet the specific needs of different members.

Part of MDC's statement of purpose is to celebrate "... the experience of parenthood as worthy of one's best efforts," and they strive to foster ". . . awareness of the immense importance and value of family life in the development of the full human potential of parents and children," (http://www.mothering.com/mdc/ webpurpose.html/). Through discussions and sharing of information, MDC is a community that can help women to reach this goal. MDC embodies all that is a 
community of practice: a practice, connecting and supporting of others, participation at the periphery and at the core, and of course, learning. Learning the culture of NFL. 


\section{REFERENCES}

Abimommy (2009, August 5). PLEASE READ: Adoptive/Foster Parenting Forum Guidelines including Respectful Adoption/Foster Parenting Language \& Terminology \& Non-Solicitation [Msg. 1]. Message posted to http://www.mothering.com/discussions/showthread.php?t=1120418

About us. (n.d.). Retrieved August 3, 2009, from http://www.mothering.com/about-us

Ahappymel (2009, April 4). My 7 yr old's profane letter [Msg. 1]. Message posted to http://www.mothering.com/discussions/showthread.php?t=1064944\&highlight=

Ahdoula (2007, June 30). Today the day?? [Msg. 12]. Message posted to http:// http://www.mothering.com/discussions/showthread.php?t=703277\&highlight=

Akind1 (2009, August 31). How annoyed do you get with mainstream baby thinkers? [Msg. 8]. Message posted to http://www.mothering.com/discussions/ showthread.php?t=1130871

Altalib, H. (2002). Situated cognition: Describing the theory. ERIC Reproduction Services ED 475183.

Amber Lion (2009, January 1). I know that TECHNICALLY a 9 wk old is a minor...[Msg. 1]. Message posted to http://www.mothering.com/discussions/ showthread.php?t=1019478

Amberskyfire (2010, February 2). Small, uncontrolled study - Eating the placenta [Msg. 1]. Message posted to http://www.mothering.com/discussions/ showthread.php?t=1190775

Ammaarah (2009, September 5). Natural lubrication methods safe for swimmers?

[Msg. 13]. Message posted to http://www.mothering.com/ discussions/ showthread.php?t=1133027

Anewmama (2007, July 19). The spiritual side of not-vaccinating [Msg. 1]. Message posted to http://www.mothering.com/discussions/showthread.php?t= 714797

Angelchristin (2009, June 13). Is this common? [Msg. 19]. Message posted to http://www.mothering.com/discussions/showthread.php?t=1098098 
Angelmariebee (2009, March 17). Wodering why [Msg. 17]. Message posted to http://www.mothering.com/discussions/printthread.php?t=1071756\&pp=200

AniT (2009, June 22) If you got this email after a "playdate," what would you do? [Msg. 116]. http://www.mothering.com/discussions/printthread.php?t=1101754

Annettemarie, (2006, September 26). Not terribly crunchy -what? [Msg. 14]. Message posted to http://www.mothering.com/discussions/showthread.php?=517018

Annettemarie (2009, April 12). Astonished! [Msg. 15]. Message posted to http://www.mothering.com/discussions/showthread.php?t=1069545

Ann-Marita (2009, December 19). From ABC News, sex is equally satisfying with or without all the parts [Msg. 1]. Message posted to http://www.mothering.com/ discussions/showthread.php?t=1174667

Apple, R. D. (2006). Perfect motherhood: Science and childrearing in America. New Brunswick, NJ: Rutgers University Press.

Arendell, T. (2000). Conceiving and investigating motherhood: The decade's scholarship. Journal of Marriage and Family, 62(4), 1192-1207.

Artgoddess (2009, June 22). If you got this email after a "playdate," what would you do? [Msg. 59]. Message posted to http://www.mothering.com/discussions/ printthread.php?t=1101754

Arwyn, 2006. Not terribly crunchy -what? [Msg 14].Message posted to http://www.mothering.com/discussions/showthread.php?t=517018

Ashleedio (2009, July 23). Did anyone else refuse consent? [Msg. 1]. Message posted to http://www.mothering.com/discussions/showthread.php?t=1115135

Ashworth, T., \& Nobile, A. (2008). Dirty little secrets from otherwise perfect moms. San Francisco, Chronicle Books LLC.

AutumnWind (2003, July 12). Housecleaning as spiritual? [Msg. 1]. Message posted to http://www.mothering.com/discussions/showthread.php?t=170073

Averysmomma (2009, November 4). 'Gatekeeping Mothers' [Msg. 57]. Message posted to http://www.mothering.com/discussions/showthread.php?t=1157377

AverysMomma (2009, May 12). It takes a village [Msg. 24]. Message posted to http://www.mothering.com/discussions/showthread.php?t=1083760

Bassin, D., Honey, M., \& Kaplan, M. M. (1994). Introduction. in D. Bassin, M. Honey, \& 
M. M. Kaplan (Eds.), Representations of motherhood (pp. 1-25). New Haven, CT: Yale University Press.

Batsoup (2006, September 21). How to be CRUNCHY but not OBSESSIVE, NEUROTIC, or JUDGEMENTAL? [Msg. 1]. Message posted to http://www.mothering.com/discussions/showthread.php?t=524873

BeckyBird (2009, September 2). How annoyed? [Msg. 34]. Message posted to http://www.mothering.com/discussions/showthread.php?t=1130871

Betsyj (2009, June 22). If you got this email after a "playdate", what would you do? [Msg. 141]. http://www.mothering.com/discussions/printthread.php?t=1101754

Blair, K., \& Takayoshi, P. (1999). Feminist cyberscapes: Mapping gendered academic spaces. Stamford: CT: Ablex Publishing Corporation.

Bluegoat (2009, May 12). It takes a village [Msg. 1]. Message posted to http://www.mothering.com/discussions/showthread.php?t=1083760

BlueIrises (2006, July 27). Not-terribly-crunchy-mamas? [Msg. 6]. Message posted to http://www.mothering.com/discussions/printthread.php?t=482376\&pp=200

Blueridgewoman (2009, June 14). What else does she WANT from me?! [Msg. 1]. Message posted to http://www.mothering.com/ discussions/showthread.php?t=1098337

Bmcneal (2009, January 3). How Crunchy Are You Quiz (UPDATED - \#49). [Msg. 2]. Message posted to http://www.mothering.com/discussions/ showthread.php?t=1020351

Bobel, C. (2002). The Paradox of natural mothering. Philadelphia: Temple University.

Borchard, T. J. (2006). The imperfect mom: Candid confessions of mothers living in the real world. New York: Broadway Books.

Boyd, M. H. (n.d.). The secret Language of Motherhood. Mothering.com, Web exclusive. Retrieved October 22, 2009, from http://www.mothering.com/parenting/secretlanguage-motherhood\#

Brant31 (2009, December 21). From ABC News, sex is equally satisfying with or without all the parts [Msg. 7]. Message posted to http://www.mothering.com/ discussions/showthread.php?t=1174667

Bredo, E. (1997). The social construction of learning. In G. D. Phye (Ed.), Handbook of academic learning: Construction of knowledge, (pp. 3-45). San Diego, CA:

Academic Press. 
Brosnan, K., \& Burgess, R. (2003). Web based continuing professional development a learning architecture approach. Journal of Workplace Learning, 15(1), 24-33.

Brown Lioness (2009, June 17). What bring you to MDC? [Msg. 20]. Message posted to http://www.mothering.com/discussions/printthread.php?t=1099331\&pp=200

Buckley, S. J. (2005). Mothering, mindfulness and a baby's bottom. Mothering.com. Retrieved August 3, 2009, from http://mothering.com/green-living/ mothering-mindfulness-and-babys-bottom

Calynde (2006, February 15). Non-AP mamas who want to think they're AP? [Msg. 1]. Message posted to http://www.mothering.com/discussions/ showthread.php?t=411384

CameronsMama (2009, September 8). Being part of a community, which one? [Msg. 7]. Message posted to http://www.mothering.com/discussions/ showthread.php?t=1133664\&highlight=

CarrieCo (2009, August 31). How annoyed do you get with mainstream baby thinkers? [Msg. 1]. Message posted to http://www.mothering.com/discussions/ printthread.php?t=1130871

Carter'sMummy (2009, October 27). 20 yr old, 4 induction methods, 37 hour labour, Emerg. c-section, ill be burning my birth plan! [Msg. 1]. Message posted to http:// www.mothering.com/discussions/showthread.php?t=1154655

Chipper26 (2009, May 13). It takes a village [Msg. 23]. Message posted to http://www.mothering.com/discussions/showthread.php?t=1083760

Chirp (2009, May 14). My LO is still waaaay dependent on me... [Msg. 1]. Message posted to http://www.mothering.com/discussions/ showthread.php?t=1084689\&highlight=

Chloe'sMama (2009, September 30). How do you get over the fear??? [Msg. 1]. Message posted to http://www.mothering.com/discussions/showthread.php?t=1143433

Chodorow, N. (1978). The reproduction of mothering: Psychoanalysis and the sociology of gender. Berkeley, CA: University of California Press.

Choli (2008, August 13). What ever happened to "it takes a village to raise a child?" [Msg. 21]. Message posted to http://www.mothering.com/discussions/ showthread.php?t=949230

Churndash (2009, June 14). Is this Common? [Msg. 44]. Message posted to http://www.mothering.com/discussions/showthread.php?t=1098098 
Coffee.caugh (2009, April 12). Astonished! Friends FF baby...[Msg. 20]. Message posted to http://www.mothering.com/discussions/showthread.php?t=1069545

Corvus (2005, June 21). It takes a village? [Msg. 19]. Message posted to http://www.mothering.com/discussions/showthread.php?t=303807

Cothrel, J., \& Williams, R. L. (1999). On-line communities: Helping them form and grow. Journal of Knowledge Management, 3(1), 54-60.

CougBride07 (2009, October 17). Book recommendations for fear of birth? [Msg. 1] Message posted to http://www.mothering.com/discussions/ showthread.php?t=1150367

Cuthbert, A., Clark, D., \& Linn, M. (2002). WISE learning communities: Design considerations. In K. Renninger \& W. Shumar (Eds.), Building virtual communities: Learning and change (pp. 215-246). Cambridge, UK: Cambridge University Press.

Cynthia Mosher (2001, November 23). What does ds and dd Mean? - Acronyms, abbreviations, and emoticons [Msg. 1]. Message posted to http://www.mothering.com/discussions/showthread.php?t=2080

Daisymommy (2006, August 15). Crunchy mamas: What does your home look like? [Msg. 1]. Message posted to http://www.mothering.com/discussions/ showthread.php?t=502494

DaisyRose (2005, February 23). Library Book Circles [Msg. 1]. Message posted to http://www.mothering.com/discussions/showthread.php?t=254315

Danielle, (2009). Unconditional Love. Retrieved December 2, 2009, from http://attachmentparenting.org/blog/2009/09/16/unconditional-love/

Davis, L. (2003, September-October). Breathing in, I am nursing my baby: Breastfeeding as a spiritual practice. Mothering, 120. Retrieved September 2, 2009, from http://www.mothering.com/breastfeeding/breathing-i-am-nursing-my-babybreastfeeding-spiritual-practice.

DebraBaker (2003, July 30). Wildflower picking as spiritual [Msg. 4]. Message posted to http://www.mothering.com/discussions/showthread.php?t=76638

Debrown (2006, July 20). What to do with afterbirth placenta? [Msg. 1]. Message posted to http://www.mothering.com/discussions/printthread.php?t=486509

Dentmom3 (2006, September 24). How to be CRUNCHY but not OBSESSIVE, NEUROTIC, or JUDGEMENTAL? [Msg. 30]. Message posted to http://www.mothering.com/discussions/showthread.php?t=524873 
De Souza, C. S, \& Preece, J. (2004). A framework for analyzing and understanding online communities. Interacting with computers, The Interdisciplinary Journal of Human-Computer Interaction, 16 (3), 579-610.

Dirty deeds done dirt cheap (n.d.). Retrieved January 5, 2009 from http:// www.mothering.com/mdc/ddddc

Doubledutch (2009, September 8). Being part of a community, which one? [Msg. 10]. Message posted to http://www.mothering.com/discussions/ showthread.php?t=1133664\&highlight=

Douglas, S., \& Michaels, M. (2005). The mommy myth: The idealization of motherhood and how it has undermined all women. New York: Free Press.

Doulanichole (2009, November 20). Does anyone else intentionally drive themselves nuts? [Msg. 12]. Message posted to http://www.mothering.com/discussions/ showthread.php?t=1164395

Dreamy (2008, December 17). Need sleep advice for 7 month old [Msg. 4]. Message posted to http://www.mothering.com/discussions/showthread.php?t=1013924

Drentea, P., \& Moren-Cross, J. L. (2005). Social capital and social support on the web: The case of an internet mother site. Sociology of Health and Illnesses, 27(7), 920-943.

Dunham, P., Hurshman, A., Litwin, E., Gusella, J., Ellsworth, C., \& Dodd, P. W. D. (1998). Computer-mediated social support: Single young mothers as a model System. American Journal of Community Psychology, 26(2), 281-305.

Earthmama369 (2009, June 17). What brings you to MDC? [Msg. 24]. Message posted to http://www.mothering.com/discussions/printthread.php?t=1099331\&pp=200

Eble, M., \& Breault, R. (2002). The primetime Agora: Knowledge, power, and "mainstream" resource venues for women online. Computers and Composition, (19)3, 315-329.

EFMom (2009, June 21). Summer homework assignments for K going to 1st grade??? [Msg. 25]. Message posted to http://www.mothering.com/discussions/ showthread.php?t=1091937

Eis, D. (2008, Winter). Offline, off kilter. Brain Child, 9 (1), 41-45.

Elanorh (2009, August 27). Keeping your lips sealed around mainstream mamas -SO HARD! [Msg. 17]. Message posted to http://www.mothering.com/ discussions/showthread.php?p=14279970 
Elishveva(2009, September 1). How annoyed do you get with mainstream baby thinkers? [Msg. 11]. Message posted to http://www.mothering.com/discussions/ printthread.php?t=1130871

EnviroBecca (2009, May 12). It takes a village [Msg. 25]. Message posted to http://www.mothering.com/discussions/showthread.php?t=1083760

EvansMomma (2006, July 12). Not-terribly-crunchy-mamas? [Msg. 23]. Message posted to http://www.mothering.com/discussions/ printthread.php?t= $482376 \& p p=200$

Fellow Traveler (2009, December 19). From ABC News, sex is equally satisfying with or without all the parts [Msg. 2]. Message posted to http://www.mothering.com/ discussions/showthread.php?t=1174667

Firstkid4me (2006, June 19). How crunchy are you? [Msg. 1]. Message posted to http://www.mothering.com/discussions/showthread.php?t=470885\&highlight=

Fontaine, M. (2001). Keeping communities of practice afloat. Knowledge Management Review, 4(4), 16-21.

Foucalut, M. (1981). Power/knowledge: Selected interview and other writing, 1972-1977. New York: Pantheon Books.

Frogautumn (2009, June 17). What brings you to MDC? [Msg. 14]. Message posted to http://www.mothering.com/discussions/showthread.php?t=1099331

Fullofgrace (2006, September 14). START HERE: Everything you need to know in one MDC FAQ [Msg 1]. Message posted to http://www.mothering.com/discussions/ showpost.php? $\mathrm{p}=6027427 \&$ postcount $=2$

Geertz, C. (1966). Religion as a Cultural System, in M. Banton (Ed.), Anthropological approaches to the study of religion pp. 1-46). New York: Praeger.

Geertz, C. (1973). The interpretation of cultures. New York: Basic Books.

Genusa, A. (2001, May 1). Women's websites insult my intelligence. CIO Magazine. Retrieved November 20, 2009, from http://www.cio.com/archive/050101/ reality.html

Georgia (2009, August 31). Surviving Abuse Forum Rules and Guidelines [Msg. 1] Message posted to http://www.mothering.com/discussions/showthread/php?t $=1130804$

Gertie (2009, August, 26). Keeping your lips zipped around mainstream mamas -SO 
HARD! [Msg. 35]. Message posted to http://www.mothering.com/discussions/ showthread.php?t=1127928

Goldingoddess (2009, June 9). Help me sort out my reaction to a mainstream mama [Msg 1].Message posted to http://www.mothering.com/discussions/ printthread.php?t=1096518

Grace24 (2009, April 4). Bath drama. [Msg. 1, 10]. Message posted to http://www.mothering.com/discussions/showthread.php?t=1069820\&highlight=

Greeba (2010, January 1). Nursing strike. Just looking for some BTDT support [Msg. 5]. Message posted to http://www.mothering.com/discussions/ showthread.php?t=1177360

Hajenkatt (2006, July 7). Not-terribly-crunchy-mamas? [ Msg. 18]. Message posted to http://www.mothering.com/discussions/printthread.php?t=482376\&pp=200

Hamman, R. (2006). Bye-bye boardroom: Confessions from a new breed of stay at home moms. Herndon, VA: Capital Books, Inc.

Handley, K., Sturdy, A., Finchman, R., \& Clark, T. (2006). Within and beyond communities of practice: Making sense of learning through participation, identity and practice. Journal of Management Studies, 43(3), 641-653.

Hawisher, G. E, \& Sullivan, P. A. (1999). Fleeting images: Women visually writing on the Web. In Gail E. Hawisher \& Cynthia L. Selfe (Eds.), Passion, pedagogies, and $21^{\text {st }}$-century technologies (pp. 268-291). Logan, UT, Utah State UP.

Hays, S. (1996). The cultural contradictions of motherhood. New Haven: Yale University Press.

Hazlenut (April 7, 2009). Oprah today on Motherhood. [Msg. 10]. Message posted to http://www.mothering.com/discussions/showthread.php?t=1067047

Heavenly (2009, November 20). Mothering and intuition. [Msg. 3]. Message posted to http://www.mothering.com/discussions/showthread.php?t=1167484

Hempmama (2009, June 13). Is this common? [Msg. 3]. Message posted to http://www.mothering.com/discussions/showthread.php?t=1098098

Hesperia (2009, September 21). Fear, how to block it out? [Msg. 1]. Message posted to http://www.mothering.com/discussions/showthread.php?t=1139859

Hewlett, S. A. (2007). Off-ramps and on-ramps: Keeping talented women on the road to success. Boston: Harvard Business School Publishing. 
Hey Mama! (2009, June 22). If you got this email after a "playdate", what would you do? [Msg. 113). Message posted to http://www.mothering.com/discussions/ printthread.php?t=1101754

Hirshman, L. (2006). Get to work: A manifesto for women of the world. New York: The Penguin Group.

Hoffman, D. M. (2008). How (Not) to Feel: Culture and the politics of emotion in the American parenting advice literature. Unpublished paper, University of Virginia, Charlottesville, VA.

Holland, D., Lachiotte, L., Skinner, D., \& Cain, C. (1998). Identity and agency in cultural worlds. Cambridge, MA: Harvard University Press.

Hopefulfaith (2006, June 22). When did you become 'crunchy' and why? [Msg. 13]. Message posted to http://www.mothering.com/discussions/ showthread.php?t=472893

Hoppus, S., Norwood, M., Denoon, A., (2007). Rock star momma: The hip guide to looking gorgeous through all nine months and beyond. New York: Rock Star Momma, LLC.

Hulbert, A. (2003). Raising America: Experts, parents, and a century of advice about children. New York: Random House, Inc.

Igraine (2006, July 12). Not-terribly-crunchy-mamas? [Msg. 5]. Message posted to http://www.mothering.com/discussions/printthread.php?t=482376\&pp=200

Iliex (2006, February 3). Parenting and rage [Msg. 30]. Message posted to http://www.mothering.com/discussions/showthread.php?t=394579

Ilovejeff (2009, May 5). Doulas, Hypnobabies and Homebirth...I need advice! [Msg. 1]. Message posted to http://www.mothering.com/discussions/printthread.php? $\mathrm{t}=1082239$

Imken, O. (1999). The convergence of virtual and actual in the global matrix: Artificial life, geo-economics, and pyschogeography. In Crang, M., Crang, P., \& May, J. (Eds.), Virtual geographies (pp. 92-106). London: Routledge.

Indeospero (2008, November 29). Resources for the spiritual side of pregnancy. [Msg. 1]. Message posted to http://www.mothering.com/discussions/ showthread.php?t=800824

Isamama (2009, June 20). What brings you to MDC? [Msg. 33]. Message posted to http://www.mothering.com/discussions/showthread.php?p=13966184 
Iverson, J. O., \& McPhee, R. D. (2002). Knowledge management in communities of practice: Being true to the communicative character of knowledge. Management Communication Quarterly, 16(2), 259-266.

Ivymae (2009, June 20). Lubrication and trying not to kill sperm on a budget. LOL. [Msg. 13]. Message posted to http://www.mothering.com/discussions/ printthread.php?t=1101252

JayJay (2009, February 16). Just a little thread to say.....[Msg. 1]. Message posted to http://www.mothering.com/discussions/showthread.php?t=1043030

Jenneology (2007, November 2). Anyone ever file a claim over a bad birth experience? [Msg. 4]. Message posted to http://www.mothering.com/discussions/ printthread.php?t=783012

JessC (2006, September 8). Not terribly crunchy -what? [Msg 1]. Message posted to http://www.mothering.com/discussions/showthread.php?t=517018

JessicaTX (2009, July 30). Wanna play doctor? [Msg. 1]. Message posted to www.mothering.com/discussions/showthread.php?t=1117953

Joanna (2002, May 9). HELP! My basil is all shriveled up. [Msg. 1]. Message posted to http://www.mothering.com/discussions/search.php?searchid=11277105

Joanna (2003, June 15). Some advice please.. I want to give up soda! [Msg. 1]. Message posted to http://www.mothering.com/discussions/showthread.php? $\mathrm{t}=66796$

Joanna (2006, December 21). Travel vaccinations. [Msg. 1]. Message posted to http://www.mothering.com/discussions/showthread.php?t=580921

Joanna (2007, May 19). Yes! [Msg. 1]. Message posted to http://www.mothering.com/discussions/showthread.php?t=677496

Joanna (2007, June 1). $* * * \sim$ Weekly Thread May $28^{\text {th }}-$ June $4^{\text {th }} \sim * * * . ~[M s g . ~ 52]$. Message posted tohttp://www.mothering.com/discussions/ showthread.php?p=8278785

Joanna (2007, June 10). Does burned (charred) food hurt baby? [Msg. 1]. Message posted to http://www.mothering.com/discussions/showthread.php?p=8351981

Joanna (2007, June 11). Fatigue! Message posted to [Msg. 19]. Message posted to http://www.mothering.com/discussions/showthread.php?p=8352922\&highlight=\# post8352922

Joanna (2007, June 12). Help. My belly seem sooo huge! [Msg. 1]. Message posted to 
http://www.mothering.com/discussions/showthread.php?p=8369566\&highlight=\# post 8369566

Joanna (2007, July 2). When do you stop having to PEE all the darn time? [Msg. 1]. Message posted to http://www.mothering.com/discussions/showthread.php? $\mathrm{p}=8531537$ \&highlight=\#post 8531537

Joanna (2007, July 2). Tearfulness anyone? [Msg. 19]. Message posted to http://www.mothering.com/discussions/showthread.php?p=8531849\&highlight=\# post8531849

Joanna (2007, July 2). * ** Weekly Thread: July 2-8! ****. [Msg. 3]. Message posted to http://www.mothering.com/discussions/showthread.php?p=8533831\&highlight=\# post 8533831

Joanna (2007, July 4). What are you reading right now? [Msg. 7]. Message posted to http://www.mothering.com/discussions/showthread.php?p=8534510\&highlight=\# post 8534510

Joanna (2007, August 11). I'm so confused (I'm pregnant with fraternal twins). [Msg. 1]. Message posted to http://www.mothering.com/discussions/ printthread.php?t=728806

Joanna (2007, August 27). How do I find out my options for homebirth (TWINS). [Msg. 1]. Message posted to http://www.mothering.com/discussions/showthread.php? $\mathrm{t}=739239$

Joanna (2007, December 31). My twins born at 34 weeks. [Msg. 1]. Message posted to http://www.mothering.com/discussions/showthread.php?t=819727

Joanna (2008, February 16). Joanna had her twins! [Msg. 1]. Message posted to http://www.mothering.com/discussions/showthread.php?p=10559186\&highlight= \#post 10559186

Joanna (2009, January 12). Introductions!! [Msg. 98]. Message posted to http://www.mothering.com/discussions/printthread.php?t=1014964\&pp=200

Joanna (2009, February 12). Scared. [Msg. 1]. Message posted to http://www.mothering.com/discussions/showthread.php?t=1041363\&highlight=

Joanna (2009, March 13). Joanna, How are you? [Msg. 3]. Message posted to http://www.mothering.com/discussions/showthread.php?t=1054775\&highlight=

Joanna (2009, October 21). Don't know who I can talk to about this. [Msg. 1]. Message posted to http://www.mothering.com/discussions/showthread.php? $\mathrm{t}=1152021$ \&highlight $=$ 
Joensally (2009, April 4). What classifies a child as gifted? [Msg. 4]. Message posted to http://mothering.com/discussion/printthread.php?t=1067420

Joy seeker (2009, April 13). I used to...but now I.... [Msg. 1]. Message posted to http://www.mothering.com/discussions/printthread.php?t=1070134

JSerene (2007, November 8). If humans were meant to nurse into toddlerhood...[Msg. 1]. Message posted to http://www.mothering.com/discussions/ printthread.php?t=786622

Just_lily (2009, September 12). Staying Intellectually Stimulated. [Msg. 1]. Message posted tohttp://www.mothering.com/discussions/ printthread.php?t=1135923

Justmama (2007, April 14). What does "banned" mean? [Msg. 5]. Message posted to http://www.mothering.com/discussions/showthread.php?t=654708

Kanga1622 (2009, June 18). What bring you to MDC? [Msg. 20]. Message posted to http://www.mothering.com/discussions/printthread.php?t=1099331\&pp=200

Karamom (2009. April 13). Wasting time on MDC. [Msg. 1]. Message posted to http://www.mothering.com/discussions/showthread.php?t=1123901

KariM (2007, March 8). Spiritual/conscious conception [Msg. 1]. Message posted to http://www.mothering.com/discussions/showthread.php?t=631192

Kathryn (2009, August 28). Please take a look at my chart, 19DPO and no period or gyn apt in sight [Msg. 1, 6, 8]. Message posted to http://www.mothering.com/discussions/showthread.php?t=1130053

Kathryn (2009, August 28). The August testers thread! (Obsess and test!) [Msg. 23]. Message posted to http://www.mothering.com/discussions/showthread.php? $\mathrm{p}=14302812$

Kathryn (2009, August 31). Chart stalker, do I still have hope? [Msg. 13]. Message posted to http://www.mothering.com/discussions/showthread.php?p=14311146

Kathryn (2009, September 3). Cervix-Low/Medium/High Soft/Firm Questions. [Msg. 1]. Message posted to http://www.mothering.com/discussions/printthread.php? $\mathrm{t}=1132545$

Kathryn (2009, September 5). Natural lubrication methods safe for swimmers? [Msg. 1, 4, 10, 18, 20, 22]. Message posted to http://www.mothering.com/ discussions/showthread.php?t=1133027 
Kathryn (2009, September 21). Am I miscarrying? (X posted) [Msg. 3]. Message posted to http://www.mothering.com/discussions/showthread.php?p=14416722

Kathryn (2009, October 3). Look what I got!!!!!!!!!!! [Msg. 1, 5, 15, 21]. Message posted to http://www.mothering.com/discussions/ showthread.php?t=1144589

Kathryn (2009, October 12). October no stressers/no obsessers!! [Msg. 44]. Message posted to http://www.mothering.com/discussions/showthread.php?p=14513547

Kiara7 (2009, April 2). Need advice: son crying at night [Msg. 6]. Message posted to http://www.mothering.com/discussions/printthread.php?t=1065201

Kidzaplenty (2009, June 22). If you got this email after a "playdate", what would you do? [Msg. 24]. Message posted to http://www.mothering.com/discussions/ printthread.php?t=1101754

Kirsten (2009, June 22). If you got this email after a "playdate", what would you do? [Msg. 18]. Message posted to http://www.mothering.com/discussions/ printthread.php?t=1101754

Kirstenb (June 17, 2009). What bring you to MDC? [Msg. 9]. Message posted to http://www.mothering.com/discussions/printthread.php?t=1099331\&pp=200

Kitty_Jo (2006, July 24). Not-terribly-crunchy-mamas? [Msg. 33]. Message posted to http://www.mothering.com/discussions/printthread.php?t=482376\&pp=200

KweenKrunch (2009, September 6). MIL purchased plastic toy - wrong on so many levels! [Msg. 1]. Message posted to http://www.mothering.com/discussions/ showthread.php?t=1133610

Lai, K. W., Pratt, K., Anderson, M., \& Stigter, J. (2006). Literature review and synthesis: Online communities of practice. A report submitted to the Ministry of Education. Wellington, NZ.

Lake, R. (Producer), \& Epstein, A (Director). (2008). The business of being born. [Motion Picture]. United States: Red Envelope Entertainment.

Lamb, A. (2007). Smotherhood: Wickedly funny confessions from the early years. Guilford: CT, skirt!

Lave, J., \& Wenger, E. (1991). Situated learning: Legitimate peripheral participation. Cambridge, England: Cambridge University Press. 
Lave, J. (1993). The practice of learning. In S. Chaiklin \& J. Lave (Eds.), Understanding practice: Perspectives on activity and context (pp. 3-32). Cambridge, England: Cambridge University Press.

Leerypolyp (2008, July 27). Foremilke/hindmilk and dairy issues [Msg. 2]. Message posted to http://www.mothering.com/discussions/showthread.php?t=938978

Lewars, C. (2008, July 25). Follow Your Heart. Mothering.com, Web exclusive. Retrieved July 14, 2009, from http://www.mothering.com/health/follow-yourheart

Lilysmama1124 (2009, July 9). Best book for newly pg "mainstream" mama [Msg. 1]. Message posted to http://www.mothering.com/discussions/ showthread.php?t=1108813

Lincoln, Y., \& Guba, E. (1985). Naturalistic inquiry. Beverly Hills, CA: Sage Publications.

Lisoula (2009, September 5). Natural lubrication methods safe for swimmers? [Msg. 16]. Message posted to http://www.mothering.com/ discussions/ showthread.php?t=1133027

Litt, J. S. (2000). Medicalized motherhood: Perspectives from the lives of AfricanAmerican and Jewish women. New Brunswick, NJ: Rutgers University Press.

Live Laugh Love (2006, October 24). How crunchy quiz [Msg. 6]. Message posted to http://www.mothering.com/discussions/showthread.php?t=545623

Livingstone, D. W. (2006). Informal learning: Conceptual distinctions and preliminary Findings. In Z. Bekerman, N. Burbules, C \& D. Silberman-Keller (Eds.), Learning in places: The informal educational reader. New York: Peter Lang.

Lizanneh (2006, July 24). Not-terribly-crunchy-mamas? [Msg. 83]. Message posted to http://www.mothering.com/discussions/printthread.php?t=482376\&pp=200

Loh. S. T. (2003, May). The baby experts. The Atlantic. Retrieved May 3, 2009, on http://www.theatlantic.com/doc/200305/tsingloh

Lolalola (2006, October 24). "Granola factor" quiz, i.e. how crunchy are we? [Msg. 5]. Message posted to http://www.mothering.com/discussions/ showthread.php?t=545554

Londergan, B. (2006). I'm too sexy for my Volvo: A mom's guide to staying fabulous! Avon, MA: Adams Media.

LTK (2008, February 28). "Medical” Marijuana during Labor. [Msg. 1]. Message posted 
to http://www.mothering.com/discussions/showthread.php?t=856455

Lucky Charm (2003, June 6). Do you find your online experiences to be fulfilling? [Msg. 7]. Message posted to http://www.mothering.com/discussions/ showthread.php?t=64503

Lula (2006, September 28). None of this judgment helps. [Msg. 33]. Message posted to http://www.mothering.com/discussions/showthread.php?t=524873

Lusa's Mom (2009, April 12). Astonished! Friends FF baby... [Msg. 10]. Message posted to http://www.mothering.com/discussions/showthread.php?t=1069545

Madge, C., \& O'Connor, H. (2004). Mothers in the making? Exploring liminality in cyber/space. Transaction of the Institute of British Geographers, 30(1), 83-87.

Madge, C., \& O’Connor, H. (2006). Parenting gone wired: empowerment of new mothers on the internet? Social and Cultural Geography, 7(2), 199-220.

Maisy (2006, July 22). What to do with afterbirth placenta? [Msg 14]. Message posted to http://www.mothering.com/discussions/printthread.php?t=486509

Maisy (2006, August 4). What was you're a-ha moment about natural birth/drugs/interventions? [Msg 26]. Message posted to http:// www.mothering.com/discussions/showthread.php?t=494985\&page $=2$

Maisy (2006, August 29). A very personal question to the TTC ladies [Msg. 4]. Message posted to http://www.mothering.com/discussions/showthread.php? $\mathrm{p}=5898966$

Maisy (2006, August 29). I'm getting out of debt, with the snowball method. Wanna play? [Msg. 4]. Message posted to http://www.mothering.com/discussions/ showthread.php? $\mathrm{p}=5901663$

Maisy (2006, September 23). The ONE THREAD: 9/17-9/23 [Msg. 21]. Message posted to http://www.mothering.com/discussions/showthread.php?t= 522544\&highlight=

Maisy (2007, September 22). Where do I go from here? [Msg. 1] Message posted to http://www.mothering.com/discussions/printthread.php?t=755877

Maisy (2008, July 2). Surro moms and parent by surrogacy support [Msg. 501]. Message posted to http://www.mothering.com/discussions/showthread/php?= 11604069

Maisy (2008, November 10). My home birth montage (xposted in HB) [Msg. 1]. Message posted to http://www.mothering.com/discussions/ 
showthread.php?t=996601

Maisy (2008, November 18). "Preparedness" forum? [Msg. 6]. Message posted to http://www.mothering.com/discussions/showthread.php?p=12636638

Maisy (2009, September 19). Anyone in Spencer, WV? [Msg. 2]. Message posted to http://www.mothering.com/discussions/showthread.php?p=14405110

Mama2Jesse (2009, May 13). It takes a village [Msg. 12]. Message posted to http:// www.mothering.com/discussions/showthread.php?t=1083760

Mama.Pajama (2009, June 13). Is this common? [Msg. 7]. Message posted to http://www.mothering.com/discussions/showthread.php?t=1098098

Mamaoui (2003, June 6). Do you find your online experiences to be fulfilling? [Msg. 6]. Message posted to http://www.mothering.com/discussions/ showthread.php?t=64503

MamaRuga (2009, June 30). DH says “BAD!" to DD [Msg. 1]. Message posted to http://www.mothering.com/discussions/showthread.php?t=1105127\&highlight=

Mamatoablessing (2009, June 17). Is this Common? [Msg. 99]. Message posted to http://www.mothering.com/discussions/showthread.php?t=1098098

Mammal_Mama (2009, June 21). If you got this email after a "playdate," what would you do? [Msg. 2]. Message posted to http://www.mothering.com/discussions/ printthread.php?t=1101754

May-Baby (2009, November 20). Does anyone else intentionally drive themselves nuts? [Msg. 6]. Message posted to http://www.mothering.com/discussions/ showthread.php?t=1164395

May May (2005, June 22). It takes a village? [Msg. 46]. Message posted to http://www.mothering.com/discussions/showthread.php?t=303807

Marshall, C. \& Rossman, G. B. (1999). Designing qualitative research ( $3^{\text {rd }}$ ed.) Thousand Oaks, CA: Sage Publications, Inc.

Mauthner, N. S. (1995). Postpartum depression: The significance of social contacts between mothers. Women's International Forum, 18, 311-23.

Maxwell, J. (1996). Qualitative research design: An interactive approach (Vol. 41). Thousand Oaks, CA: Sage Publications.

MCatLvrMom2A\&X (2009, June 17). What brings you to MDC? [Msg. 10]. Message posted to http://www.mothering.com/discussions/showthread.php? 
$\mathrm{p}=13966184$

McDermott, R. (1999, May-June). Learning across teams: The role of communities of practice in team organizations. Knowledge Management Review. Retrieved June 21, 2009 from http://www.co-i-l.com/coil/knowledge-garden/cop/learning. shtml

McTamaney, C. (n. d.) Attachment parenting and the c-section. Mothering.com, Web exclusive. Retrieved November 12, 2009, from http://www.mothering.com/ pregnancy-birth/attachment-parenting-and-c-section

Mead-Ferro, M. (2004). Confessions of a slacker mom. Cambridge, MA: De Capo Lifelong Books.

Media kit (2009, December 21). Retrieved September 23, 2009, from http://206.251.72.146/resources/mediakit.pdf

Meemee (2009, April 14). Jumpers: are they safe? [Msg 14]. Message posted to http://www.mothering.com/discussions/printthread.php?t=1070289

Meemee (2009, April 11). Mothering and intuition. [Msg. 11]. Message posted to http://www.mothering.com/discussions/showthread.php?t=1167484

MegBoz (2008, August 3). I hate breastfeeding. Just a rant [Msg 1]. Message posted to www.mothering.com/discussions/printthread.php?t=943038

MegBoz (2009, August 24). Keeping your Lips Zipped around Mainstream Mamas - SO HARD! [Msg. 1]. Message posted to http://www.mothering.com/discussions/ printthread.php?t=

Mellor, C. (2004). The three-martini playdate: A practical guide to happy parenting. San Francisco: Chronicle Books LLC.

Mickelson, K. D. (1997). Seeking social support: Parents in electronic support groups. In S. Kiesler (ed.), (2001). Culture of the internet (pp. 158-178). Mahwah, NJ: Lawrence Erlbaum.

Miles, M. B. \& Huberman, A. M. (1994). Qualitative data analysis, (2 ${ }^{\text {nd }}$ ed.) Thousand Oaks, CA: Sage Publications, Inc.

Mischievium (2009, November 20). Does anyone else intentionally drive themselves nuts? [Msg. 8]. Message posted to http://www.mothering.com/discussions/ showthread.php?t=1164395

MissRubyandKen (2010, January 15). Bank error - anyone bdtd? [Msg. 1]. Message posted to http://www.mothering.com/discussions/showthread.php?t=1183994 
MittensKittens (2009, June 5). Do you feel judged by other moms? [Msg. 39]. Message posted to http://www.mothering.com/discussions/showthread.php?t= 1094461

MittensKittens (2009, June 17). What bring you to MDC? [Msg. 11]. Message posted to http://www.mothering.com/discussions/printthread.php?t=1099331\&pp=200

Miyata, K. (2002). Social support for Japanese mothers online and offline. In Wellman, B. and Haythornthwaite, C. (Eds.), The Internet in Everyday Life. Malden, MA: Blackwell Publishers.

MommyDOK (2009, November 12). Dr. Michael Dixon [Msg. 4]. Message posted to http://www.mothering.com/discussions/showthread.php?t=1155498

Mommyshoppinghabit (2009, March 10). What do you talk about with mainstream mothers? [Msg. 1]. Message posted to http://www.mothering.com/discussions/ printthread.php?t=1053768

Mommyswen (2008, August 27). Final update post \#527 eveyone home. [Msg. 531]. Message posted to http://www.mothering.com/discussions/ showthread.php?t=892854

Momtwice (2003, June 7). Do you find your online experiences to be fulfilling? [Msg. 13]. Message posted to http://www.mothering.com/discussions/ showthread.php?t=64503

Monarchgrrl (2009, June 16). What brings you to MDC? [Msg. 6]. Message posted to http://www.mothering.com/discussions/showthread.php? $\mathrm{p}=13966184$

Moonfirefaery, How to be CRUNCHY but not OBSESSIVE, NEUROTIC, or JUDGEMENTAL? [Msg. 14]. Message posted to http://www.mothering.com/discussions/showthread.php?t=524873

MotheringDotCommunity User Agreement. (n.d.). Retrieved August 3, 2009, from http://www.mothering.com/mdc/webpurpose.html

Mountaingirl3 (2006, February 24). Non-AP mamas who think they're AP? [Msg. 85]. Message posted to http://www.mothering.com/discussions/ showthread.php?t=411384\&

Ms. Cellaneous (2009, May 4). Long-time MDC lurker, first-time poster joining the Oct '09 DDC. [Msg. 8]. Message posted to http://www.mothering.com/ discussions/printthread.php?t=1079767

MynameisMom (2009, December 29). Nursing strike. Just looking for some BTDT 
support [Msg. 1]. Message posted to http://www.mothering.com/discussions/ showthread.php?t=1177360

Nattymom (2009, April 2). Need advice: son crying at night. [Msg. 1]. Message posted to http://www.mothering.com/discussions/printthread.php?t=1065201

Nichani, M., \& Hung, D. (2002). Can a community of practice exist online? Educational Technology, 42(4), 49-54.

NiteNicole (2006, September 22). How to be CRUNCHY but not OBSESSIVE, NEUROTIC, or JUDGEMENTAL? [Msg. 16]. Message posted to http://www.mothering.com/discussions/showthread.php?t=524873

Not Now (2009, June 13). Is this Common? [Msg. 1]. Message posted to http://www.mothering.com/discussions/showthread.php?t=1098098

No5no5 (2009, April 4). What classifies a child as gifted? [Msg. 2, 5]. Message posted to http://www.mothering.com/discussions/ showthread.php?t=1067420\&highlight=what+classifies+child+as+gifted

Nugent, K. (1998). A doula makes the difference! Mothering, 87. Retrieved May 18, 2009, from http://www.mothering.com/pregnancy-birth/doula-makes-difference.

Olien (2009, April 11). Astonished! Friends FF baby...[Msg. 1]. Message posted to http://www.mothering.com/discussions/showthread.php?t=1069545

Olliepop (2008, October 6). When to introduce race to child? [Msg. 1]. Message posted to http://www.mothering.com/discussions/printthread.php?t=978345

OnTheFence (2005, June 21). It takes a village? [Msg. 26]. Message posted to http://www.mothering.com/discussions/showthread.php?t=303807

O'Mara, P. (2000). Natural family living: The Mothering magazine guide to parenting. New York: The Philip Lief Group, Inc. and Mothering Magazine, Inc.

O'Mara, P. (2001). Foreword. In J. Hunt (Eds.), The natural child (pp. xiii-xvi). Gabriola Island, BC: New Society Publishers.

O’Mara, P. (2005). What is natural family living? Mothering Magazine, 130, 8-11.

O’Mara (2009a, July-August). A quiet place: Longing for community. Mothering, 155, 8-12.

O’Mara, P. (2009b, November-December). A quiet place: Killer fear. Mothering, 157, 1014. 
O’Mara, P. (2010, January-February ). A quiet place. The new health journalism: Challenging the status quo. Mothering, 158, 12-16.

OTMomma, (2006, March 27). Spiritual side of infertility? [Msg. 1]. Message posted to http://www.mothering.com/discussions/showthread.php?t=429152

Palloff, R. M., \& Pratt, K. (1999). Building learning communities in cyberspace: Effective strategies for the online classroom. San Francisco: Jossey-Bass.

Peri, C., \& M. K. (1999). Mothers who think: Tales of real-life parenthood. New York: Pocket Books.

Peskowitz, M. (2005). The truth behind the "Mommy Wars": Who decides what makes a good mother? Emeryville, CA: Seal Press.

Phoenix, A., Woollett, A. and Lloyd, E. (1992). Motherhood: Meanings, practices and ideologies. London: Sage.

Pi (2009, April 2). Adjusting to daycare: how? [Msg. 3]. Message posted to http://www.mothering.com/discussions/printthread.php?t=1068612

Pickle It (2005, May 18). Acronyms that MDC needs. [Msg. 118]. Message posted to http://www.mothering.com/discussions/showthread.php?t=287763

Piglet68 (2003, June 4). Do you find your online experiences to be fulfilling? [Msg. 3]. Message posted to http://www.mothering.com/discussions/ showthread.php?t=64503

Pitman, T. (n.d.). Finding your tribe: Feed your soul while feeding your kids. Retrieved on October 12, 2009, from http://www.mothering.com/finding-your-tribe-feedyour-soul-while-feeding-your-kids

Poetgirl (2009, March 7). * Spring 2009 IVF Thread * [ Msg 31]. Message posted to http://www.mothering.com/discussions/printthread.php?t=1051334\&pp=200

Porter, L. J. (2003, July-August). The science of attachment: The biological roots of love. Mothering, 119. Retrieved September 2, 2009, from http://www.mothering.com/ science-attachment-biological-roots-love

Preece, J. (2001). Sociability and usability: Twenty years of chatting online. Behavior and Information Technology Journal, 20(5), 347-356.

RasJi7 (2008, October 6). When to introduce race to child? [Msg. 2]. Message posted to http://www.mothering.com/discussions/printthread.php?t=978345

Rate card (2009, December 21). Retrieved September 23, 2009, from http:// 


\subsubsection{6/resources/ratecard.pdf}

Readytobedone (2009, June 14). What else does she WANT from me?! [Msg. 5].

Message posted to http://www.mothering.com/discussions/

showthread.php?t=1098337

Rhiengold, H. (2000). The virtual community: Homesteading on the electronic frontier. Cambridge: MIT Press.

Rich, A. (1977). Of woman born: Motherhood as experience and institution. New York: Bantam Books.

Ridings, C. \& Gefen, D. (2004). Virtual community attraction: Why people hang out online. Journal of Computer-Mediated Communication, 10(1). Retrieved March 27, 2009 from http://jcmc.indiana.edu/

Riverscout (2009, May 13). It takes a village [Msg. 17]. Message posted to http://www.mothering.com/discussions/showthread.php?t=1083760

RomanGoddess (2006, September 26). Not terribly crunchy -what? [Msg 17].Message posted to http://www.mothering.com/discussions/ showthread.php? $\mathrm{t}=517018$

Rtnsgirly (2007, April 14). What does "banned" mean? [Msg. 1]. Message posted to http://www.mothering.com/discussions/showthread.php?t=654708

RubyOrganique (2008, July 25). What do you wish you would have known beforehand? [Msg. 142]. Message posted to http://www.mothering.com/discussions/ showthread.php?t=438630\&page $=8$

Ruthla (2006, October 29). Why do people care about their thread count? [Msg. 2]. Message posted to http://www.mothering.com/discussions/ showthread.php?t=548760

Ruthla, (2008, February 4). Have you ever, would you ever, live in a commune? [Msg. 5]. Message posted to http://www.mothering.com/discussions/ showthread.php?t=841827

SAHDS (2009, June 16). Is this common? [Msg. 71]. Message posted to http://www.mothering.com/discussions/showthread.php?t=1098098

Salmansohn, K. (2003). Hot mama: How to have a babe and be a babe. San Francisco: Chronicle Books LLC.

Samy23 (2009, September 8). Being part of a community, which one? [Msg. 1]. Message posted to http://www.mothering.com/discussion/showthread/ 
php?t=1133664\&highlight=

Sarah (2008). Raised with respect. Retrieved December 2, 2009, from http://attachmentparenting.org/blog/2008/11/18/raised-with-respect/

SarahElizabeth (November 30, 2009). Mothering and intuition. [Msg. 3]. Message posted to http://www.mothering.com/discussions/showthread.php?t=1167484

Sarhaj (2009, June 13). Is this common? [Msg. 37]. Message posted to http://www.mothering.com/discussions/showthread.php?t=1098098

Sarkadi, A., \& Breber, S. (2004). Socially unbiased parenting support on the Internet: A cross-sectional study of users of a large Swedish parenting website. Child: Care, Health \& Development 31(1), 43-52.

SashaBreeze (2009, June 22). If you got this email after a "playdate," what would you do? [Msg. 78]. Message posted to http://www.mothering.com/discussions/ printthread.php?t=1101754

Schlager, M. S., \& Fusco, J. \& Schank, P. (2004). Evolution of an online education community of practice. In K. Renninger \& W. Shumar (Eds.), Building virtual communities: Learning and change in cyberspace (pp. 129-158). Cambridge, UK: Cambridge University Press.

Schultz, V. (2001, January-February). Mom medicine: Offering up the day to a sick child. Mothering, 104. Retrieved April 5, 2009, from http://www.mothering.com/ health/mom-medicine-offering-day-sick-child

Schwarzer, E. S. (2006). Motherhood is not for wimps: No answers, just stories. United States of America: Elizabeth Soutter Schwarzer.

Sears, W. S (2000). Foreword. In P. O’Mara, P. (Eds.), Natural family living: The Mothering magazine guide to parenting (p. ix). New York: The Philip Lief Group, Inc. and Mothering Magazine, Inc.

Seashells (2009, November 20). Mothering and intuition. [Msg. 6]. Message posted to http://www.mothering.com/discussions/showthread.php?t=1167484

ScootchsMom (2009, November 26). What is wrong with my son, need advice [Msg. 1]. http://www.mothering.com/discussions/showthread.php?t=1166445\&highlight=

Shakenbake (2009, July 17). Ok bad fear and I know I'm stupid [Msg. 1]. Message posted to http://www.mothering.com/discussions/showthread.php?t=1112457

Sharf, B. F. (1997). Communicating breast cancer on-line: support and empowerment on the internet, Women and Health (26), 1. 
Snuzzmom (2009, April 16). Wodering why [Msg. 2]. Message posted to http://www.mothering.com/discussions/showthread.php?t=1071756

Snuzzmom (2009, June 15). Is this Common? [Msg. 61]. Message posted to http://www.mothering.com/discussions/showthread.php?t=1098098

Softmama (2009, May 12). It takes a village [Msg. 4]. Message posted to http://www.mothering.com/discussions/showthread.php?t=1083760

Solter, A. (2000). The disadvantages of time-out. Retrieved on February 1, 2009, from http://www.awareparenting.com/timeout.htm

Sparklefairy (2009, June 16). Is this common? [Msg. 72]. Message posted to http://www.mothering.com/discussions/showthread.php?t=1098098

Sparkly (2009, April 7). Oprah today on Motherhood. [Msg. 11]. Message posted to http://www.mothering.com/discussions/showthread.php?t=1067047

Sprout77 (2008, June 20). What do you wish you would have known beforehand? Message posted to http://www.mothering.com/discussions/ printthread.php?t=438630\&pp=200

Spughy (2008, May 18). Describe your ideal commune/cult [Msg. 11]. Message posted to http://www.mothering.com/discussions/showthread.php?t=899738

Stayseeliz (2005, June 21). It takes a village? [Msg. 1]. Message posted to http://www.mothering.com/discussions/showthread.php?t=303807

Steiner, L. M. (2007). Mommy wars: Stay-at-home and career moms face off on their choices, their lives, their families. New York: Random House, Inc.

Steiner, P. (1993, July 5). On the Internet, nobody knows you're a dog. The New Yorker, 69(20), p. 61.

Stephandowen (2009, June 21). If you got this email after a "playdate", what would you do? [Msg. 1, 32, 55, 70]. Message posted to http://www.mothering.com/ discussions/printthread.php?t=1101754

Stone, P. (2008). Opting out: Why women really quit careers and head home. Berkeley, CA: University of California Press.

Storm Bride (2009, April 7). Oprah today on Motherhood. [Msg. 14]. Message posted to http://www.mothering.com/discussions/showthread.php?t=1067047

Stuckey, B. (2004, March). Making the most of the good advice: Meta-analysis of 
guidelines for establishing an internet-mediated community of practice [draft]. Paper presented at the IADIS Web Based Communities Conference, Lisbon, Portugal. Retrieved March 9, 2009 from http://www.bronwyn.ws/publications/ papers/good_advice.pdf

Sunflowers (2006, October 29). Why do People Care about their thread count? [Msg. 1]. Message posted to http://www.mothering.com/discussions/ showthread.php?t=548760

Suzukiaustin (2009, May 13). It takes a village [Msg. 13]. Message posted to http://www.mothering.com/discussions/showthread.php?t=1083760

Sweetpea_119 (2009, August 26). Keeping your lips zipped around mainstream mamas SO HARD! [Msg. 41]. Message posted tohttp://www.mothering.com/ discussions/showthread.php?t=1127928

Sydnee (2006, July 27). Not-terribly-crunchy? [Msg. 56]. Message posted to http://www.mothering.com/discussions/showthread.php?t=482376\&page=3

Tanibani (2009, June 22). If you got this email after a "playdate", what would you do? [Msg. 66]. http://www.mothering.com/discussions/printthread.php?t=1101754

Tattooed Hand (2009, September 1). How annoyed do you get with mainstream baby thinkers? [Msg. 28]. Message posted to http://www.mothering.com/discussions/ showthread.php? $\mathrm{p}=14315713$

TeaBag (2006, January 12). Parenting and Rage [Msg. 9]. Message posted to http://www.mothering.com/discussions/showthread.php?t=394579

Teale (2009, June 22). If you got this email after a "playdate", what would you do? [Msg. 32]. Message posted to http://www.mothering.com/discussions/ printthread.php?t=1101754

Thefreckledmama (2009, November 20). Does anyone else intentionally drive themselves nuts? [Msg. 1]. Message posted to http://www.mothering.com/discussions/ showthread.php?t=1164395

The Holistic Moms Network (Producer). (2007). Peggy O'Mara on the Holistic Moms Network [Video recording]. Accessed on January 15, 2010 from http://www.holisticmoms.org/category/aboutus/what-moms-are-saying/

Theoretica (2009, January 3). How crunchy are you quiz (UPDATED - \#49) [Msg. 1]. Message posted to http://www.mothering.com/discussions/ showthread.php?t=1020351

Thismama (2005, June 6). What do you say to non-ap parents about their parenting? 
[Msg. 15]. Message posted to http://www.mothering.com/discussions/ showthread.php?t=298145

3happygirls (2006, July 27). Not-terribly-crunchy? Msg[ 46]. Message posted to http://www.mothering.com/discussions/showthread.php?t=482376\&page=3

Tigerchild (2009, June 26). It takes a village [Msg. 36]. Message posted to http://www.mothering.com/discussions/showthread.php?t=1083760

Tigerchild (2009, June 15). Is this Common? [Msg. 67]. Message posted to http://www.mothering.com/discussions/showthread.php?t=1098098

Tigerchild (2009, September 7). Being part of a community, which one? [Msg. 8]. Message posted to http://www.mothering.com/discussion/showthread/ php?t=1133664

Tracymom (2005, May 18). Acronyms that MDC needs. [Msg. 119]. Message posted http://www.mothering.com/discussions/showthread.php?t=287763

Tradd (2009, September 7). Being part of a community, which one? [Msg. 6]. Message posted to http://www.mothering.com/discussion/showthread/php $? \mathrm{t}=1133664$

Trentin, G. (2002). From distance education to virtual communities of practice: The wide range of possibilities for using the Internet in continuous education and training. International Journal on e-Learning, Jan-March, 55-66.

Trillian11 (2008, December 17). Need sleep advice for 7 month old [Msg. 2]. Message posted to http://www.mothering.com/discussions/showthread.php?t=1013924

Trinity6232000 (2009, June 22). If you got this email after a "playdate", what would you do? [Msg. 118]. http://www.mothering.com/discussions/printthread.php? $\mathrm{t}=1101754$

Trishy (2005, May 18). Acronyms that MDC needs. [Msg. 41]. Message posted to http://www.mothering.com/discussions/showthread.php?t=287763

UhOhWhatNow (2009, June 14). Is this common? [Msg. 57]. Message posted to http://www.mothering.com/discussions/showthread.php?t=1098098

Um Hanna (2009, January 3). How Crunchy Are You Quiz (UPDATED - \#49). [Msg. 3]. Message posted to http://www.mothering.com/discussions/ showthread.php?t=1020351

Unlegal (2009, February 13). Anyone interested in participating in a medical anthropology study? [Msg. 1]. Message posted to http://www.mothering.com/ 
discussions/showthread.php?t=1041677\&highlight=study

USAmma (2005, June 8). What do you say to non-ap parents about their parenting?

[Msg. 135]. Message posted to http://www.mothering.com/discussions/ showthread.php?t=298145

USAmma (2005, June 22). It takes a village? [Msg. 42]. Message posted to http://www.mothering.com/discussions/showthread.php?t=303807

Vancouver Mommy (2009, April 7). Difficult questions - I'm not ready! [Msg. 1]. Message posted to http://www.mothering.com/discussions/ printthread.php?t=1067221

Vaw (2009, April 7). What classifies a child as gifted? [Msg. 7]. Message posted to http://mothering.com/discussion/printthread.php?t=1067420

Vivensmama (2009, October 3). Baby screams when Daddy holds her [Msg. 1]. Message posted to http://www.mothering.com/discussions/showthread.php?t=1144716

Walker, S. K, \& Riley, D. A (2001). Involvement of the personal social network as a factor in parent education effectiveness, Family Relations, 50(2), 186-198.

Weetize (2003, June 7). Do you find your online experiences to be fulfilling? [Msg. 12]. Message posted to http://www.mothering.com/discussions/ showthread.php?t=64503

Wellman, B. and Gulia, M. (1999). Virtual communities as communities: Net surfers don't ride alone. In Smith, M. A., and Kolloock, P. (eds) Communities in cyberspace, Routledge, London, pp. 167-194.

Wendy (2008, October 23). S/o of totallt burned out...tell me about you LO! [Msg. 1]. Message posted to http://www.mothering.com/discussions/ showthread.php? $\mathrm{p}=12452640$

Wendy (2008, November 8). Peninsula AP moms? [Msg. 6]. Message posted to http://www.mothering.com/discussions/showthread.php?p=12570813

Wendy (2008, November 18). Our oncologist appt :( . [Msg. 13]. Message posted to http://www.mothering.com/discussions/showthread.php?p=12639779

Wendy, (2008, December 1). Walnut yogurt? [Msg. 3]. Message posted to http://www.mothering.com/discussions/showthread.php?p=12709151

Wendy (2008, December 16). Need Sleep Advice for 7 Month Old. [Msg. 1, 3]. Message posted to http://www.mothering.com/discussions/showthread.php? $\mathrm{t}=1013924$ 
Wendy (2008, December 31). HAPPY NEW YEAR MAMAS! We made it through 2008! [Msg. 5]. Message posted to http://www.mothering.com/discussions/ search.php?searchid $=11269168 \& p p=20 \&$ page $=17$

Wendy (2009, January 7). Ped visit turned NIGHTMARE!!! [Msg. 11]. Message posted to http://www.mothering.com/discussions/showthread.php?p=12939559

Wendy (2009, January 14). Back from CST Appt and Have Questions [Msg. 1]. Message posted to http://www.mothering.com/discussions/showthread.php? $\mathrm{t}=1026766 \&$ highlight $=$

Wendy (2009, January 23). Medical Intuitive. [Msg. 1]. Message posted to http://www.mothering.com/discussions/showthread.php?t=1031372\&highlight=

Wendy (2009, February 8). Chat thread: Feb 7-13. [Msg. 159]. Message posted to http://www.mothering.com/discussions/showthread.php?p=13155352\&highlight= \#post13155352

Wendy (2009, February 18). Happy Valentine's Day! (Chat thread 14-20). [Msg. 36]. Message posted to http://www.mothering.com/discussions/ showthread.php? $\mathrm{p}=13194555$ \& highlight=\#post 13194555

Wendy (2009, February 18). How to manage mental overload? [Msg. 20]. Message posted to http://www.mothering.com/discussions/showthread.php?t=1043634

Wendy (2009, March 15). Chat Thread: March 14-20. [Msg. 105]. Message posted to http://www.mothering.com/discussions/showthread.php?p=13371914

Wendy (2009, December 1). November Chat! (no, I'm not creative). [Msg. 1149]. Message posted to http://www.mothering.com/discussions/ showthread.php? $\mathrm{p}=14743289$

Wenger, E. (1998). Communities of practice: Learning as a social system. The System Thinker, 9 (5). Retrieved December 12, 2007, from http://www.co-il.com/coil/knowledge-garden/cop/lss.shtml

Wenger, E. (2001). Supporting communities of practice: A survey of community-oriented technologies (draft version 1.3). Retrieved December 2, 2007, from http://www.ewenger.com

Wenger, E., McDermott, R., \& Snyder, W. (2002). Cultivating communities of practice: A guide to managing knowledge. Cambridge, England: Harvard Business School Press.

Whitneymum (2009, June 22). If you got this email after a "playdate", what would you do? [Msg. 100]. Message posted to http://www.mothering.com/discussions/ 
printthread.php?t=1101754

Wipfler, P. (2002, November-December). Cry for connection: A fresh approach to tantrums. Mothering, 115. Retrieved on December 22, 2009, from http:// www.mothering.com/parenting/cry-connection-fresh-approach-tantrums

Wilder-Taylor, S. (2006). Sippy cups are not for chardonnay: And other things I had to learn as a new mom. New York: Simon Spotlight Entertainment.

WingonWing (2009, June 22). If you got this email after a "playdate", what would you do? [Msg. 77]. Message posted to http://www.mothering.com/discussions/ printthread.php?t=1101754

Wolf, N. (2001). Misconceptions: Truth, lies, and the unexpected on the journey to motherhood. New York: Doubleday.

Wtg4miracle (2009, March 18). Spring 2009 IVF Thread. [Msg. 4]. Message posted to http://www.mothering.com/discussions/printthread.php?t=1051334\&pp=200

WuWei (2006, February 17). Parenting and rage [Msg. 60]. Message posted to http://www.mothering.com/discussions/showthread.php?t=394579

WuWei (2009, February 18). Automated Suspension/UAV tracking, [Msg 52]. Message posted to http://www.mothering.com/discussions/printthread.php? $\mathrm{t}=1043896 \& \mathrm{pp}=200$

Yoga (2004, September 1). It's seriously time to do the commune thing, mamas [Msg. 1]. Message posted to http://www.mothering.com/discussions/ showthread.php?t=189300

Zjande (2009, June 16). What bring you to MDC? [Msg. 6]. Message posted to http://www.mothering.com/discussions/printthread.php?t=1099331\&pp=200

Zinemama (2009, November 3). 'Gatekeeping mothers' [Msg. 3]. Message posted to http://www.mothering.com/discussions/showthread.php?t=1157377 


\section{APPENDICES \\ Appendix A \\ Interview Questions}

\section{BASIC INFO}

1. What is your age?

2. Where are you from? What is your occupation?

3. How many children do you have, and what are their ages? DEFINING NATURAL FAMILY LIVING

4. What would you define holistic mothering?

5. What are some of the major ideas/practice behind NFL?

6. How does NFL differ from other types of mothering?

7. How long would you say you have been a holistic mother?

8. Were you involved in NFL before becoming a mother? MOTHERINGDOTCOMMUNITY \& LEARNING

9. How did you come to be a part of MDC?

10. What has been your history of involvement at MDC? Did you lurk for awhile, or jump right into posting and sharing?

11. Which MDC forums do you read/post at regularly?

12. Have you ever been involved in a post that involved tension (flaming)? 
13. Have you formed relationships with other members? If so, how would you describe them?

14. What have you learned from MDC? Are there examples of how you have applied what you learned to your own parenting philosophy and practices?

15. Is there a time that you taught something to another group member (sharing information, pointing others to additional resources, etc.)?

16. What are the pros/cons of being online?

17. Besides MDC, what other resources do you rely on regularly for parenting guidance?

18. Is there anything else you would like to share about your experiences learning through MDC that I did not ask?

Thank you again for your time! If you are interested in seeing the final result, you can contact me in May of 2010 when I will have completed my dissertation. I will gladly share my work with you. 


\section{Appendix B}

Codes for Archived Messages and Interviews

NFL mother
a. Alternative medicine
b. Questions mainstream experts
c. Breast-feeding
d. Intensive mothering
e. Attention to diet
f. Attachment parenting

Decision Making
a. Family members
b. Health care providers
c. Childhood experts
d. Educators
e. Books
f. Internet
g. What feels natural

Identity
a. Defines NFL mother
b. Defines other mothers

Community Roles
a. Newcomer
b. Veteran

Internet Usage
a. Anonymity
b. Time
c. Feeling connected at all times 